\title{
Vascular calcifications and matrix Gla protein in hypertensive subjects
}

Citation for published version (APA):

Rennenberg, R. (2011). Vascular calcifications and matrix Gla protein in hypertensive subjects. [Doctoral Thesis, Maastricht University]. Datawyse / Universitaire Pers Maastricht. https://doi.org/10.26481/dis.20110706rr

Document status and date:

Published: 01/01/2011

DOI:

10.26481/dis.20110706rr

Document Version:

Publisher's PDF, also known as Version of record

\section{Please check the document version of this publication:}

- A submitted manuscript is the version of the article upon submission and before peer-review. There can be important differences between the submitted version and the official published version of record.

People interested in the research are advised to contact the author for the final version of the publication, or visit the DOI to the publisher's website.

- The final author version and the galley proof are versions of the publication after peer review.

- The final published version features the final layout of the paper including the volume, issue and page numbers.

Link to publication

\footnotetext{
General rights rights.

- You may freely distribute the URL identifying the publication in the public portal. please follow below link for the End User Agreement:

www.umlib.nl/taverne-license

Take down policy

If you believe that this document breaches copyright please contact us at:

repository@maastrichtuniversity.nl

providing details and we will investigate your claim.
}

Copyright and moral rights for the publications made accessible in the public portal are retained by the authors and/or other copyright owners and it is a condition of accessing publications that users recognise and abide by the legal requirements associated with these

- Users may download and print one copy of any publication from the public portal for the purpose of private study or research.

- You may not further distribute the material or use it for any profit-making activity or commercial gain

If the publication is distributed under the terms of Article $25 \mathrm{fa}$ of the Dutch Copyright Act, indicated by the "Taverne" license above, 
Vascular calcifications and matrix Gla protein in hypertensive subjects 
(C) Roger Rennenberg, Maastricht

Layout: Tiny Wouters

Cover design: Nicole Opgenoorth

Production: Datawyse | Universitaire Pers Maastricht

ISBN: 978-94-6159-065-7 


\title{
Vascular calcifications and matrix Gla protein in
}

\author{
hypertensive subjects
}

\section{PROEFSCHRIFT}

Ter verkrijging van de graad van doctor aan de Universiteit Maastricht, op gezag van de Rector Magnificus, Prof. mr. G.P.M.F. Mols,

volgens het besluit van het College van Decanen,

in het openbaar te verdedigen

op woensdag 6 juli 2011 om 12:00 uur

door

Roger Rennenberg

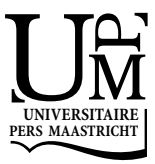




\section{Promotores}

Prof. dr. P.W. de Leeuw

\section{Co-Promotor}

Dr. A.A. Kroon

Dr. L.J. Schurgers

\section{Beoordelingscommissie}

Prof. dr. M. van Dieijen-Visser, voorzitter Prof. dr. A.A. Bast

Prof. dr. J. Floege, Universitätsklinikum RWTH Aachen, Duitsland Prof. dr. Y. van der Graaf, UMC Utrecht

Prof. dr. J.E. Wildberger 
Geloven is goed,

controleren is beter

Aan Pap \& Mam 



\section{Contents}

Chapter 1 Introduction and outline of the thesis 9

Chapter 2 Arterial calcifications 23

Chapter $3 \quad$ Vascular calcifications as a marker of increased $\quad 41$

cardiovascular risk: A meta-analysis

Chapter $4 \quad$ Levels of Matrix Gla Protein, a marker for vascular 59

calcification, in human hypertension

Chapter $5 \quad$ Renal handling of matrix Gla protein in humans with 69

moderate to severe hypertension

Chapter $6 \quad$ Non-phosphorylated uncarboxylated Matrix Gla Protein, 83

a marker of insufficient inhibition of calcification, is related

to blood pressure and arterial stiffness: the Hoorn Study

Chapter $7 \quad$ Calcium scores and Matrix Gla Protein levels: association

with vitamin $\mathrm{K}$ status

Chapter $8 \quad$ Chronic coumarin treatment is associated with increased 109 extracoronary arterial calcification in humans

$\begin{array}{lll}\text { Chapter } 9 & \text { Main findings in perspective } & 117\end{array}$

Summary 127

Samenvatting 131

List of publications $\quad 135$

Dankwoord 141

$\begin{array}{ll}\text { Curriculum Vitae } & 149\end{array}$ 



\section{Chapter 1}

Introduction and outline of the thesis 
10 Chapter 1 


\section{Introduction}

Hypertensive patients have an increased risk of a variety of atherosclerotic complications. Although our knowledge of the mechanisms which are involved in the pathogenesis of atherosclerosis has increased considerably over the past decades, it is not fully understood how an elevated blood pressure contributes to the damage in certain vascular beds. A phenomenon that has not yet received much attention is the occurrence of vascular calcifications in hypertension. Why do they occur and what is their clinical significance? In this paper we will briefly review what is known about the mechanisms leading to vascular calcification, in particular in patients with high blood pressure.

\section{Pathobiology of vascular calcifications}

Bone morphogenetic proteins (BMP) are primarily involved in the maintenance and repair of human bone tissue, but they also play a role in the vessel wall. Although three forms, namely BMP-2, BMP-4 and BMP-6, are expressed in vascular calcification, it is primarily the activation of BMP-2 which results in inhibition of vascular smooth muscle cell differentiation, probably by interruption of the cell cycle through p21 inhibition of cyclin dependant kinases. ${ }^{1}$ Furthermore, in vitro loss of vascular smooth muscle cell markers is induced by exposure to BMP-2. ${ }^{2}$ Finally, BMP-2 is associated with increased apoptosis, which is critical for the initiation and propagation of the calcification proces. ${ }^{3}$ Continued exposure to BMP-2 could then stimulate msh homeobox 2 (MSX2), a transcription factor promoting osteogenic gene expression and thus inducing core binding factor-1 (also called Runx2) and osterix. The latter stimulates the differentiation of multipotent vascular mesenchymal cells into "osteoblast-like" cells which are capable of enhancing intramembranous bone formation in the artery wall. ${ }^{4-7}$ This ensuing calcification of the vascular wall is further modified by stimulatory and inhibitory factors in a complex relationship which is probably similar in most patient subgroups (Figure 1.1). ${ }^{8}$ However, there are some differences in the main triggering factors that initiate and maintain the calcification process in various disease states. For diabetes, renal insufficiency and hypertension this is shown in Figure 1.2.

\section{Diabetes Mellitus}

Vascular calcification is more prevalent in subjects with diabetes than in non-diabetic subjects and is located mainly in the coronary arteries and the thoracic aorta (Table 1.1).

One of the main triggering factors for vascular calcification in diabetes seems to be a high ambient glucose level as demonstrated by the independent association of $\mathrm{HbA1C}$ levels and the prevalence of calcifications. ${ }^{9-11}$ The exact mechanisms are not very well 
understood but may involve advanced glycation end products (AGEs) which are strongly correlated with the presence of coronary artery calcification. ${ }^{12,13}$ In addition, in an experimental setting AGEs were able to stimulate rat aortic vascular smooth muscle cell calcification and upregulation of Runx2 messenger RNA in human aortic vascular smooth muscle cells. ${ }^{14,15}$

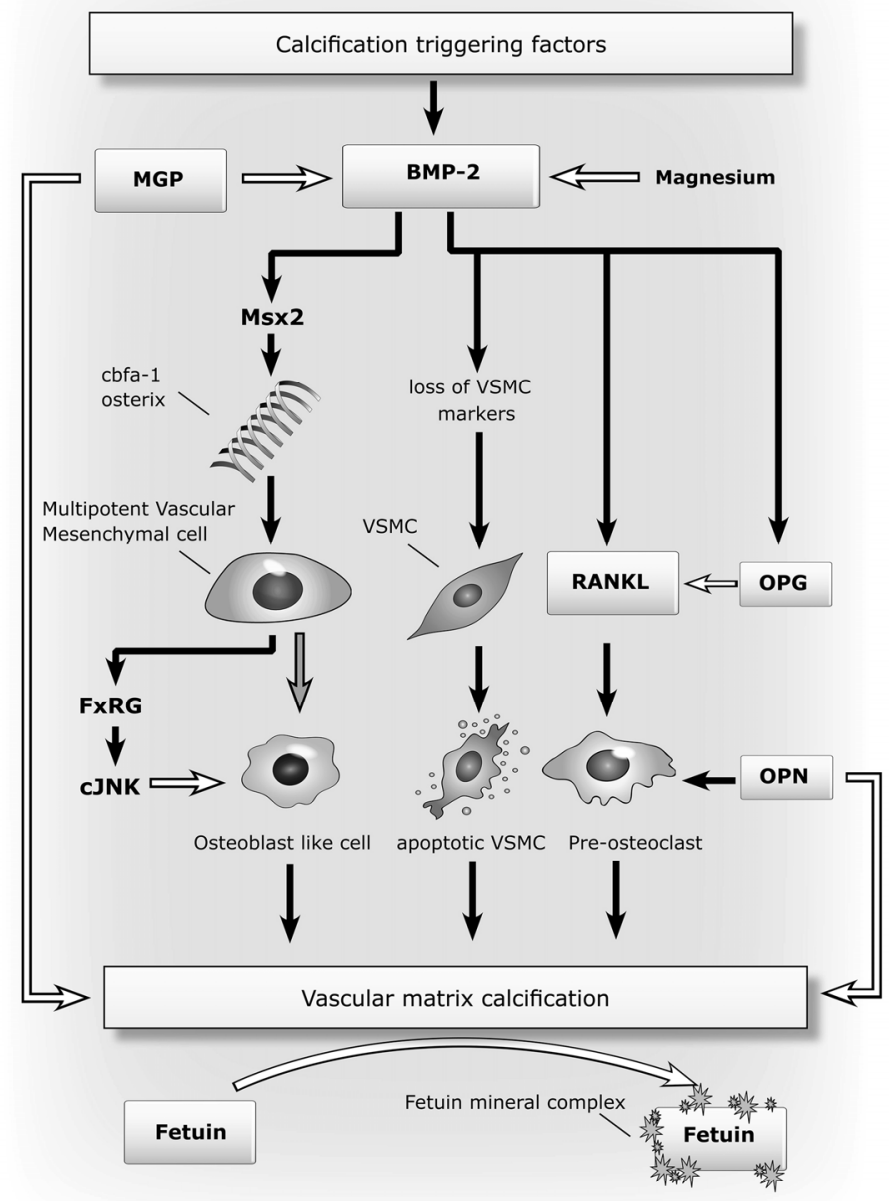

Figure 1.1 Common pathway of calcification.

White arrows denote an inhibiting effect, black arrows denote a stimulating effect, grey arrow denotes transition. MGP: matrix Gla protein, BMP-2: bone morphogenic protein type 2, RANKL: receptor activator of nuclear factor kappa B ligand, OPG: osteoprotegerin, OPN: osteopontin. Inflammation and lipid peroxidation modify regulatory genes. BMP-2 promotes differentiation of the mesenchymal vascular cells through induction of osteoregulatory genes. These cells then differentiate into "osteoblast-like" cells that are capable of producing a calcified interstitial matrix by several ossification systems. FxRG Farnesoid X Receptor Gene, cJNK c-Jun N-Terminal kinase. 

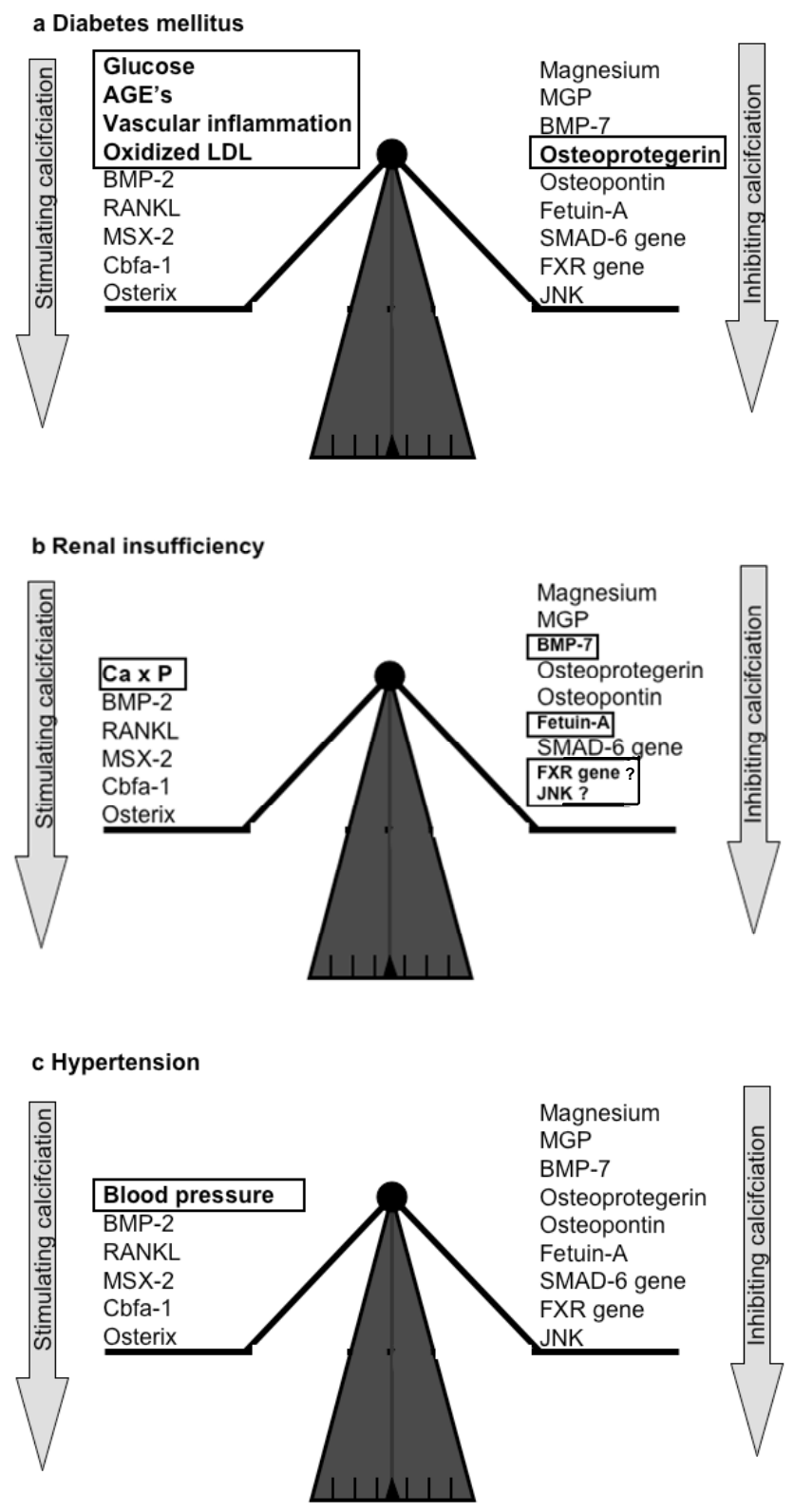

Figure 1.2 Balance between stimulating and inhibiting factors of vascular calcification in a: Diabetes Mellitus patients, b: patients with renal insufficiency and c: patients with hypertension. AGE's Advanced Glycosylation Endproducts; BMP Bone Morphogenetic Protein; RANKL Receptor Activator for Nuclear factor Kappa B Ligand; MSX-2 msh homeobox 2; Cbfa-1 Core Binding Factor-1; MGP Matrix Gla Protein; FXR gene Farnesoid X Receptor gene; jnk Jun N-Terminal Kinase; Ca Calcium; P Phosphate. 
Besides their high glucose, diabetic subjects have more vascular inflammation compared to non-diabetic subjects and this may stimulate BMP-2. Moreover, diabetes is associated with increased levels and uptake of acetylated and oxidized low density cholesterol (LDL) by macrophages and hence increased foam cell formation. ${ }^{16}$ It has been shown that acetylated LDL cholesterol stimulates osteogenic differentiation of human vascular smooth muscle cells through an interaction with the scavenger receptor class $A 1$ and that it possibly also inhibits the removal of apoptotic cells by preventing macrophage binding. ${ }^{17,18}$ However, the higher levels of osteoprotegerin as found in diabetes, independently of vascular inflammation, suggest another, yet unknown, pathophysiological mechanism of vascular calcification in diabetes. ${ }^{19-22}$

\section{Renal insufficiency}

Vascular calcification is also more prevalent in renal insufficiency patients than in normal subjects, and located mainly in the aorta, the subclavian arteries and the coronary arteries (Table 1.1).

Increased phosphate levels and hence a higher calcium phosphate product, which is typically also found in patients with renal insufficiency, is positively associated with vascular calcification. ${ }^{23-26}$ Indeed, intracellular phosphate stimulates the production of core binding factor-1 (Runx2), ${ }^{27}$ and both calcium and phosphate promote vesicle release from vascular smooth muscle cells. The latter may initially serve as a protective mechanism against high intracellular calcium contents but eventually it will enhance apoptosis and form a nidus for further matrix calcification. ${ }^{28}$ Besides the higher calcium phosphate product, subjects with renal insufficiency also have compromised defence mechanisms against calcification as illustrated by their lower serum levels of fetuin-A and bone morphogenetic protein type-7. 27

Table 1.1 Prevalence of vascular calcification in different populations (\%)

\begin{tabular}{lcccc}
\hline Blood vessel & Normal subjects $^{31}$ & Diabetes $^{31}$ & Renal insufficiency & Hypertension $^{31}$ \\
\hline General & & & $66^{32,55}-75^{56}$ & \\
Coronaries & 55 & 78 & $40^{57}-83^{58}$ & 64 \\
Carotid arteries & 29 & 60 & $71^{59}$ & 46 \\
Subclavian arteries & 31 & 34 & $75^{60}$ & 38 \\
Thoracic aorta & 35 & 52 & $51^{61}-75^{60}$ & 45 \\
Abdominal aorta & 52 & 67 & $82^{62}$ & 68 \\
Ilio femoral axis & 47 & $41^{63}-64-71^{64}$ & $61^{56}-64^{65}$ & 54 \\
\hline
\end{tabular}

\section{Hypertension}

In hypertensive patients vascular calcification is more prevalent than in normal subjects and located mainly in the abdominal aorta and the coronary arteries (Table 1.1). 
There is a clear association between the height of blood pressure and vascular calcification. ${ }^{29-33}$ Moreover, therapy resistant isolated systolic hypertension is closely related to the extent of aortic calcification. ${ }^{34}$ Although ongoing vascular calcification leads to an increase in blood pressure (mainly pulse pressure), high blood pressure itself probably also induces vascular calcification. ${ }^{35,36}$ The proposed mechanism is an increase in BMP-2 action by mechanical stress to the vasculature. ${ }^{37,38}$

\section{Clinical implications of vascular calcification}

Vascular calcification is associated with adverse cardiovascular outcomes in almost all subjects. However, in patients with comorbidity that comprises a higher cardiovascular risk (e.g. diabetes mellitus, renal insufficiency), the presence of vascular calcification implies a much larger increase in risk compared to healthy subjects. $^{39}$ The presence of calcium in blood vessels doubled the risk for any cardiovascular event in diabetic subjects and multiplied it by six in subjects with renal insufficiency compared to their fellow patients without vascular calcifications. ${ }^{39}$ Although calcification is also prevalent in hypertensive subjects, there are no studies which have addressed the association between vascular calcification and cardiovascular end points in these subjects. However, calcification of the aorta is positively associated with blood pressure and pulse pressure, which in turn raises cardiovascular risk. $^{31}$

\section{Treatment}

Several treatments to lower the calcium content of blood vessels have been investigated. In this respect, calcium channel blockers (CCBs) are likely candidates to have anti calcification properties since these drugs inhibit calcium entry in smooth muscle cells by blocking L-type calcium channels. Indeed verapamil, a phenylalkylamine, reduces calcification of bovine vascular smooth muscle cells and rat aorta. ${ }^{40}$ Although the dihydropyridine CCBs also block L-type calcium channels, these drugs do not show this effect, suggesting that verapamil has a specific yet unknown action. ${ }^{40}$ Indeed, recent data show that verapamil occupies a different binding site of L-type calcium channels when compared to dihydropyridine calcium antagonists. ${ }^{41}$ In contrast, in the aorta of male Wistar rats elastocalcinosis induced by warfarin can be completely prevented by administration of amlodipine. ${ }^{42}$ In humans with hypertension significantly less progression of coronary calcification was seen with nifedipine compared to co-amilozide. ${ }^{43}$ Nevertheless, there was no difference in the occurrence of cerebrovascular and cardiovascular end points in this study.

Reports about the potential of bisphosphonates to reduce vascular calcification are conflicting and the mechanisms are not fully understood. Aortic calcification induced 
by warfarin and vitamin $D$ in rats was absent when bisphosphonates were administered concomitantly. ${ }^{44,45}$ Risedronate combined with alfacalcidol, used to treat osteoporosis in 13 diabetic Japanese postmenopausal women, appeared to halt progression of abdominal aortic calcification compared to matched non osteoporotic control subjects with diabetes. ${ }^{46}$ Etidronate was effective in reducing progression of coronary artery calcification in dialysis patients. ${ }^{47}$ On the contrary, there was no inhibitory effect of alendronate on progressive calcification in the abdominal aorta in dialysis patients who were treated for 18 months. ${ }^{48}$

The vitamin K dependent Matrix Gla protein (MGP) is a potent inhibitor of calcification. The intake of vitamin $\mathrm{K}$ is associated with cardiovascular outcome and blocking the recycling of vitamin $\mathrm{K}$ by warfarin leads to excess calcification of blood vessels. $^{49}$ Whether treating patients on warfarin with vitamin $\mathrm{K}$ to stimulate carboxylation of MGP reduces calcification has yet to be explored.

Statins are known to reduce vascular inflammation and therefore may influence the vascular calcification process. However, a recent meta-analysis showed no effect of statins on coronary calcification. ${ }^{50}$

The calcium sensor receptor agonist cinecalcet was able to halt progression of vascular calcification in rats with renal insufficiency. ${ }^{51}$ Recently evidence was presented that cinecalcet might also slow progression of coronary and heart valve calcification in patients with renal insufficiency on dialysis compared to subjects using vitamin D to lower parathyroid hormone levels (PTH). ${ }^{52}$ The proposed mechanism is a lowering of PTH without increasing serum calcium levels and thus resulting in a lower calcium phosphate product.

Several new calcification inhibitor pathways like magnesium induced up regulation of the magnesium transporter and up regulation of the farnesoid $X$ receptor gene have been reported but their potency to inhibit calcification in humans has not yet been investigated. ${ }^{53,54}$

\section{Conclusion}

Although it seems reasonable to treat subjects with calcifications and accompanying risk factors according to guidelines, there are no trials on treatment strategies focussing on the reduction of calcification as a means to lower morbidity and mortality. However, given the fact that vascular calcification is an independent cardiovascular risk factor, the aforementioned differences in the process of calcification and the availability of possible interventions in the calcification process, it is conceivable that this has consequences for further treatment in these patients. 


\section{Outline of the thesis}

In this thesis we aim to answer several questions with regard to the cardiovascular risk associated with vascular calcification in different patient groups, and to further explore the biological properties and function of one specific protein, MGP, in vascular calcification.

Calcification is a highly complex process. Many of the regulators of calcification are proteins. In chapter $\mathbf{2}$ we discuss the biological properties of these proteins and their function in stimulating or inhibiting vascular calcification.

There are several meta-analyses linking coronary artery calcification to cardiovascular risk. There are only a few reports on calcification found elsewhere in the body with different imaging techniques. In Chapter $\mathbf{3}$ we describe a meta-analysis to answer the question if any form of vascular calcification as detected with any imaging technique has consequences for the cardiovascular risk in different patient populations.

Chapter $\mathbf{4}$ describes the exploration of MGP levels in hypertensive subjects compared to healthy controls. Hypertensive subjects are more prone to vascular calcification. We wondered whether this is associated with different MGP levels in hypertensives. There is abundant research about the production of MGP by smooth muscle cells and chondrocytes. There are no reports about how MGP is cleared from the circulation. Because of its size we expect MGP to be cleared by the kidney. Therefore, in Chapter 5 we describe the measurements of renal clearance of MGP in hypertensive subjects. There are several reports about calcification contributing to vascular stiffness. As MGP plays an important role in vascular calcification, we expect that MGP levels are also associated with vascular stiffness. To answer the question if this assumption is correct we determined MGP in the Hoorn cohort, which contains patients with DM2, subjects with impaired glucose tolerance, and healthy subjects, in which extensive measurements of vascular stiffness were done. The results of this study are reported in Chapter 6.

As MGP is activated by vitamin $\mathrm{K}$ and several reports studied the effect of vitamin $\mathrm{K}$ on coronary calcification in humans, we wondered if there is a clear association between vitamin K, MGP and vascular calcification in different arteries besides the coronaries. In Chapter $\mathbf{7}$ we therefore investigate the relationship between vascular calcification of the coronaries, the carotid arteries, the abdominal aorta, MGP and vitamin $\mathrm{K}$ status.

Coumarin treatment in rats generates extensive vascular calcification. In humans there is an association between coumarin treatment and coronary calcification. To answer the question if coumarin treatment also leads to enhanced extra-coronary vascular calcification we looked for calcium deposits in the femoral arteries of relatively young patients on long term coumarin treatment and compared them to a healthy control population and the results are reported in Chapter $\mathbf{8}$. 
Finally, in Chapter 9 we discuss the main findings of the above mentioned studies. We discuss possible future research necessary to expand knowledge about vascular calcification and MGP. 


\section{References}

1. Wong GA, Tang V, El-Sabeawy F, Weiss RH. BMP-2 inhibits proliferation of human aortic smooth muscle cells via p21Cip1/Waf1. American journal of physiology 2003;284:E972-9.

2. Hruska KA, Mathew S, Saab G. Bone morphogenetic proteins in vascular calcification. Circ Res 2005; 97:105-14.

3. Proudfoot D, Skepper JN, Hegyi L, Bennett MR, Shanahan CM, Weissberg PL. Apoptosis regulates human vascular calcification in vitro: evidence for initiation of vascular calcification by apoptotic bodies. Circ Res 2000;87:1055-62.

4. Ahrens M, Ankenbauer T, Schroder D, Hollnagel A, Mayer H, Gross G. Expression of human bone morphogenetic proteins-2 or -4 in murine mesenchymal progenitor C3H10T1/2 cells induces differentiation into distinct mesenchymal cell lineages. DNA Cell Biol 1993;12:871-80.

5. Ghosh-Choudhury N, Choudhury GG, Harris MA, Wozney J, Mundy GR, Abboud SL, Harris SE. Autoregulation of mouse BMP-2 gene transcription is directed by the proximal promoter element. Biochem Biophys Res Commun 2001;286:101-8.

6. Nakashima K, Zhou X, Kunkel G, Zhang Z, Deng JM, Behringer RR, de Crombrugghe B. The novel zinc finger-containing transcription factor osterix is required for osteoblast differentiation and bone formation. Cell 2002;108:17-29.

7. Rifas L, Arackal S, Weitzmann MN. Inflammatory T cells rapidly induce differentiation of human bone marrow stromal cells into mature osteoblasts. J Cell Biochem 2003;88:650-9.

8. Rennenberg RJ, Schurgers LJ, Kroon AA, Stehouwer CD. Arterial calcifications. J Cell Mol Med 2010;14:2203-10.

9. Ishimura E, Okuno S, Kitatani K, Kim M, Shoji T, Nakatani T, Inaba M, Nishizawa Y. Different risk factors for peripheral vascular calcification between diabetic and non-diabetic haemodialysis patients--importance of glycaemic control. Diabetologia 2002;45:1446-8.

10. McNeely MJ, McClelland RL, Bild DE, Jacobs DR Jr, Tracy RP, Cushman M, Goff DC Jr, Astor BC, Shea S, Siscovick DS. The association between $\mathrm{A} 1 \mathrm{C}$ and subclinical cardiovascular disease: the multi-ethnic study of atherosclerosis. Diabetes Care 2009;32:1727-33.

11. Anand DV, Lim E, Darko D, Bassett P, Hopkins D, Lipkin D, Corder R, Lahiri A. Determinants of progression of coronary artery calcification in type 2 diabetes role of glycemic control and inflammatory/vascular calcification markers. J Am Coll Cardiol 2007;50:2218-25.

12. Conway B, Edmundowicz D, Matter N, Maynard J, Orchard T. Skin fluorescence correlates strongly with coronary artery calcification severity in type 1 diabetes. Diabetes Technol Ther 2010;12:339-45.

13. Basta G, Corciu Al, Vianello A, Del Turco S, Foffa I, Navarra T, Chiappino D, Berti S, Mazzone A. Circulating soluble receptor for advanced glycation end-product levels are decreased in patients with calcific aortic valve stenosis. Atherosclerosis;210:614-8.

14. Tanikawa T, Okada Y, Tanikawa R, Tanaka Y. Advanced glycation end products induce calcification of vascular smooth muscle cells through RAGE/p38 MAPK. J Vasc Res 2009;46:572-80.

15. Ren X, Shao H, Wei Q, Sun Z, Liu N. Advanced glycation end-products enhance calcification in vascular smooth muscle cells. The Journal of international medical research 2009;37:847-54.

16. Fukuhara-Takaki K, Sakai M, Sakamoto Y, Takeya M, Horiuchi S. Expression of class A scavenger receptor is enhanced by high glucose in vitro and under diabetic conditions in vivo: one mechanism for an increased rate of atherosclerosis in diabetes. The Journal of biological chemistry 2005;280:3355-64.

17. Proudfoot D, Davies JD, Skepper JN, Weissberg PL, Shanahan CM. Acetylated low-density lipoprotein stimulates human vascular smooth muscle cell calcification by promoting osteoblastic differentiation and inhibiting phagocytosis. Circulation 2002;106:3044-50.

18. Parhami F, Morrow AD, Balucan J, Leitinger N, Watson AD, Tintut Y, Berliner JA, Demer LL. Lipid oxidation products have opposite effects on calcifying vascular cell and bone cell differentiation. A possible explanation for the paradox of arterial calcification in osteoporotic patients. Arterioscler Thromb Vasc Biol 1997;17:680-7.

19. Bucay N, Sarosi I, Dunstan CR, Morony S, Tarpley J, Capparelli C, Scully S, Tan HL, Xu W, Lacey DL, Boyle WJ, Simonet WS. osteoprotegerin-deficient mice develop early onset osteoporosis and arterial calcification. Genes Dev 1998;12:1260-8. 
20. Collin-Osdoby P. Regulation of vascular calcification by osteoclast regulatory factors RANKL and osteoprotegerin. Circulation research 2004;95:1046-57.

21. Rasmussen LM, Ledet T. Osteoprotegerin and diabetic macroangiopathy. Horm Metab Res 2005;37 Suppl 1:90-4.

22. O'Sullivan EP, Ashley DT, Davenport C, Devlin N, Crowley R, Agha A, Thompson CJ, O'Gorman D, Smith D. Osteoprotegerin and biomarkers of vascular inflammation in type 2 diabetes. Diabetes/metabolism research and reviews 2010;26:496-502.

23. Wang TK, Bolland MJ, van Pelt NC, Horne AM, Mason BH, Ames RW, Grey AB, Ruygrok PN, Gamble GD, Reid IR. Relationships between vascular calcification, calcium metabolism, bone density, and fractures. J Bone Miner Res 2010;25:2777-85.

24. Oh J, Wunsch R, Turzer M, Bahner M, Raggi P, Querfeld U, Mehls O, Schaefer F. Advanced coronary and carotid arteriopathy in young adults with childhood-onset chronic renal failure. Circulation 2002;106:100-5.

25. Block GA, Hulbert-Shearon TE, Levin NW, Port FK. Association of serum phosphorus and calcium $x$ phosphate product with mortality risk in chronic hemodialysis patients: a national study. Am J Kidney Dis 1998;31:607-17.

26. Goodman WG, Goldin J, Kuizon BD, Yoon C, Gales B, Sider D, Wang Y, Chung J, Emerick A, Greaser L, Elashoff RM, Salusky IB. Coronary-artery calcification in young adults with end-stage renal disease who are undergoing dialysis. N Engl J Med 2000;342:1478-83.

27. Farzaneh-Far A, Shanahan CM. Biology of vascular calcification in renal disease. Nephron Exp Nephrol 2005;101:e134-8.

28. Shroff RC, McNair R, Skepper JN, Figg N, Schurgers LJ, Deanfield J, Rees L, Shanahan CM. Chronic mineral dysregulation promotes vascular smooth muscle cell adaptation and extracellular matrix calcification. J Am Soc Nephrol 2010;21:103-12.

29. Jamjoum LS, Bielak LF, Turner ST, Sheedy II PF, Boerwinkle E, Raghunathan TE, Peyser PA. Relationship of blood pressure measures with coronary artery calcification. Med Sci Monit 2002;8:CR775-81.

30. Rodrigues TC, Canani LH, Schvartzman P, Gross JL. Hypertension is the Metabolic Syndrome Component Most Strongly Associated with Microvascular Complications and Coronary Artery Calcification in Type 1 Diabetes. J Endocrinol Invest 2010; Epub ahead of print.

31. Jensky NE, Criqui MH, Wright MC, Wassel CL, Brody SA, Allison MA. Blood pressure and vascular calcification. Hypertension 2010;55:990-7.

32. Blacher J, Guerin AP, Pannier B, Marchais SJ, London GM. Arterial calcifications, arterial stiffness, and cardiovascular risk in end-stage renal disease. Hypertension 2001;38:938-42.

33. Bielak LF, Turner ST, Franklin SS, Sheedy PF, 2nd, Peyser PA. Age-dependent associations between blood pressure and coronary artery calcification in asymptomatic adults. Journal of hypertension 2004;22:719-25.

34. McEniery CM, McDonnell BJ, So A, Aitken S, Bolton CE, Munnery M, Hickson SS, Yasmin, Maki-Petaja KM, Cockcroft JR, Dixon AK, Wilkinson IB; Anglo-Cardiff Collaboration Trial Investigators. Aortic calcification is associated with aortic stiffness and isolated systolic hypertension in healthy individuals. Hypertension 2009;53:524-31.

35. Essalihi R, Dao HH, Yamaguchi N, Moreau P. A new model of isolated systolic hypertension induced by chronic warfarin and vitamin K1 treatment. Am J Hypertens 2003;16:103-10.

36. Lemarie CA, Tharaux $\mathrm{PL}$, Lehoux $\mathrm{S}$. Extracellular matrix alterations in hypertensive vascular remodeling. J Mol Cell Cardiol 2010;48:433-9.

37. Csiszar A, Smith KE, Koller A, Kaley G, Edwards JG, Ungvari Z. Regulation of bone morphogenetic protein-2 expression in endothelial cells: role of nuclear factor-kappaB activation by tumor necrosis factor-alpha, $\mathrm{H} 2 \mathrm{O} 2$, and high intravascular pressure. Circulation 2005;111:2364-72.

38. Ungvari Z, Csiszar A, Kaminski PM, Wolin MS, Koller A. Chronic high pressure-induced arterial oxidative stress: involvement of protein kinase C-dependent $\mathrm{NAD}(\mathrm{P}) \mathrm{H}$ oxidase and local reninangiotensin system. The American journal of pathology 2004;165:219-26.

39. Rennenberg RJ, Kessels AG, Schurgers LJ, van Engelshoven JM, de Leeuw PW, Kroon AA. Vascular calcifications as a marker of increased cardiovascular risk: A meta-analysis. Vasc Health Risk Manag 2009;5:185-97. 
40. Chen NX, Kircelli F, O'Neill KD, Chen X, Moe SM. Verapamil inhibits calcification and matrix vesicle activity of bovine vascular smooth muscle cells. Kidney international 2010;77:436-42.

41. Du H, He J, Wang S, He L. Investigation of calcium antagonist-L-type calcium channel interactions by a vascular smooth muscle cell membrane chromatography method. Analytical and bioanalytical chemistry 2010;397:1947-53.

42. Essalihi R, Zandvliet ML, Moreau S, Gilbert LA, Bouvet C, Lenoël C, Nekka F, McKee MD, Moreau P. Distinct effects of amlodipine treatment on vascular elastocalcinosis and stiffness in a rat model of isolated systolic hypertension. Journal of hypertension 2007;25:1879-86.

43. Motro M, Shemesh J. Calcium channel blocker nifedipine slows down progression of coronary calcification in hypertensive patients compared with diuretics. Hypertension 2001;37:1410-3.

44. Price PA, Faus SA, Williamson MK. Bisphosphonates alendronate and ibandronate inhibit artery calcification at doses comparable to those that inhibit bone resorption. Arterioscler Thromb Vasc Biol 2001;21:817-24.

45. Lomashvili KA, Monier-Faugere MC, Wang X, Malluche HH, O'Neill WC. Effect of bisphosphonates on vascular calcification and bone metabolism in experimental renal failure. Kidney international 2009;75:617-25.

46. Kanazawa I, Yamaguchi T, Hayashi K, Takase H, Shimizu T, Sugimoto T. Effects of treatment with risedronate and alfacalcidol on progression of atherosclerosis in postmenopausal women with type 2 diabetes mellitus accompanied with osteoporosis. The American journal of the medical sciences 2010;339:519-24.

47. Nitta K, Akiba T, Suzuki K, Uchida K, Watanabe R, Majima K, Aoki T, Nihei H. Effects of cyclic intermittent etidronate therapy on coronary artery calcification in patients receiving long-term hemodialysis. Am J Kidney Dis 2004;44:680-8.

48. Toussaint ND, Lau KK, Strauss BJ, Polkinghorne KR, Kerr PG. Effect of alendronate on vascular calcification in CKD stages 3 and 4: a pilot randomized controlled trial. Am J Kidney Dis 2010;56:57-68.

49. Rennenberg RJ, van Varik BJ, Schurgers $L$, Hamulyak K, Ten Cate H, Leiner T, Vermeer C, de Leeuw PW, Kroon AA. Chronic coumarin treatment is associated with increased extracoronary arterial calcification in humans. Blood 2010;115:5121-3.

50. Henein MY, Owen A. Statins moderate coronary stenoses but not coronary calcification: Results from meta-analyses. International journal of cardiology 2010;Article in press.

51. Henley C, Colloton M, Cattley RC, Shatzen E, Towler DA, Lacey D, Martin D. 1,25-Dihydroxyvitamin D3 but not cinacalcet $\mathrm{HCl}$ (Sensipar/Mimpara) treatment mediates aortic calcification in a rat model of secondary hyperparathyroidism. Nephrol Dial Transplant 2005;20:1370-7.

52. Raggi P, Chertow GM, Torres PU, Csiky B, Naso A, Nossuli K, Moustafa M, Goodman WG, Lopez N, Downey G, Dehmel B, Floege J; on behalf of the ADVANCE Study Group. The ADVANCE study: a randomized study to evaluate the effects of cinacalcet plus low dose vitamin $D$ on vascular calcification in patients on hemodialysis. Nephrol Dial Transplant. 2011;26:1327-39.

53. Montezano AC, Zimmerman D, Yusuf H, Burger D, Chignalia AZ, Wadhera V, van Leeuwen FN, Touyz RM. Vascular smooth muscle cell differentiation to an osteogenic phenotype involves TRPM7 modulation by magnesium. Hypertension 2010;56:453-62.

54. Miyazaki-Anzai S, Levi M, Kratzer A, Ting TC, Lewis LB, Miyazaki M. Farnesoid X receptor activation prevents the development of vascular calcification in ApoE-/- mice with chronic kidney disease. Circulation research 2010;106:1807-17.

55. Guerin AP, London GM, Marchais SJ, Metivier F. Arterial stiffening and vascular calcifications in endstage renal disease. Nephrol Dial Transplant 2000;15:1014-21.

56. Adragao T, Pires A, Lucas C, Birne R, Magalhaes L, Gonçalves M, Negrao AP. A simple vascular calcification score predicts cardiovascular risk in haemodialysis patients. Nephrol Dial Transplant 2004;19:1480-8.

57. Russo D, Palmiero G, De Blasio AP, Balletta MM, Andreucci VE. Coronary artery calcification in patients with CRF not undergoing dialysis. Am J Kidney Dis 2004;44:1024-30.

58. Raggi P, Boulay A, Chasan-Taber S, Amin N, Dillon M, Burke SK, Chertow GM. Cardiac calcification in adult hemodialysis patients. A link between end-stage renal disease and cardiovascular disease? Journal of the American College of Cardiology 2002;39:695-701. 
59. Sumida Y, Nakayama M, Nagata M, Nakashita S, Suehiro T, Kaizu Y, Ikeda H, Izumaru K. Carotid artery calcification and atherosclerosis at the initiation of hemodialysis in patients with end-stage renal disease. Clinical nephrology 2010;73:360-9.

60. Toussaint ND, Lau KK, Polkinghorne KR, Kerr PG. Measurement of vascular calcification using CT fistulograms. Nephrol Dial Transplant 2007;22:484-90.

61. Fabbian F, Catalano C, Orlandi V, Conte MM, Lupo A, Catizone L. Evaluation of aortic arch calcification in hemodialysis patients. Journal of nephrology 2005;18:289-93.

62. Hanada S, Ando R, Naito S, Kobayashi N, Wakabayashi M, Hata T, Sasaki S. Assessment and significance of abdominal aortic calcification in chronic kidney disease. Nephrol Dial Transplant;25:1888-95.

63. Niskanen L, Siitonen O, Suhonen M, Uusitupa MI. Medial artery calcification predicts cardiovascular mortality in patients with NIDDM. Diabetes Care 1994;17:1252-6.

64. Lehto S, Niskanen L, Suhonen M, Ronnemaa T, Laakso M. Medial artery calcification. A neglected harbinger of cardiovascular complications in non-insulin-dependent diabetes mellitus. Arterioscler Thromb Vasc Biol 1996;16:978-83.

65. London GM, Guerin AP, Marchais SJ, Metivier F, Pannier B, Adda H. Arterial media calcification in endstage renal disease: impact on all-cause and cardiovascular mortality. Nephrol Dial Transplant 2003;18:1731-40. 


\section{Chapter 2}

\section{Arterial calcifications}

Rennenberg RJ, Schurgers LJ, Kroon AA, Stehouwer CDA J Cell Mol Med. 2010;14:2203-10 
| Chapter 2 


\section{Introduction}

Modern imaging techniques often reveal arterial calcifications as an unexpected finding. Previously, such calcifications were considered to represent an inert endpoint of atherosclerosis, but recent data suggest that vascular calcification is an active process occurring already in early stages of atherosclerotic lesions. ${ }^{1-3}$ In addition, calcification of arterial vessels is associated with adverse cardiovascular outcomes, especially in subjects with coronary calcification and in patients with renal insufficiency. ${ }^{4-9}$ Even in otherwise normal subjects who participated in a screening program calcification as measured with electron beam computed tomography (EBCT) appeared to be an independent risk factor for the development of cardiovascular events. Although vascular calcification is associated with several known cardiovascular risk factors ${ }^{10,11}$, it predicts cardiovascular risk independently of these risk factors. ${ }^{10,12-14}$ Thus, the presence of calcification is not as innocent as it may seem. ${ }^{8,12,13,15}$

Calcification is mostly present in the vascular intima in association with atherosclerosis but it can also occur in the media. The latter is frequently seen in elderly populations, in diabetic patients, and in uremic patients, and in those populations it is not necessarily associated with the presence of atherosclerotic plaques.

Deposits of calcium in the vascular wall are usually detected with X-ray. When vascular regions on these X-rays of e.g. chest, abdomen, or other large arteries have a density similar to that of bone, calcification is diagnosed. These images are useful not only as a localisation tool, but also for estimation of the overall number of calcified regions in the body and, hence, cardiovascular risk. ${ }^{16} \mathrm{X}$-ray images, however, are not reliable enough to quantify the amount of calcium. This can be done more accurately using computed tomography (CT). With CT, density of pixels is expressed as Hounsfield units and calcium is usually suspected when a pixel exceeds 130 Hounsfield units. At least in the coronary arteries, this technique is currently the only validated one for quantification of calcification. ${ }^{17}$

In the following we will discuss the clinical importance of large artery calcification and the currently known mechanisms of calcification in different populations. Such information may help us to better understand the arterial calcification process which, in turn, could eventually lead to the development of specific intervention strategies.

\section{Pathobiology of arterial calcification}

Studies in experimental animals as well as in-vitro studies in human cells have identified several proteins which play a role in the calcification process. ${ }^{18-22}$ Unravelling the function and the mechanism of action of these proteins has been a topic for many researchers in the past few years. Some proteins act as inhibitors of calcification, whereas others promote the deposition of calcium in the vascular wall. 
Vascular smooth muscle cells (VSMCs) which migrate to the intimal layer of the vasculature lose their contractile phenotype, and transform into so-called synthetic VSMCs. When the latter become apoptotic in the atherosclerotic lesion they may form the nidus for calcification. ${ }^{23,24}$ Moreover, VSMCs can change their phenotype upon calcification and develop features of osteoblast- or chondrocyte-like cells with respect to gene expression. ${ }^{25}$ Table 2.1 shows proteins involved in calcification subdivided according to their calcification-inhibiting or -promoting properties. Below we discuss these proteins and their biological properties in more detail.

Table 2.1 Proteins involved in arterial calcification.

\begin{tabular}{ll}
\hline Inhibitor proteins & Promoter proteins \\
\hline Matrix Gla Protein & Bone Morphogenetic Protein type 2 \\
Fetuin-A & Receptor Activator for Nuclear Factor Kappa B Ligand \\
Osteopontin & \\
Osteoprotegerin & \\
Bone Morphogenetic Protein type 7 & \\
\hline
\end{tabular}

\section{Matrix Gla-Protein}

Matrix Gla-Protein (MGP) is a $10 \mathrm{kD}$ vitamin K-dependent protein which was first discovered by Price et al. ${ }^{26}$ It is produced by vascular smooth muscle cells and chondrocytes, and accumulates at sites of calcification. ${ }^{22}$ Its production is stimulated by an increase in local calcium levels and during this production process MGP is changed by two posttranslational modifications: phosphorylation and vitamin K-driven $\gamma$-glutamyl carboxylation. ${ }^{27-29}$ The active (carboxylated) protein is believed to be a regulator of bone morphogenetic protein type 2 (BMP2), but it can also bind directly to calcium crystals in the vascular matrix, thereby preventing further calcification growth. ${ }^{30}$ Animal studies show that a deficiency or impairment of MGP due to, for instance, a mutation in the epoxide reductase subsegment 1 or blockade of vitamin $\mathrm{K}$ leads to extreme calcification of the vascular matrix. ${ }^{31-34}$ In the human "Keutel syndrome", an autosomal recessive disorder in which patients lack MGP, excessive calcification of large arteries is seen. ${ }^{35}$ Serum unphosphorylated MGP (dpMGP) levels are inversely proportional to coronary calcification and uncarboxylated MGP (UCMGP) levels were significantly lower in patients who underwent PTCA than in a healthy control population. ${ }^{36,37}$ Several experimental studies suggest that MGP, which is produced in the vascular matrix, is transported into plasma in combination with fetuin (see below) as the fetuin-mineral complex. ${ }^{38,39}$ Whether serum MGP levels are a reliable reflection of the calcification process in the vascular wall is not yet clear, although from the previously mentioned studies it would seem that patients with high cardiovascular risk have lower serum dpMGP and ucMGP levels as opposed to higher dp-ucMGP levels. ${ }^{28}$ An obvious advantage of MGP is that the protein's activity 
completely depends upon vitamin $\mathrm{K}$, and thereby can be modulated by extra vitamin $\mathrm{K}$ intake. On the other hand, blocking carboxylation of MGP (i.e. with coumarines) or low vitamin $\mathrm{K}$ levels (i.e. deficient intake) result in excess calcification. ${ }^{40-42}$

\section{Fetuin-A}

Fetuin-A is a $56 \mathrm{kDa}$ glycoprotein which is produced in the liver and circulates at high serum concentrations $(0.4-1.0 \mathrm{~g} / \mathrm{l}) .{ }^{43}$ It acts as a negative acute phase protein and is a powerful inhibitor of calcification. ${ }^{43-45}$ Together with MGP, fetuin-A makes up a complex with calcium and phosphate which transports and clears the insoluble calcium-phosphate salt, and so prevents extra skeletal deposition of calcium. ${ }^{46}$ In transgenic fetuin-A deficient mice (Fetuin-A-/- mice), extra skeletal calcification, including soft tissue and perivertebral arterial calcification, develop. ${ }^{44}$ Other arteries are spared from calcifications, most likely because of up-regulation of other potent calcification inhibitors such as MGP and osteopontin. ${ }^{47}$ In dialysis patients serum fetuin-A levels vary inversely with the degree of coronary artery calcification. ${ }^{48}$ Studies also show that low levels of fetuin-A are associated with enhanced all-cause and cardiovascular mortality. ${ }^{49-51}$ This effect may be mediated in part by inflammation, as low fetuin correlates with higher levels of C-reactive protein (CRP).

\section{Bone Morphogenetic Protein (BMP)}

Bone morphogenetic proteins are members of the TGF-ß superfamily, and play key signalling roles in the maintenance and repair of bone and other tissues in the adult. Their role in vascular calcification is complex. When VSMCs change their phenotype from contractile to synthetic cells, they enter a state of proliferation in which the expression of smooth muscle markers is diminished. However, they produce large amounts of extracellular matrix proteins and even become osteoblast-like cells. Two forms of BMP, BMP-2 and BMP-7, have been extensively studied in relation to vascular calcification. $^{52,53}$

Strikingly, BMP-2 is associated with a decrease in smooth muscle cell markers whereas BMP-7 promotes the vascular smooth muscle cell phenotype. In chronic kidney disease levels of BMP-7, which is mainly produced by the kidney, are low. ${ }^{54}$ This might be one of the reasons why especially chronic renal failure patients are prone to excessive calcification (see section on chronic kidney disease below) 


\section{Osteopontin (OPN)}

Osteopontin is an acidic extracellular phosphoprotein. The phosphoserines within OPN are negatively charged amino acids, which have a strong affinity for hydroxyapatite. It is normally present in mineralised tissues like bones and teeth. Mice lacking OPN are susceptible to vascular calcifications. ${ }^{21}$ OPN regulates mineralization in two different ways. On the one hand it inhibits apatite crystal growth, on the other it promotes osteoclast function. In normal arteries OPN is absent, whereas in calcified plaques it is abundantly present. Research suggests that OPN is important in regulating calcification when the artery is injured. ${ }^{55}$

\section{Receptor Activator for Nuclear factor Kappa B Ligand (RANKL)}

RANKL is a 316-amino acid transmembrane protein. It is highly expressed by T-cells in lymphoid tissue and by osteoblasts in trabecular bone. RANKL binds to RANK, a 616amino acid transmembrane receptor which is present amongst others on osteoclasts and their precursors. This binding generates multiple intracellular signals that regulate cell differentiation, function and survival. RANKL action can be blocked by osteoprotegerin (OPG) thereby inhibiting vascular calcification. RANK/RANKL/OPG belong to the TNF-alpha family. RANKL is upregulated in osteoblasts by $1 \alpha, 25$ dihydroxyvitamin $D_{3}$, parathyroid hormone, glucocorticoids, prostaglandin E2, interleukin-1 $\alpha$, TNF- $\alpha$, interleukin-6, interleukin-11, interleukin-17, calcium or immuno-suppressants like cyclosporin A. Downregulation of RANKL is mediated through transforming growth factor $\beta$. In animal studies RANKL increases osteoclast size and function. Disruption of RANKL results in inhibition of osteoclast formation and function. ${ }^{56-59}$

\section{Osteoprotegerin (OPG)}

Osteoprotegerin is a $\mathbf{3 8 0}$ amino acid acting as a soluble (decoy)-receptor for RANKL. It is produced by many tissues in the body, including the cardiovascular system. OPG expression is particularly high in vascular smooth muscle cells and vascular endothelial cells of the aorta and the renal arteries. It prevents the binding of RANKL to RANK. ${ }^{56,58}$ OPG is increased by some of the stimuli that also increase RANKL and by estrogen, TGF- $\beta$ and BMP-2. Decreased levels are seen with increased parathyroid hormone levels, glucocorticoids, prostaglandin $E_{2}$, insulin-like growth factor-1 or immunosuppressants. A steady balance between RANKL and osteoprotegerin prevents disorders in bone remodelling and vascular calcification. Low osteoprotegerin expression leads to unopposed RANKL binding to RANK and thus osteoporosis and 
vascular calcification, whereas high osteoprotegerin expression leads to osteopetrosis. $^{60,61}$ Clinically, high serum levels of OPG are associated with atherosclerotic disease or risk factors for atherosclerotic disease indicating a compensatory role for OPG in vascular calcification. ${ }^{61-63}$

If there is an imbalance between the protective factors and calcification factors, progressive vascular calcification can be the result. Figure 2.1 depicts the different proteins and their role in the calcification process. First the conventional vascular risk factors result in intimal damage and subintimal lipid deposition. Subsequently, the inflammatory response induced leads to increased BMP-2. If not balanced by active (carboxylated) MGP, multipotent mesenchymal vascular cells are stimulated to differentiation into "osteoblast-like" cells. At this point the presence of enough active MGP is important both for blocking the action of BMP-2 and for binding directly to calcium crystals in the vascular matrix. ${ }^{20,30,64,65}$ The use of vitamin $\mathrm{K}$ antagonists and/or a low vitamin $\mathrm{K}$ diet results in an increase of dysfunctional MGP and thus favouring calcification. ${ }^{32,66}$ In addition, the interactions among RANKL, osteopontin and osteoprotegerin influence the rate of calcification. (Figure 2.1)

\section{Prevalence of calcifications and relation to cardiovascular outcomes}

Calcifications of the arteries are usually detected with plain X-ray or with CT. The prevalence is highly dependent upon the studied population. In a population-based cohort of over 100,000 men and women aged 30 to 89 years (mean age 47 years), who had a chest X-ray for screening purposes, prevalence of calcification in the aorta was $1.9 \%$ in male subjects and $2.6 \%$ in female subjects. ${ }^{10}$ Although calcification of the thoracic aorta commonly increases with age, the presence of these calcifications enhances the risk for cardiovascular events independently of age. ${ }^{10}$ Most of the risk factors that are associated with calcification of the aortic arch are also well known cardiovascular risk factors. (Table 2.2) Despite this similarity, aortic arch calcification itself is an independent predictor of cardiovascular risk. ${ }^{10}$ Recent research showed changes in the mechanical properties of the atherosclerotic lesion and increased inflammation in response to calcification, which may increase the risk of plaque rupture. ${ }^{10,67,68}$ In contrast to intimal calcification, medial calcification (also known as Mönckeberg's sclerosis) exclusively involves vascular smooth muscle cells (VSMCs) in the absence of inflammation and lipid infiltration. 


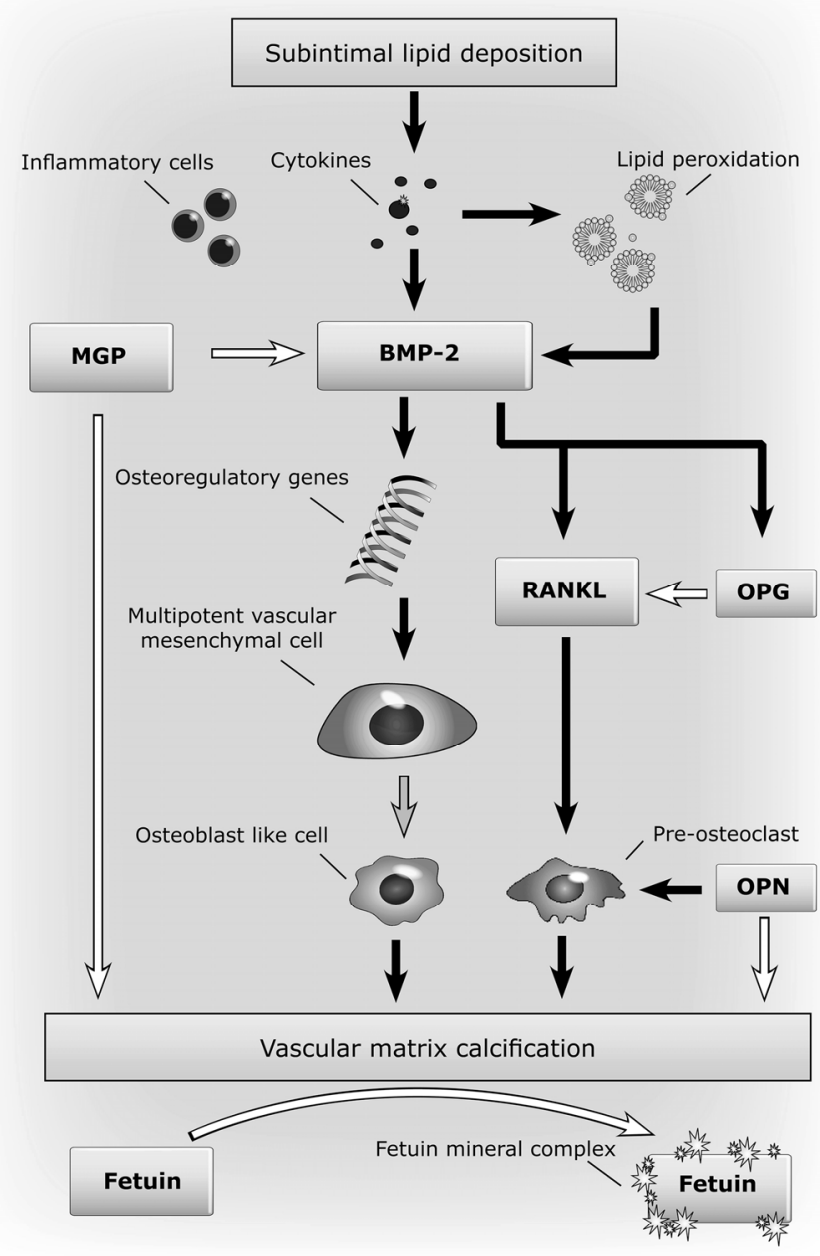

Figure 2.1 Schematic representation of proteins involved in arterial calcification.

White arrows denote an inhibiting effect, black arrows denote a stimulating effect, grey arrow denotes transition. MGP: matrix Gla protein, BMP-2: bone morphogenic protein type 2, RANKL: receptor activator of nuclear factor kappa B ligand, OPG: osteoprotegerin, OPN: osteopontin. Inflammation and lipid peroxidation modify regulatory genes. BMP-2 promotes differentiation of the mesenchymal vascular cells through induction of osteoregulatory genes. These cells then differentiate into "osteoblast-like" cells that are capable of producing a calcified interstitial matrix by several ossification systems. 
Table 2.2 Risk factors associated with aortic arch calcification as determined in 116.309 subjects. ${ }^{10}$

\begin{tabular}{ll}
\hline Risk factor & Odds ratio $(95 \% \mathrm{Cl})^{\text {q }}$ \\
\hline Age & men $2.74(2.58-2.91)$ \\
& women $3.52(3.32-3.74)$ \\
African descent & women $1.35(1.11-1.63)$ \\
No college education & men $1.17(1.00-1.36)$ \\
& women $1.31(1.14-1.50)$ \\
Total cholesterol $>6.6 \mathrm{mmol} / \mathrm{I}$ & women $1.28(1.06-1.55)$ \\
Current smoking & men $1.30(1.10-1.53)$ \\
& women $1.16(1.01-1.33)$ \\
Hypertensiont & men $1.27(1.11-1.46)$ \\
& women $1.38(1.23-1.54)$ \\
\hline
\end{tabular}

$\mathrm{Cl}$, confidence interval; ", only significant correlations are depicted; $\dagger$, This might also be caused or aggravated by vascular calcification

EBCT or multi-slice computed tomography (MSCT) are reproducible methods to measure coronary calcifications. ${ }^{17,69}$ Among a healthy American population aged 40 to 45 years, prevalence of coronary artery calcifications $(\mathrm{CaC})$ was $19.2 \%$ in white subjects and $10.3 \%$ in Afro-American subjects. ${ }^{70}$ Although Afro-Americans, compared to white subjects, in this study had more cardiovascular risk factors, they had significantly less coronary artery calcification, indicating differences in prevalence in different racial populations. ${ }^{70}$ In another study among healthy subjects older than 40 years, prevalence was $29 \%$ among men and $19 \%$ among women. ${ }^{71}$ The presence of coronary calcifications in asymptomatic individuals has been shown to be associated with an increased risk for cardiovascular endpoints. Over a variable follow up period from 3 to 4.3 years and depending on the characteristics of the studied population, the relative risk for any coronary event varied from 2.6 in low-risk females to 11.8 in healthy men aged 40 to 50 years. ${ }^{8,12,13,15}$

Calcification of the abdominal aorta as seen with CT is associated with the presence of hypertension, older age, coronary artery disease and peripheral vascular disease. ${ }^{72}$ The total area of calcification on X-ray films of the abdominal aorta is positively correlated with age, systolic blood pressure and aortic stiffness. ${ }^{73}$

Limited data exist on the association between femoral artery calcification and cardiovascular mortality. However, in patients with type 2 diabetes, femoral artery calcification is an independent predictor of cardiovascular morbidity and mortality. ${ }^{74,75}$ At present it is not clear whether measuring vascular calcification with EBCT, MSCT or plain X-ray can be used as a cost-effective strategy for cardiovascular risk stratification. A disadvantage of these techniques is the considerable amount of radiation to which patients or, indeed, asymptomatic individuals, are exposed. 


\section{Arterial calcification in specific patient populations at high risk for cardiovascular disease}

In two patient groups with excessive calcifications the involvement and defects of the above mentioned proteins have been studied in more detail. Here we discuss prevalence, specific pathobiology and clinical consequences of arterial calcifications in subjects with chronic kidney disease and type 2 diabetes mellitus.

\section{Chronic kidney disease (CKD)}

Calcification in dialysis patients is a complex process influenced by metabolic and physiological disturbances. Calcifications develop early after the start of dialysis, and is much less an age related process. ${ }^{76}$ Fore example, coronary artery calcifications have been shown in $92 \%$ of dialysis patients aged 19 to 39 years with childhood-onset CKD. $^{77}$

In end-stage renal disease calcification is present in two major forms. ${ }^{6,78}$ One form involves the intimal layer of the arteries and occurs within plaques, whereas the other form, also common in patients with diabetes mellitus, affects the medial layer and initially occurs within the elastic laminae. ${ }^{79}$ This latter process not only involves large elastic arteries but also smaller elastic arteries, and used to be described as Mönckeberg's calcification. ${ }^{80}$ Subjects with medial calcification are younger and have less traditional atherosclerotic risk factors than subjects with intimal calcification. Nonetheless, both forms are associated with increased cardiovascular mortality. ${ }^{6}$ Higher calcification scores are generally associated with greater cardiovascular morbidity. ${ }^{81}$ Arterial intima calcification, abundantly present in most advanced stages of atherosclerosis, tend to be more calcified in dialysis patients than in controls. ${ }^{82}$ Arterial media calcification, mostly localized in muscle-type conduit arteries such as femoral and tibial arteries, in their most pure form, do not obstruct the arterial lumen. This form of calcification has been associated with increased arterial stiffness. ${ }^{83,84}$ The VSMC plays a pivotal role in intimal as well as medial calcification. ${ }^{85,86}$ In vitro, human VSMCs spontaneously convert to osteo/chondrocyte-like cells and express proteins that regulate mineralization, such as BMP- $2 .^{87}$ In dialysis patients this osteogenic differentiation has also been seen in vivo in calcified arteries. ${ }^{88}$

Elevated circulating levels of phosphate (P), calcium (Ca) and calcium-phosphate product $(\mathrm{P} \times \mathrm{Ca}$ ) are frequently encountered in dialysis patients and are associated with increased vascular calcifications ${ }^{76,77,89}$. Media containing $P$ levels $>1.4 \mathrm{mmol} / \mathrm{l}$, which is below the K/DOQI guideline of $1.78 \mathrm{mmol} / \mathrm{I}^{90}$, enhance in vitro the osteogenic differentiation of VSMCs. ${ }^{91}$ These effects are mediated via the sodium-dependent phosphate co-transporter (pit-1) and result in the production of core binding factor 1 (Cbfa-1 or RUNX2), a central transcription factor in osteogenic differentiation, the expression of alkaline phosphatase and production of calcium-binding proteins such as osteocalcin and osteopontin. ${ }^{92,93}$ In this osteogenification process, calcium- 
containing matrix vesicles are formed and released, finally resulting in the formation of hydroxyl-apatite. The calcification process is not exclusively influenced by $\mathrm{P}$ and $\mathrm{Ca}$. Many traditional and non-traditional risk factors may affect VSCM-associated calcification, but their precise roles await clarification. ${ }^{10,11,85,94}$

\section{Patients with diabetes mellitus}

Type 2 diabetes mellitus patients suffer from increased rates of cardiovascular mortality and morbidity, which is most prominent in women. ${ }^{95}$ Specific changes in the vascular wall, referred to as diabetic macroangiopathy, are prevalent in these patients. ${ }^{96}$ Medial artery calcification, i.e. Mönckeberg's sclerosis, is often seen and is associated with age and the severity of hyperglycemia. ${ }^{97,98}$ In a study that screened newly diagnosed diabetes patients for calcification of the arteries in the thigh medial calcification was found in $23 \%$ and $11 \%$ of the man and women, respectively, and intimal calcification was observed in $33 \%$ and $13 \%$, respectively. ${ }^{75}$ It has been shown that in patients with diabetes arterial calcifications were more than 4 times more prevalent than in subjects without diabetes. ${ }^{99}$ The arteries are stiffened but not occluded. ${ }^{100}$ Diabetes patients commonly have multiple cardiovascular risk factors like dyslipidemia and hypertension. OPG is increased in the tunica media but not in the intima of the vasculature of diabetic subjects. ${ }^{101}$ Moreover, increased serum levels of OPG are positively associated with $\mathrm{HbA} 1 \mathrm{c}$ levels and hypertension in type 1 diabetic patients and might contribute to excessive calcification. ${ }^{102}$ Also, estradiol together with glucose has been shown to stimulate rat bone marrow stromal cells to differentiate and express osteoblastic features more than glucose alone. ${ }^{103}$ Clinically, diabetic patients with medial calcifications have a significant excess risk for total mortality, stroke mortality and cardiovascular mortality than patients without. They also had a significantly higher incidence of coronary heart disease events, stroke events and lower extremity amputations. ${ }^{74,75}$

\section{Treatment and prevention of calcifications}

Currently there is no evidence-based treatment regimen that can reduce calcification of large arteries. Experiments using calcium channel blockers or statins have not been convincing. ${ }^{104-106}$ Although the effect of treating cardiovascular risk factors on the progression of large artery calcification has not yet been evaluated, it seems reasonable to treat patients according to current guidelines because of their increased cardiovascular risk. Some treatments, however, may be associated with an increased risk of calcification. For example, long term treatment of patients with coumarins could results in accelerated cardiac valve and coronary calcification. ${ }^{41,42}$ Similarly, in end-stage renal disease, treatment of hyperphosphatemia with a calcium-containing phosphate binder contains calcium has been associated with more coronary artery 
calcifications compared to treatments with phosphate binders without calcium salts. $^{107}$

\section{Summary}

Arterial calcification is an actively regulated process, which involves different stimuli, genes and proteins. Patients with calcification, especially of the coronary arteries, have an increased cardiovascular risk when compared to similar patients without coronary calcification. A possible mechanism is that vascular calcification leads to increased arterial stiffness. Therefore, the presence of vascular calcification can be seen as an additional risk factor for cardiovascular events. Although there are no trials that prove risk reduction from aggressive risk management in patients with arterial calcifications, such patients probably benefit when cardiovascular risk factors, like hypertension and dyslipidemia, are identified and treated according to current guidelines. Moreover, in patient groups with a strongly elevated risk for arterial calcification, like renal insufficiency, patient-specific measures are necessary to prevent cardiovascular events and possibly arterial calcifications. 


\section{References}

1. Demer LL, Tintut Y. Mineral exploration: search for the mechanism of vascular calcification and beyond: the 2003 Jeffrey M. Hoeg Award lecture. Arterioscler Thromb Vasc Biol 2003;23:1739-43.

2. Abedin M, Tintut $\mathrm{Y}$, Demer LL. Vascular calcification: mechanisms and clinical ramifications. Arterioscler Thromb Vasc Biol 2004;24:1161-70.

3. Reslerova M, Moe SM. Vascular calcification in dialysis patients: pathogenesis and consequences. Am J Kidney Dis 2003;41(3 Suppl 1):S96-9.

4. Blacher J, Guerin AP, Pannier B, Marchais SJ, London GM. Arterial calcifications, arterial stiffness, and cardiovascular risk in end-stage renal disease. Hypertension 2001;38:938-42.

5. Goodman WG. Vascular calcification in chronic renal failure. Lancet 2001;358:1115-6.

6. London GM, Guerin AP, Marchais SJ, Metivier F, Pannier B, Adda H. Arterial media calcification in endstage renal disease: impact on all-cause and cardiovascular mortality. Nephrol Dial Transplant 2003;18:1731-40.

7. Bonifacio DL, Malineni K, Kadakia RA, Soman SS, Sandberg KR, McCullough PA. Coronary calcification and cardiac events after percutaneous intervention in dialysis patients. J Cardiovasc Risk 2001;8: 133-7.

8. Kondos GT, Hoff JA, Sevrukov A, Daviglus ML, Garside DB, Devries SS, Chomka EV, Liu K. Electronbeam tomography coronary artery calcium and cardiac events: a 37-month follow-up of 5635 initially asymptomatic low- to intermediate-risk adults. Circulation 2003;107:2571-6.

9. Becker A, Knez A, Becker C, Leber A, Anthopounou L, Boekstegers P, Steinbeck G. [Prediction of serious cardiovascular events by determining coronary artery calcification measured by multi-slice computed tomography]. Dtsch Med Wochenschr 2005;130:2433-8.

10. Iribarren C, Sidney S, Sternfeld B, Browner WS. Calcification of the aortic arch: risk factors and association with coronary heart disease, stroke, and peripheral vascular disease. Jama 2000;283: 2810-5.

11. Newman AB, Naydeck BL, Sutton-Tyrrell K, Feldman A, Edmundowicz D, Kuller LH. Coronary Artery Calcification in Older Adults to Age 99: Prevalence and Risk Factors. Circulation 2001;104:2679-84.

12. Taylor AJ, Bindeman J, Feuerstein I, Cao F, Brazaitis M, O'Malley PG. Coronary calcium independently predicts incident premature coronary heart disease over measured cardiovascular risk factors: mean three-year outcomes in the Prospective Army Coronary Calcium (PACC) project. Journal of the American College of Cardiology 2005;46:807-14.

13. Arad Y, Goodman KJ, Roth M, Newstein D, Guerci AD. Coronary calcification, coronary disease risk factors, C-reactive protein, and atherosclerotic cardiovascular disease events: the St. Francis Heart Study. Journal of the American College of Cardiology 2005;46:158-65.

14. Shaw $U$, Raggi P, Schisterman E, Berman DS, Callister TQ. Prognostic value of cardiac risk factors and coronary artery calcium screening for all-cause mortality. Radiology 2003;228:826-33.

15. Wong ND, Hsu JC, Detrano RC, Diamond G, Eisenberg H, Gardin JM. Coronary artery calcium evaluation by electron beam computed tomography and its relation to new cardiovascular events. Am J Cardiol 2000;86:495-8.

16. Simon A, Giral P, Levenson J. Extracoronary Atherosclerotic Plaque at Multiple Sites and Total Coronary Calcification Deposit in Asymptomatic Men : Association With Coronary Risk Profile. Circulation 1995;92:1414-21.

17. Kopp AF, Ohnesorge B, Becker C, Schröder S, Heuschmid M, Küttner A, Kuzo R, Claussen CD. Reproducibility and accuracy of coronary calcium measurements with multi-detector row versus electron-beam CT. Radiology 2002;225:113-9.

18. Shanahan CM, Proudfoot D, Farzaneh-Far A, Weissberg PL. The role of Gla proteins in vascular calcification. Crit Rev Eukaryot Gene Expr 1998;8:357-75.

19. Proudfoot D, Skepper JN, Shanahan CM, Weissberg PL. Calcification of human vascular cells in vitro is correlated with high levels of matrix Gla protein and low levels of osteopontin expression. Arterioscler Thromb Vasc Biol 1998;18:379-88.

20. Zebboudj AF, Shin V, Bostrom K. Matrix GLA protein and BMP-2 regulate osteoinduction in calcifying vascular cells. J Cell Biochem 2003;90:756-65. 
21. Speer MY, McKee MD, Guldberg RE, Liaw L, Yang HY, Tung E, Karsenty G, Giachelli CM. Inactivation of the osteopontin gene enhances vascular calcification of matrix Gla protein-deficient mice: evidence for osteopontin as an inducible inhibitor of vascular calcification in vivo. J Exp Med 2002;196:1047-55.

22. Dhore CR, Cleutjens JP, Lutgens E, Cleutjens KB, Geusens PP, Kitslaar PJ, Tordoir JH, Spronk HM, Vermeer C, Daemen MJ. Differential expression of bone matrix regulatory proteins in human atherosclerotic plaques. Arterioscler Thromb Vasc Biol 2001;21:1998-2003.

23. Clarke MC, Littlewood TD, Figg N, Maguire JJ, Davenport AP, Goddard M, Bennett MR. Chronic apoptosis of vascular smooth muscle cells accelerates atherosclerosis and promotes calcification and medial degeneration. Circulation research 2008;102:1529-38.

24. Shroff RC, McNair R, Figg N, Skepper JN, Schurgers L, Gupta A, Hiorns M, Donald AE, Deanfield J, Rees $\mathrm{L}$, Shanahan CM. Dialysis accelerates medial vascular calcification in part by triggering smooth muscle cell apoptosis. Circulation 2008;118:1748-57.

25. Shanahan CM, Cary NR, Metcalfe JC, Weissberg PL. High expression of genes for calcificationregulating proteins in human atherosclerotic plaques. J Clin Invest 1994;93:2393-402.

26. Price PA, Urist MR, Otawara Y. Matrix Gla protein, a new gamma-carboxyglutamic acid-containing protein which is associated with the organic matrix of bone. Biochem Biophys Res Commun 1983;117:765-71.

27. Farzaneh-Far A, Proudfoot D, Weissberg PL, Shanahan CM. Matrix gla protein is regulated by a mechanism functionally related to the calcium-sensing receptor. Biochem Biophys Res Commun 2000;277:736-40.

28. Cranenburg EC, Koos R, Schurgers LJ, Magdeleyns EJ, Schoonbrood TH, Landewé RB, Brandenburg VM, Bekers $\mathrm{O}$, Vermeer $\mathrm{C}$. Characterisation and potential diagnostic value of circulating matrix Gla protein (MGP) species. Thrombosis and haemostasis 2010;104:811-22.

29. Schurgers LJ, Spronk HM, Skepper JN, Hackeng TM, Shanahan CM, Vermeer C, Weissberg PL, Proudfoot D. Post-translational modifications regulate matrix Gla protein function: importance for inhibition of vascular smooth muscle cell calcification. J Thromb Haemost 2007;5:2503-11.

30. Zebboudj AF, Imura M, Bostrom K. Matrix GLA protein, a regulatory protein for bone morphogenetic protein-2. J Biol Chem 2002;277:4388-94. Epub 2001 Dec 6.

31. Luo G, Ducy P, McKee MD, Pinero GJ, Loyer E, Behringer RR, Karsenty G. Spontaneous calcification of arteries and cartilage in mice lacking matrix GLA protein. Nature 1997;386:78-81.

32. Price PA, Faus SA, Williamson MK. Warfarin causes rapid calcification of the elastic lamellae in rat arteries and heart valves. Arterioscler Thromb Vasc Biol 1998;18:1400-7.

33. Kohn MH, Price RE, Pelz HJ. A cardiovascular phenotype in warfarin-resistant Vkorc1 mutant rats. Artery Res 2008;2:138-47.

34. Teichert M, Visser LE, van Schaik RH, Hofman A, Uitterlinden AG, De Smet PA, Witteman JC, Stricker $\mathrm{BH}$. Vitamin $\mathrm{K}$ epoxide reductase complex subunit 1 (VKORC1) polymorphism and aortic calcification: the Rotterdam Study. Arterioscler Thromb Vasc Biol 2008;28:771-6.

35. Munroe PB, Olgunturk RO, Fryns JP, Van Maldergem L, Ziereisen F, Yuksel B, Gardiner RM, Chung E. Mutations in the gene encoding the human matrix Gla protein cause Keutel syndrome. Nat Genet 1999;21:142-4.

36. Schurgers LJ, Teunissen KJ, Knapen MH, Kwaijtaal M, van Diest R, Appels A, Reutelingsperger CP, Cleutjens JP, Vermeer C. Novel Conformation-Specific Antibodies Against Matrix \{gamma\}Carboxyglutamic Acid (Gla) Protein. Undercarboxylated Matrix Gla Protein as Marker for Vascular Calcification. Arterioscler Thromb Vasc Biol 2005;25:1629-33.

37. Jono S, Ikari Y, Vermeer C, Dissel P, Hasegawa K, Shioi A, Taniwaki H, Kizu A, Nishizawa Y, Saito S. Matrix Gla protein is associated with coronary artery calcification as assessed by electron-beam computed tomography. Thrombosis and haemostasis 2004;91:790-4.

38. Price PA, Lim JE. The inhibition of calcium phosphate precipitation by fetuin is accompanied by the formation of a fetuin-mineral complex. J Biol Chem 2003;278:22144-52.

39. Price PA, Thomas GR, Pardini AW, Figueira WF, Caputo JM, Williamson MK. Discovery of a high molecular weight complex of calcium, phosphate, fetuin, and matrix gamma-carboxyglutamic acid protein in the serum of etidronate-treated rats. J Biol Chem 2002;277:3926-34.

40. Geleijnse JM, Vermeer C, Grobbee DE, Schurgers $U$, Knapen MH, van der Meer IM, Hofman A, Witteman JC. Dietary intake of menaquinone is associated with a reduced risk of coronary heart disease: the Rotterdam Study. J Nutr 2004;134:3100-5. 
41. Koos R, Mahnken AH, Muhlenbruch G, Brandenburg V, Pflueger B, Wldberger JE, Kuhl HP. Relation of oral anticoagulation to cardiac valvular and coronary calcium assessed by multislice spiral computed tomography. Am J Cardiol 2005;96:747-9.

42. Schurgers LJ, Aebert H, Vermeer C, Bultmann B, Janzen J. Oral anticoagulant treatment: friend or foe in cardiovascular disease? Blood 2004;104:3231-2.

43. Ketteler M, Wanner C, Metzger T, Bongartz P, Westenfeld R, Gladziwa U, Schurgers L, Vermeer C, Jahnen-Dechent W, Floege J Deficiencies of calcium-regulatory proteins in dialysis patients: a novel concept of cardiovascular calcification in uremia. Kidney Int Suppl 2003(84):S84-7.

44. Schafer C, Heiss A, Schwarz A, Westenfeld R, Ketteler M, Floege J, Muller-Esterl W, Schinke T, JahnenDechent $W$. The serum protein alpha 2-Heremans-Schmid glycoprotein/fetuin-A is a systemically acting inhibitor of ectopic calcification. J Clin Invest 2003;112:357-66.

45. Lebreton JP, Joisel F, Raoult JP, Lannuzel B, Rogez JP, Humbert G. Serum concentration of human alpha 2 HS glycoprotein during the inflammatory process: evidence that alpha 2 HS glycoprotein is a negative acute-phase reactant. J Clin Invest 1979;64:1118-29.

46. Coen G, Ballanti P, Balducci A, Grandi F, Manni M, Mantella D, Pierantozzi A, Ruggeri M, Sardella D, Sorbo G, Bonucci E. Renal osteodystrophy: alpha-Heremans Schmid glycoprotein/fetuin-A, matrix GLA protein serum levels, and bone histomorphometry. Am J Kidney Dis 2006;48:106-13.

47. Ketteler M, Westenfeld R, Schlieper G, Brandenburg V. Pathogenesis of vascular calcification in dialysis patients. Clin Exp Nephrol 2005;9:265-70.

48. Moe SM, Reslerova M, Ketteler M, O'Neill K, Duan D, Koczman J, Westenfeld R, Jahnen-Dechent W, Chen NX. Role of calcification inhibitors in the pathogenesis of vascular calcification in chronic kidney disease (CKD). Kidney Int 2005;67:2295-304.

49. Ketteler M, Bongartz P, Westenfeld R, Wildberger JE, Mahnken AH, Bohm R, Metzger T, Wanner C, Jahnen-Dechent W, Floege J. Association of low fetuin-A (AHSG) concentrations in serum with cardiovascular mortality in patients on dialysis: a cross-sectional study. Lancet 2003;361:827-33.

50. Stenvinkel P, Wang K, Qureshi AR, Axelsson J, Pecoits-Filho R, Gao P, Barany P, Lindholm B, Jogestrand T, Heimburger O, Holmes C, Schalling M, Nordfors L. Low fetuin-A levels are associated with cardiovascular death: Impact of variations in the gene encoding fetuin. Kidney Int 2005;67:2383-92.

51. Wang AY, Woo J, Lam CW, Wang M, Chan IH, Gao P, Lui SF, Li PK, Sanderson JE. Associations of serum fetuin-A with malnutrition, inflammation, atherosclerosis and valvular calcification syndrome and outcome in peritoneal dialysis patients. Nephrol Dial Transplant 2005;20:1676-85.

52. Hruska KA, Mathew S, Saab G. Bone morphogenetic proteins in vascular calcification. Circulation research 2005;97:105-14.

53. Shao JS, Cai J, Towler DA. Molecular mechanisms of vascular calcification: lessons learned from the aorta. Arterioscler Thromb Vasc Biol 2006;26:1423-30.

54. Mathew S, Davies M, Lund R, Saab G, Hruska KA. Function and effect of bone morphogenetic protein7 in kidney bone and the bone-vascular links in chronic kidney disease. Eur J Clin Invest 2006;36 Suppl 2:43-50.

55. Giachelli CM, Speer MY, Li X, Rajachar RM, Yang H. Regulation of vascular calcification: roles of phosphate and osteopontin. Circulation research 2005;96:717-22.

56. Hofbauer LC, Heufelder AE. Role of receptor activator of nuclear factor-kappaB ligand and osteoprotegerin in bone cell biology. J Mol Med 2001;79:243-53.

57. Sattler AM, Schoppet M, Schaefer JR, Hofbauer LC. Novel aspects on RANK ligand and osteoprotegerin in osteoporosis and vascular disease. Calcif Tissue Int 2004;74:103-6.

58. Hofbauer LC, Schoppet M. Clinical implications of the osteoprotegerin/RANKL/RANK system for bone and vascular diseases. Jama 2004;292:490-5.

59. Schoppet M, Preissner KT, Hofbauer LC. RANK ligand and osteoprotegerin: paracrine regulators of bone metabolism and vascular function. Arterioscler Thromb Vasc Biol 2002;22:549-53.

60. Bucay N, Sarosi I, Dunstan CR, Morony S, Tarpley J, Capparelli C, Scully S, Tan HL, Xu W, Lacey DL, Boyle WJ, Simonet WS. osteoprotegerin-deficient mice develop early onset osteoporosis and arterial calcification. Genes Dev 1998;12:1260-8.

61. Collin-Osdoby P. Regulation of vascular calcification by osteoclast regulatory factors RANKL and osteoprotegerin. Circulation research 2004;95:1046-57. 
62. Knudsen ST, Foss CH, Poulsen PL, Andersen NH, Mogensen CE, Rasmussen LM. Increased plasma concentrations of osteoprotegerin in type 2 diabetic patients with microvascular complications. Eur J Endocrinol 2003;149:39-42.

63. Kazama JJ, Shigematsu T, Yano K, Tsuda E, Miura M, Iwasaki Y, Kawaguchi Y, Gejyo F, Kurokawa K, Fukagawa M. Increased circulating levels of osteoclastogenesis inhibitory factor (osteoprotegerin) in patients with chronic renal failure. Am J Kidney Dis 2002;39:525-32.

64. Canfield AE, Doherty MJ, Kelly V, Newman B, Farrington C, Grant ME, Boot-Handford RP. Matrix Gla protein is differentially expressed during the deposition of a calcified matrix by vascular pericytes. FEBS Lett 2000;487:267-71.

65. Murshed M, Schinke T, McKee MD, Karsenty G. Extracellular matrix mineralization is regulated locally; different roles of two gla-containing proteins. J Cell Biol 2004;165:625-30.

66. Schurgers L, Dissel PE, Spronk HM, Soute BA, Dhore CR, Cleutjens JP, Vermeer C. Role of vitamin K and vitamin K-dependent proteins in vascular calcification. Z Kardiol 2001;90(Suppl 3):57-63.

67. Vengrenyuk Y, Carlier S, Xanthos S, Cardoso L, Ganatos P, Virmani R, Einav S, Gilchrist L, Weinbaum S. A hypothesis for vulnerable plaque rupture due to stress-induced debonding around cellular microcalcifications in thin fibrous caps. Proc Natl Acad Sci U S A 2006;103:14678-83.

68. Ehara S, Kobayashi Y, Yoshiyama M, Shimada K, Shimada Y, Fukuda D, Nakamura Y, Yamashita H, Yamagishi H, Takeuchi K, Naruko T, Haze K, Becker AE, Yoshikawa J, Ueda M. Spotty calcification typifies the culprit plaque in patients with acute myocardial infarction: an intravascular ultrasound study. Circulation 2004;110:3424-9.

69. Ohnesorge B, Flohr T, Fischbach R, Kopp AF, Knez A, Schroder S, Schopf UJ, Crispin A, Klotz E, Reiser $M F$, Becker CR. Reproducibility of coronary calcium quantification in repeat examinations with retrospectively ECG-gated multisection spiral CT. Eur Radiol 2002;12:1532-40.

70. Lee TC, O'Malley PG, Feuerstein I, Taylor AJ. The prevalence and severity of coronary artery calcification on coronary artery computed tomography in black and white subjects. Journal of the American College of Cardiology 2003;41:39-44.

71. Callaway $M$, Richards $P$, Goddard $P$, Rees $M$. The incidence of coronary artery calcification on standard thoracic CT scans. Br J Radiol 1997;70:572-4.

72. Matsushita M, Nishikimi N, Sakurai T, Nimura Y. Relationship between aortic calcification and atherosclerotic disease in patients with abdominal aortic aneurysm. Int Angiol 2000;19:276-9.

73. Nakamura U, Iwase M, Nohara S, Kanai H, Ichikawa K, lida M. Usefulness of brachial-ankle pulse wave velocity measurement: correlation with abdominal aortic calcification. Hypertens Res 2003;26:163-7.

74. Lehto S, Niskanen L, Suhonen M, Ronnemaa T, Laakso M. Medial artery calcification. A neglected harbinger of cardiovascular complications in non-insulin-dependent diabetes mellitus. Arterioscler Thromb Vasc Biol 1996;16:978-83.

75. Niskanen L, Siitonen O, Suhonen M, Uusitupa MI. Medial artery calcification predicts cardiovascular mortality in patients with NIDDM. Diabetes Care 1994;17:1252-6.

76. Goodman WG, Goldin J, Kuizon BD, Yoon C, Gales B, Sider D, Wang Y, Chung J, Emerick A, Greaser L, Elashoff RM, Salusky IB. Coronary-artery calcification in young adults with end-stage renal disease who are undergoing dialysis. N Engl J Med 2000;342:1478-83.

77. Oh J, Wunsch R, Turzer M, Bahner M, Raggi P, Querfeld U, Mehls O, Schaefer F. Advanced coronary and carotid arteriopathy in young adults with childhood-onset chronic renal failure. Circulation 2002;106:100-5.

78. Goodman WG, London G, Amann K, Block GA, Giachelli C, Hruska KA, Ketteler M, Levin A, Massy Z, McCarron DA, Raggi P, Shanahan CM, Yorioka N; Vascular Calcification Work Group. Vascular calcification in chronic kidney disease. Am J Kidney Dis 2004;43:572-9.

79. Price PA, Chan WS, Jolson DM, Williamson MK. The elastic lamellae of devitalized arteries calcify when incubated in serum: evidence for a serum calcification factor. Arterioscler Thromb Vasc Biol 2006;26:1079-85.

80. Proudfoot D, Shanahan CM, Weissberg PL. Vascular calcification: new insights into an old problem. J Pathol 1998;185:1-3.

81. Raggi P, Boulay A, Chasan-Taber S, Amin N, Dillon M, Burke SK, Chertow GM. Cardiac calcification in adult hemodialysis patients. A link between end-stage renal disease and cardiovascular disease? J Am Coll Cardiol 2002;39:695-701. 
82. Savage $\mathrm{T}$, Clarke AL, Giles M, Tomson CR, Raine AE. Calcified plaque is common in the carotid and femoral arteries of dialysis patients without clinical vascular disease. Nephrol Dial Transplant 1998;13:2004-12.

83. Blacher J, Guerin AP, Pannier B, Marchais SJ, London GM. Arterial calcifications, arterial stiffness, and cardiovascular risk in end-stage renal disease. Hypertension 2001;38:938-42.

84. Guerin AP, London GM, Marchais SJ, Metivier F. Arterial stiffening and vascular calcifications in endstage renal disease. Nephrol Dial Transplant 2000;15:1014-21.

85. Trion A, van der Laarse A. Vascular smooth muscle cells and calcification in atherosclerosis. Am Heart J 2004;147:808-14.

86. Proudfoot D, Shanahan CM. Biology of calcification in vascular cells: intima versus media. Herz 2001;26:245-51.

87. Bostrom K, Watson KE, Horn S, Wortham C, Herman IM, Demer LL. Bone morphogenetic protein expression in human atherosclerotic lesions. J Clin Invest 1993;91:1800-9.

88. Moe SM, O'Neill KD, Duan D, Ahmed S, Chen NX, Leapman SB, Fineberg N, Kopecky K. Medial artery calcification in ESRD patients is associated with deposition of bone matrix proteins. Kidney Int 2002;61:638-47.

89. Block GA, Hulbert-Shearon TE, Levin NW, Port FK. Association of serum phosphorus and calcium $x$ phosphate product with mortality risk in chronic hemodialysis patients: a national study. Am J Kidney Dis 1998;31:607-17.

90. National Kidney Foundation K/DOQI Clinical Practice Guidelines for Bone Metabolism and Disease in Chronic Kidney Disease. Am J Kidney Dis 2003;42(suppl 3):s1-s202.

91. Jono S, McKee MD, Murry CE, Shioi A, Nishizawa Y, Mori K, Morii H, Giachelli CM. Phosphate regulation of vascular smooth muscle cell calcification. Circ Res 2000;87:E10-7.

92. Floege J, Ketteler M. Vascular calcification in patients with end-stage renal disease. Nephrol Dial Transplant 2004;19 Suppl 5:V59-66.

93. Giachelli CM, Jono S, Shioi A, Nishizawa $\mathrm{Y}$, Mori K, Morii H. Vascular calcification and inorganic phosphate. Am J Kidney Dis 2001;38(4 Suppl 1):S34-7.

94. Proudfoot D, Davies JD, Skepper JN, Weissberg PL, Shanahan CM. Acetylated low-density lipoprotein stimulates human vascular smooth muscle cell calcification by promoting osteoblastic differentiation and inhibiting phagocytosis. Circulation 2002;106:3044-50.

95. Huxley R, Barzi F, Woodward M. Excess risk of fatal coronary heart disease associated with diabetes in men and women: meta-analysis of 37 prospective cohort studies. BMJ 2006;332:73-8.

96. Ledet T, Rasmussen LM, Heickendorff L, Barfod K, Thogersen VB. The nature of large vessel disease in diabetes mellitus. J Diabet Complications 1990;4:63-5.

97. Ishimura E, Okuno S, Kitatani K, Kim M, Shoji T, Nakatani T, Inaba M, Nishizawa Y. Different risk factors for peripheral vascular calcification between diabetic and non-diabetic haemodialysis patients--importance of glycaemic control. Diabetologia 2002;45:1446-8.

98. Reaven PD, Sacks J. Coronary artery and abdominal aortic calcification are associated with cardiovascular disease in type 2 diabetes. Diabetologia 2005;48:379-85.

99. Neubauer B. A quantitative study of peripheral arterial calcification and glucose tolerance in elderly diabetics and non-diabetics. Diabetologia 1971;7:409-13.

100. Lachman AS, Spray TL, Kerwin DM, Shugoll GI, Roberts WC. Medial calcinosis of Monckeberg. A review of the problem and a description of a patient with involvement of peripheral, visceral and coronary arteries. Am J Med 1977;63:615-22.

101. Olesen P, Ledet T, Rasmussen LM. Arterial osteoprotegerin: increased amounts in diabetes and modifiable synthesis from vascular smooth muscle cells by insulin and TNF-alpha. Diabetologia 2005;48:561-8.

102. Rasmussen LM, Tarnow L, Hansen TK, Parving HH, Flyvbjerg A. Plasma osteoprotegerin levels are associated with glycaemic status, systolic blood pressure, kidney function and cardiovascular morbidity in type 1 diabetic patients. Eur J Endocrinol 2006;154:75-81.

103. Gopalakrishnan V, Vignesh RC, Arunakaran J, Aruldhas MM, Srinivasan N. Effects of glucose and its modulation by insulin and estradiol on BMSC differentiation into osteoblastic lineages. Biochem Cell Biol 2006;84:93-101.

104. Motro M, Shemesh J. Calcium channel blocker nifedipine slows down progression of coronary calcification in hypertensive patients compared with diuretics. Hypertension 2001;37:1410-3. 
105. Wong ND, Kawakubo M, LaBree L, Azen SP, Xiang M, Detrano R. Relation of coronary calcium progression and control of lipids according to National Cholesterol Education Program guidelines. Am J Cardiol 2004;94:431-6.

106. Kizu A, Shioi A, Jono S, Koyama H, Okuno Y, Nishizawa Y. Statins inhibit in vitro calcification of human vascular smooth muscle cells induced by inflammatory mediators. J Cell Biochem 2004;93:1011-9.

107. Chertow GM, Burke SK, Raggi P. Sevelamer attenuates the progression of coronary and aortic calcification in hemodialysis patients. Kidney Int 2002;62:245-52. 


\section{Chapter 3}

Vascular calcifications as a marker of increased cardiovascular risk: A meta-analysis

RJMW Rennenberg, AGH Kessels, LJ Schurgers, JMA van Engelshoven, PW de Leeuw, AA Kroon Vasc Health Risk Manag 2009;5:185-97 


\section{Abstract}

\section{Background}

Several imaging techniques may reveal calcification of the arterial wall or cardiac valves. Many studies indicate that the risk for cardiovascular disease is increased when calcification is present. Recent metaanalyses on coronary calcification and cardiovascular risk may be confounded by indication. Therefore, this meta-analysis was performed with extensive subgroup analysis to assess the overall cardiovascular risk of finding calcification in any arterial wall or cardiac valve when using different imaging techniques.

\section{Methods and results}

A meta-analysis of prospective studies reporting calcifications and cardiovascular end-points was performed. Thirty articles were selected. The overall odds ratios ( $95 \%$ confidence interval $(\mathrm{Cl})$ ) for calcifications versus no calcifications in 218,080 subjects after a mean follow-up of 10.1 years amounted to $4.62(\mathrm{Cl} 2.24$ to 9.53$)$ for all cause mortality, $3.94(\mathrm{Cl} 2.39$ to 6.50$)$ for cardiovascular mortality, $3.74(\mathrm{Cl} 2.56$ to 5.45) for coronary events, $2.21(\mathrm{Cl} 1.81$ to 2.69) for stroke, and $3.41(\mathrm{Cl} 2,71$ to 4.30$)$ for any cardiovascular event. Heterogeneity was largely explained by length of follow up and sort of imaging technique. Subgroup analysis of patients with end stage renal disease revealed a much higher odds ratio for any event of $6.22(\mathrm{Cl} 2.73$ to 14.14$)$.

\section{Conclusion}

The presence of calcification in any arterial wall is associated with a 3-4 fold higher risk for mortality and cardiovascular events. Interpretation of the pooled estimates has to be done with caution because of heterogeneity across studies. 


\section{Introduction}

Several imaging techniques may reveal vascular calcium deposits. Since these deposits are not always the prime reason for the investigation, the presence of calcified blood vessel walls or heart valves is often not recognized as a clinically important sign of vascular risk. Although calcifications may occur in small amounts in the earlier stages of atherosclerosis, they are usually seen in more advanced lesions. ${ }^{1}$ Indeed, various studies have observed an increased cardiovascular risk in patients with calcification. ${ }^{2-8}$ However, the latter is not a uniform finding. ${ }^{9}$ This discrepancy may be due to differences in methodology, patient selection and baseline risk. Recent meta-analyses of the relationship between calcification and vascular risk have focused exclusively on coronary calcium scores. ${ }^{10}$ As patients with coronary insufficiency are more likely to be subjected to diagnostic imaging than others, part of the relationship between coronary calcification and outcome may be confounded by indication. To overcome this problem, we performed the present meta-analysis in which we assessed the impact of calcium deposits in any artery or heart valve, with different imaging techniques, on fatal and non-fatal cardiovascular events as well as total mortality in populations with different baseline risk.

\section{Methods}

To identify studies on vascular calcification (mineralization detected in any part of the blood vessel wall or heart valves) and cardiovascular risk, a Pub med, Embase and Cochrane library search was performed using the following search terms: "plain radiography or chest $\mathrm{x}$-ray or abdominal $\mathrm{x}$-ray or mammography or panoramic radiography or ultrasound (US) or computer tomography (CT) or magnetic resonance imaging (MRI)" and (cardiovascular risk or calcification). Two investigators (RJMW Rennenberg and AA Kroon) screened all abstracts and, after applying the criteria for eligibility, decided on whether or not the full papers should be retrieved. All authors reviewed qualifying papers.

\section{Study eligibility}

Only prospective cohort studies were eligible. Paediatric studies were excluded. Articles published between 1970 and June 2008, with prospective data on human vascular calcification and well-documented end-points were selected. Case reports were excluded. Data on events in both groups, with and without calcification, had to be reported separately. To be selected for the analysis absolute numbers, i.e. a twoby-two table, should be extractable from the text. References found in the selected papers that fulfilled these criteria were also selected. Only papers published in English, German, Dutch and French were considered. When data were published in 
consecutive articles by the same authors only the article with the most comprehensive dataset was considered. ${ }^{8,11-13}$

\section{Definition of end-points}

End-points were defined as all cause mortality, cardiovascular mortality (death from any cardiovascular cause), coronary event (myocardial infarction, coronary mortality, percutaneous coronary angioplasty or coronary artery bypass operation), stroke (ischemic and hemorrhagic) and any cardiovascular event (cardiovascular mortality, coronary event, stroke, peripheral revascularisation procedures or amputation, carotid endarterectomy).

\section{Statistical analysis}

Studies reporting data suitable to make two by two tables of calcification in relation to events were used to compute odds ratio's using a random effects meta-analysis. Because we expected significant heterogeneity, a meta-regression analysis with a random effect model was performed, as suggested by Egger et al., ${ }^{14}$ taking into account the following variables: duration of follow up, type of imaging technique (plain radiograph, CT, or US) and baseline risk of the population, estimated as low (asymptomatic without known cardiovascular risk factors), intermediate (asymptomatic with one or more cardiovascular risk factors or diabetes but no renal insufficiency) and high (symptomatic or renal insufficiency). Publication bias was assessed with a funnel plot of the risk for any cardiovascular event. Statistical calculations were done using the STATA statistical program version 8.2 (copyright 1987-2005 StataCorp, 4905 Lakeway Drive, College Station, Texas 77845 USA), with the latest updates.

\section{Results}

We originally retrieved over 2,500 articles. Screening of abstracts and exclusion of case-reports resulted in 91 remaining original studies on the association between human vascular or valvular calcifications and cardiovascular risk. After applying the eligibility criteria 61 studies were excluded mainly because they were not prospective follow up studies. Only a few studies were excluded because absolute numbers could not be extracted or results were not reported as calcification versus no calcification. The remaining 30 studies, which are summarized in Table 3.1, could be included..$^{3,5-9,13,15-37}$ Ten studies concerned plain radiography, such as mammograms, chest $x$-rays or $x$-rays of the peripheral blood vessels (e.g. the femoral artery); ten studies had applied CT, mostly of the coronaries, and in 10 studies US had been used, predominantly of the heart valves. On plain radiographs vascular calcifications were 
defined as linear densities in the blood vessel area. With CT vascular calcification was defined as any vessel part with a density of 130 Hounsfield units ore more. In the US studies highly echogenic plaques producing bright white echoes with shadowing were noted as calcifications. No reports with respect to MRI fulfilled the inclusion criteria. In these 30 papers, the absolute numbers of events in relation to the presence or absence of calcifications were reported, comprising a total of 218,080 subjects. Overall, $53 \%$ of the subjects were males. The prevalence of vascular calcifications varied according to the patient group studied. The lowest prevalence of $2.3 \%$ was found in an asymptomatic population with a mean age of 47 years in which aortic arch calcifications on plain chest $x$-rays were studied. ${ }^{5}$ The highest prevalence of $88.9 \%$ was found in patients (mean age 56 years) with chest pain in whom coronary calcifications were measured by electron beam computer tomography (EBCT). ${ }^{24}$ The median prevalence of calcification in all studies was $57.5 \%$. The mean follow up to record the number of cardiovascular events in these studies was 10.1 years (range 2-26).

\section{All cause mortality}

In nine studies, with a total of 3,821 deaths among the 40,747 participants, data on all cause mortality were reported. ${ }^{11,17,19,22,27,28,33,36,37}$ Odds ratios are depicted in Figure 3.1. Among 16,528 subjects with calcifications 1,589 deaths were observed. Four of the studies comprised a population with renal insufficiency in which the event rate for all cause mortality in patients with calcifications was more than 5 times higher than in patients without calcifications. Overall OR for mortality from all causes was 4.62 (95\% $\mathrm{Cl} 2.24$ to 9.53 , Figure 3.1). The odds ratio for all cause mortality in patients without renal insufficiency was 3.43 (95\% $\mathrm{Cl} 1.26$ to 9.32$)$.

\section{Cardiovascular mortality}

Odds ratios for cardiovascular mortality are also shown in Figure 3.1. A total of 1,356 cardiovascular deaths were observed among the 17,187 participants in the 9 studies that reported data on this complication. ${ }^{8,9,13,22,27,28,30,33,36}$ Among 3,657 subjects with calcifications, 718 cardiovascular deaths were observed. In two of the 9 studies the imaging technique was US, one study employed CT, and in the remainder plain radiographs were used. The overall OR for cardiovascular mortality in the presence of calcifications was 3.94 (95\% $\mathrm{Cl} 2.39$ to 6.50$)$, but there was significant heterogeneity among the studies (Figure 3.1). 
46 $\mid$ Chapter 3

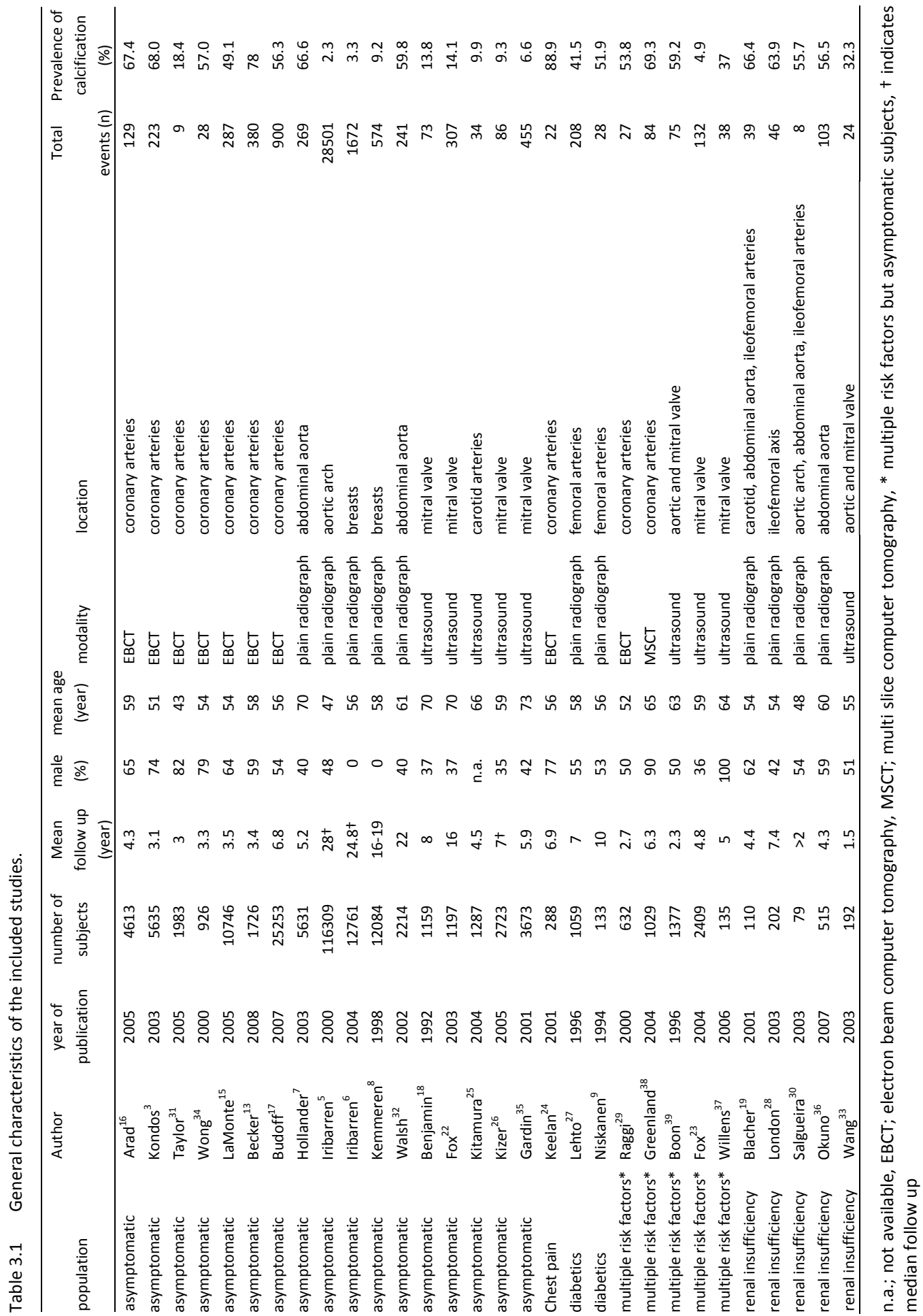


All cause mortality

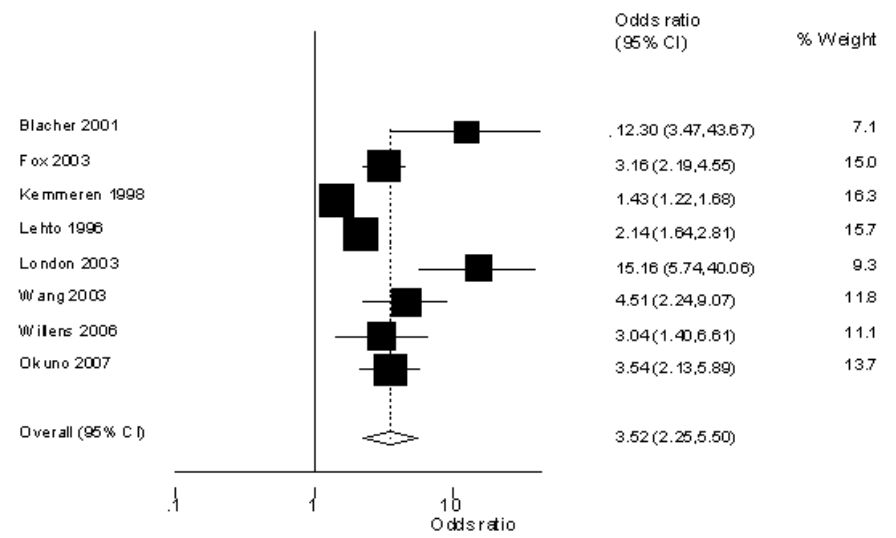

Cardiovascular mortality

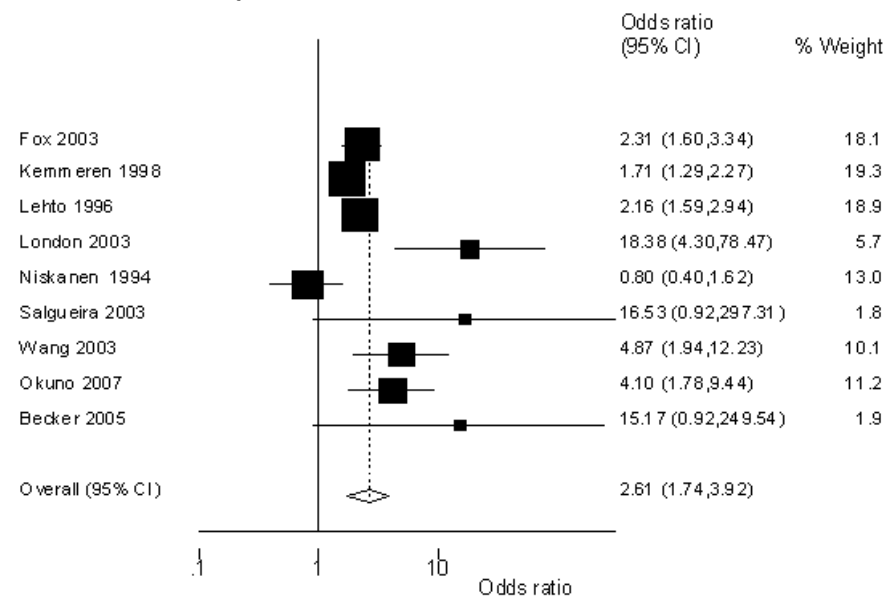

Figure 3.1 Odds ratios for mortality, all cause and cardiovascular, when calcification is present. Heterogeneity for all cause mortality chi-squared $=248.98$ (d.f. $=8) p=0.000$ Heterogeneity for cardiovascular mortality chi-squared=61.52 (d.f. $=8) p=0.000$

\section{Coronary events}

Data on coronary events were available in 16 studies (17,482 events among 173,650 subjects). ${ }^{3,5,6,8,15,16,22-24,28,29,31,33-35,38}$ In the 19,261 subjects with calcifications, 1,534 events were observed resulting in an overall OR of 3.74 (95\% Cl 2.56 to 5.45; Figure 3.2). Eight of these studies had utilized CT-scans of the coronaries and 4 plain radiography. Thirteen studies originated from a Northern American population and most of the studies were done for screening purposes in an asymptomatic population. 
Average follow up in the CT-studies was only 4 years, but 18.7 years in the studies done with plain radiography.

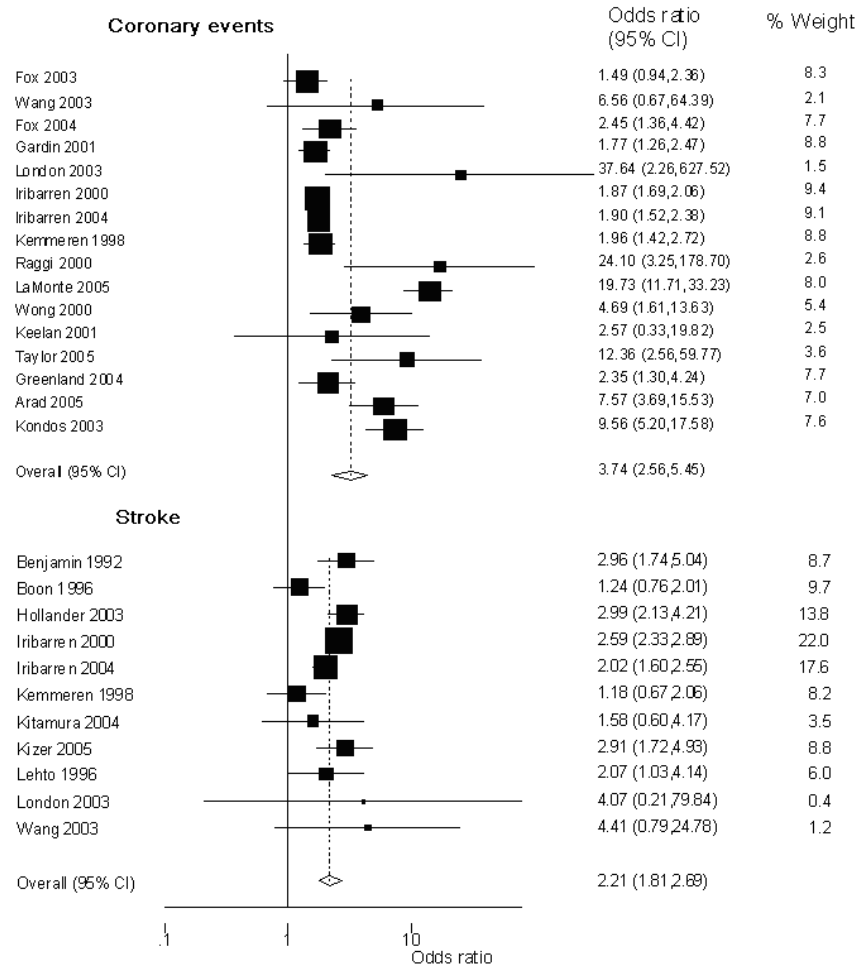

Figure 3.2 Odds ratios for coronary events and stroke, when calcification is present. Heterogeneity for coronary events chi-squared $=154.86$ (d.f. $=15) p=0.000$ Heterogeneity for stroke chi-squared $=21.67$ (d.f. $=10) p=0.017$

\section{Stroke}

Stroke was reported as primary outcome in 11 studies with a total of 154,784 subjects of whom 9,889 showed calcifications..$^{5-8,18,25-28,33,39}$ In the group with calcifications there were 874 stroke cases. The total number of events was 10,454 . Only one out of five studies with ultrasound looked at calcifications of the carotid artery, whereas in the other four US of the heart valves was performed. The remaining 6 studies, all with plain radiographs, evaluated vascular calcifications of the breast, the thoracic or abdominal aorta and peripheral arteries. None of the studies with CT assessed the incidence of stroke. The overall OR for stroke was 2.21 (95\% $\mathrm{Cl} 1.81$ to 2.69) in the presence of calcifications anywhere (Figure 3.2). 


\section{Any cardiovascular event}

In 27 studies with a total of 192,205 patients and 34,958 events, the risk for any cardiovascular event could be studied (Figure 3.3). ${ }^{3,5-9,12,15,16,18,22-36,38,39}$ In the 27,921 subjects with calcifications, 3,245 events were recorded. The average age was 59 years, but in the studies that reported the average age for the subjects with and without calcifications separately, age was significantly higher in those with calcifications (63 versus 56 years, $\mathrm{p}<0.05$ ). The overall $O R$ for any cardiovascular event with any modality was 3.41 ( $95 \% \mathrm{Cl} 2.71$ to 4.30$)$. This could be subdivided in an OR of 2.14 (95\% Cl 1.65 to 2.77 ) for ultrasound studies, 3.01 (95\% Cl 2.16 to 4.20 ) for plain radiographic studies, and $7.26(95 \% \mathrm{Cl} 4.42$ to 11.92$)$ for studies using CT as diagnostic modality.

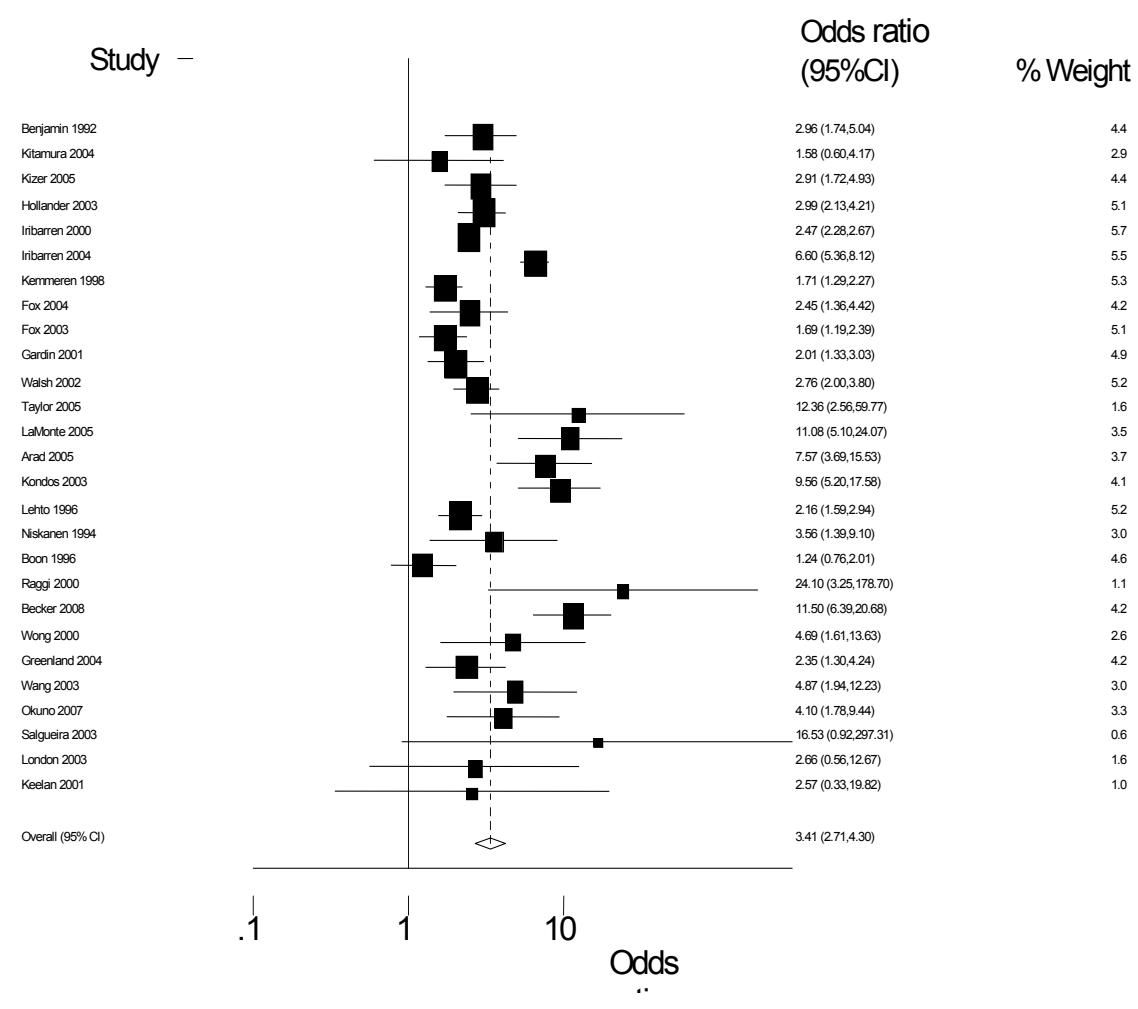

Figure 3.3 Risk for any cardiovascular event when calcification is present. Heterogeneity chi-squared $=198.94$ (d.f. $=26) p=0.000$ 


\section{Meta regression analysis for any cardiovascular event}

Meta-regression analysis with respect to the outcome of any cardiovascular event showed that the type of imaging technique and the duration of follow up were significant causes of heterogeneity. After stratifying for imaging technique and follow up, the meta-analysis showed substantially lesser or no significant heterogeneity. Figure 3.4 is shown as an example for the CT studies. However, the number of studies per group was also much smaller giving rise to less chance for heterogeneity. When data of high risk populations or populations with renal insufficiency or diabetes mellitus were analyzed separately there was also no significant heterogeneity.(chisquared=1.52 (d.f.=4) $p=0.823,3.59$ (d.f.=3) $p=0.309$ and 0.98 (d.f.=1) $p=0.322$ respectively) (Figure 3.5 and 3.6 )

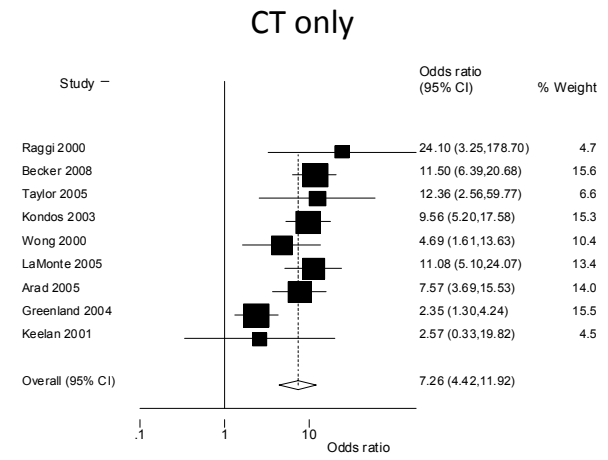

CT and follow up shorter than 5 years

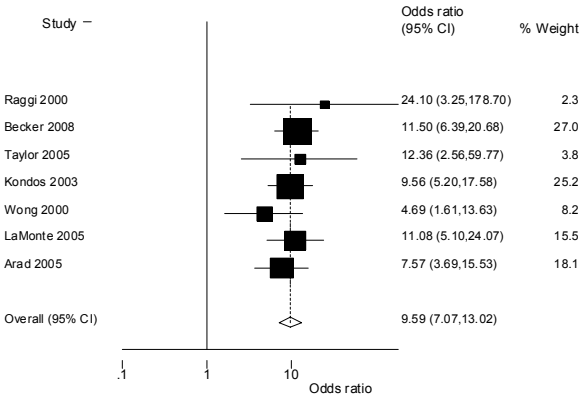

CT and follow up longer than 5 years

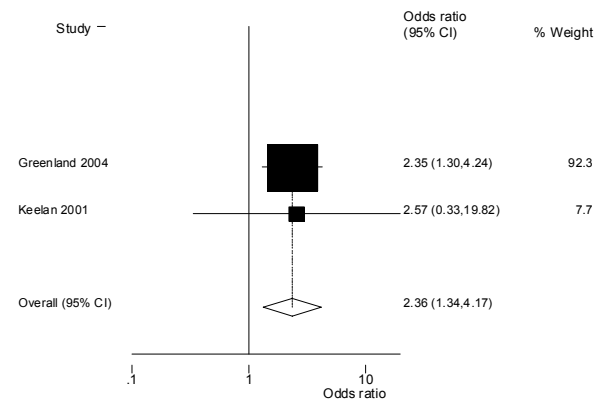

Figure 3.4 Results for any cardiovascular event stratified for imaging modality and follow up. Heterogeneity chi-squared in only CT studies $=22.32$ (d.f. $=8$ ) $p=0.004$

Heterogeneity chi-squared in CT studies with follow up shorter than 5 years=3.57 (d.f.=6) $\mathrm{p}=0.735$

Heterogeneity chi-squared in CT studies with follow up longer than 5 years $=0.01$ (d.f. $=1$ ) $\mathrm{p}=0.934$ 

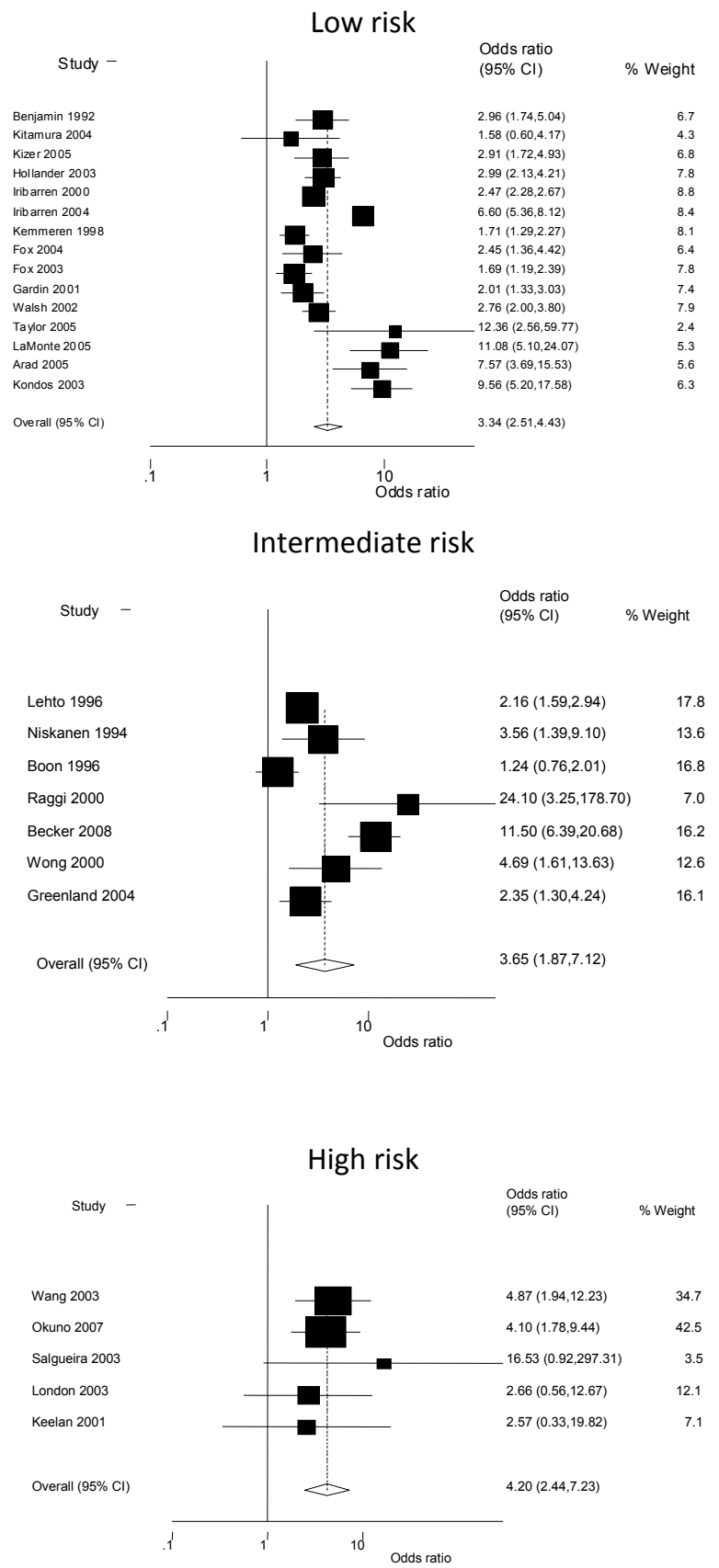

Figure 3.5 Risk for any cardiovascular event due to calcification according to baseline risk. Heterogeneity in the low risk group chi-squared=139.74 (d.f.=14) $p<0.001$ Heterogeneity in the intermediate risk group chi-squared $=55.79$ (d.f. $=6$ ) $p<0.001$ Heterogeneity in the high risk group chi-squared $=1.52$ (d.f.=4) $p=0.823$ 

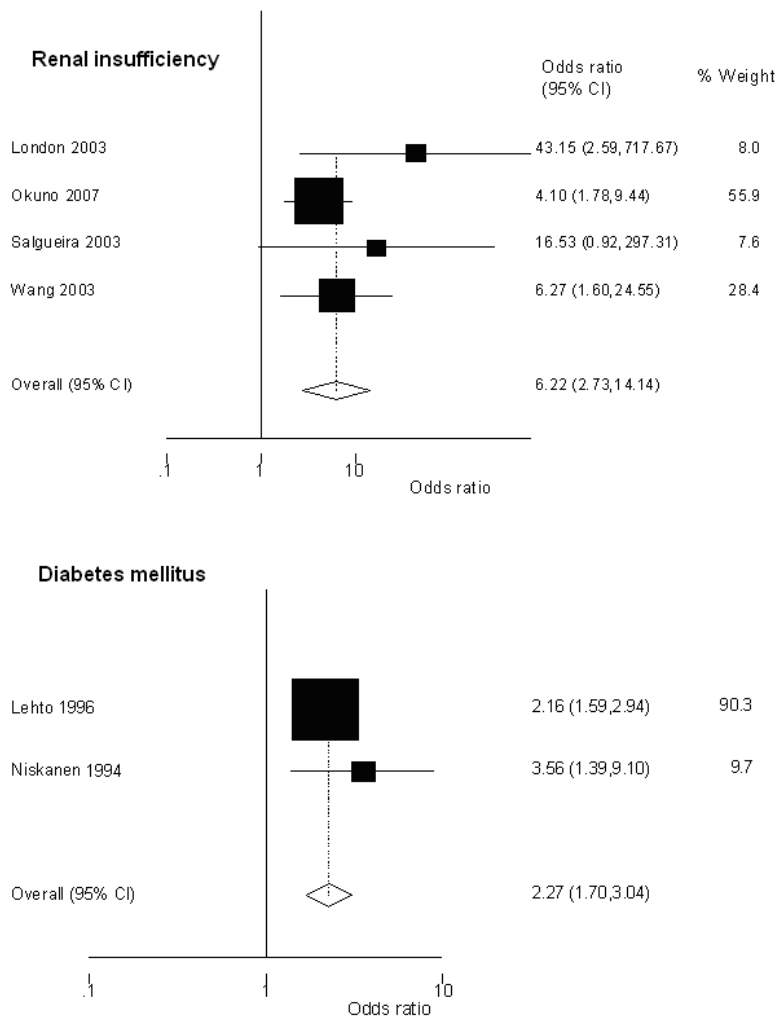

Figure 3.6 Subgroup analysis for renal insufficiency and diabetes mellitus

Heterogeneity in the renal insufficiency group chi-squared $=3.59$ (d.f. $=3$ ) $p=0.309$

Heterogeneity in the diabetes mellitus group chi-squared=0.98 (d.f. = 1) $p=0.322$

\section{Subgroup analysis}

Most studies have been performed in asymptomatic populations participating in a screening program. In some, however, the indication for the test was the presence of one or more cardiovascular risk factors. The pooled OR for any cardiovascular event was 3.34 (95\% Cl 2.51 to 4.43 ) in studies with low baseline risk $3,5-8,15,16,18,22,23,25,26,31,32,35$, 3.65 (95\% Cl 1.87 to 7.12 ) for populations with intermediate risk ${ }^{9,13,27,29,34,38,39}$ and 4.20 $(95 \% \mathrm{Cl} 2.44$ to 7.23$)$ in high risk subjects. ${ }^{24,28,30,33,36}$ (Figure 3.5$)$ There was no significant heterogeneity in the latter group for the pooled estimate.

When only subjects with renal insufficiency were considered the risk for any cardiovascular event in the presence of calcifications was even higher. ${ }^{19,28,30,33,36}$ (Figure 3.6) All patients were on hemodialysis except for the patients in one study who were on continuous ambulatory peritoneal dialysis. ${ }^{33}$ In these five studies, comprising a total of 1098 persons, 124 events were observed. Among the 599 
patients with calcifications, 104 had suffered an event. Odds ratios for any cardiovascular event were 6.22 (95\% Cl 2.73 to 14.14). This pooled estimate was without significant heterogeneity. Although the confidence intervals overlap, it seemed that the presence of calcifications had the highest predictive power for a cardiovascular or a cerebrovascular event in subjects with renal insufficiency.

Although 3 studies reported data from diabetic patients, only two of these gave sufficient information to calculate odds ratios for cardiovascular mortality $(2.27,95 \%$ $\mathrm{Cl} 1.70$ to 3.04$)$. $^{9,27}$ Of 1,192 patients, 508 had calcifications on plain radiography of the femoral arteries of which 139 of a total of 236 events occurred in the patients with calcifications.

\section{Funnel plot}

A funnel plot of the standard error of log odds ratio was performed to assess a possible publication bias (Figure 3.7). This is based on the fact that the precision in the estimation, of the underlying effect of finding calcification on outcome, will increase as the sample size of component studies increases. Effect estimates from small studies will therefore scatter more widely at the right of the graph, with the spread narrowing among larger studies to the left of the graph. In the absence of bias, the plot would appear to be symmetrical. Although it appears to be rather symmetrical, there are no studies in the right lower quadrant suggesting publication bias of small studies without any or a positive effect of calcification on cardiovascular events. However there was no bias using statistical tests for bias like the Egger (weighted regression) method ( $p$ for bias 0.24 ) or the Begg (rank correlation) method. ${ }^{14}$

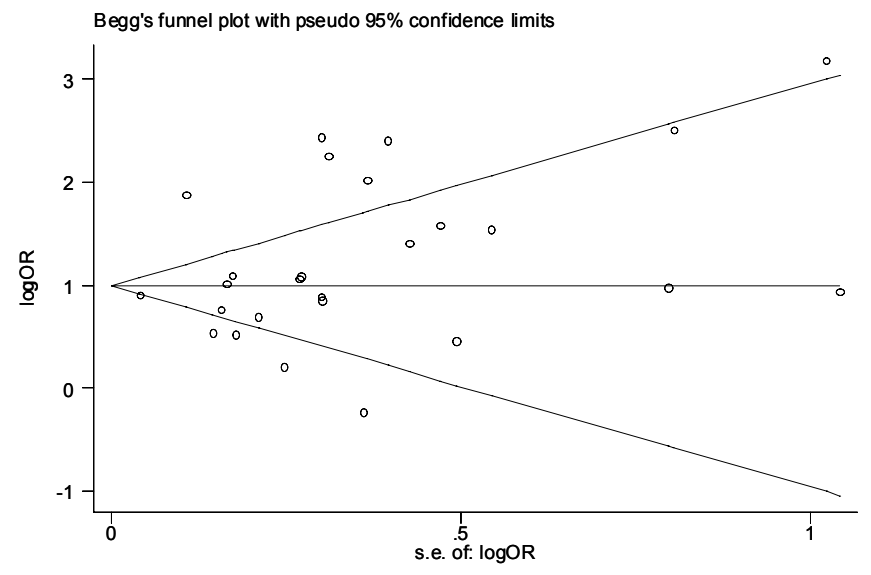

Figure 3.7 Funnel plot of standard error of $\log (\mathrm{OR})$ for any cardiovascular event. Begg's funnel plot of published studies reporting any cardiovascular event. The fact that many studies are outside the $95 \%$ confidence interval, indicated by the sloping lines, is caused by heterogeneity of the studies. 


\section{Discussion}

The objective of this meta-analysis was to assess the risks associated with calcification of the arterial wall or cardiac valves, as observed with different imaging methods in populations with different baseline risk. We showed that the presence of calcification with any type of imaging technique in these populations harbors a 3-4 times increased risk for mortality and cardiovascular events.

The present meta-analysis has several limitations. Firstly, it was not possible to adjust for age in our analysis, since age was not provided in all studies. Although calcification becomes more prevalent with age, we had to use unadjusted data to assess the general risk of calcification as seen on any mode of investigation. However, in almost all individual studies calcification was an independent risk factor. Adjustment for age did not change their outcome substantially. Secondly, the possibility of publication bias has to be considered. The asymmetry as seen in the funnel plot suggests that this could be the case for small studies with no significant effect on any cardiovascular event with calcification. However, statistical tests did not indicate significant publication bias. Furthermore, there was significant heterogeneity among the studies that could largely be explained by the different investigational tools on the one hand and different duration of follow up on the other. For example, patients who are being evaluated by CT for coronary symptoms, run a substantially higher risk with a shorter time horizon than those in whom calcifications are found accidentally. When we analyzed the risk for any cardiovascular event separately in relation to the type of imaging technique and time of follow-up ( $<5$ years and $>5$ years), heterogeneity disappeared for the US and CT studies (Figure 3.4), but significant heterogeneity remained present in studies using plain radiography with follow-up longer than five years. This persistent heterogeneity can possibly be explained by differences in population characteristics and calcification. In the studies with diabetic patients medial calcification was present in most cases. Medial calcification is associated with higher odds ratios for events than intimal calcifications in diabetic patients and might thus be an explanation for persistent heterogeneity in radiographic studies with a long follow-up period. ${ }^{9}$ Also the range of follow up time in these populations was much greater (2-26 years in plain radiograph studies, 1.5-16 in US studies and 2.7-6.9 in CT studies).

With respect to selection mechanisms and baseline risk, subgroup analysis of a renal insufficiency population showed the highest risk. Computer tomography data predicted the events best with the highest odds ratio. Moreover, when calcium was seen with coronary $\mathrm{CT}$, events occurred after a relatively short follow up period. Although coronary calcifications as detected by CT were associated with a greater risk of events than calcification in other areas, the difference in study populations preclude meaningful conclusions about the superiority of CT relative to other imaging modalities. Moreover, compared with plain X-rays or ultrasound studies, noncontrasted CT scans and EBCT are likely to be more sensitive for detecting small 
amounts of calcification. Interestingly, in hemodialysis patients were plain radiography or US were used to detect calcifications some of the highest odds ratios for all cause mortality and cardiovascular mortality were seen..$^{19,28,30,33,36}$ This might reflect their lower sensitivity for detecting any calcification. Half of the studies that reported on all cause mortality concerned a high-risk patient group with renal insufficiency. This influenced the OR resulting in a relatively high risk for all cause mortality. Nevertheless, when we calculated the OR for populations without renal insufficiency, this was still significantly increased $(3.43 ; 95 \% \mathrm{Cl} 1.26$ to 9.32$)$.

The results of this meta-analysis help to clarify the importance of calcification in all sorts of patients. Although the reported odds ratios should be interpreted with caution because of substantial heterogeneity across studies, it showed that in almost any case of calcification there is an increased cardiovascular risk. It is important to realize that subjects with vascular calcification are high-risk patients. Currently, however, there is no specific therapy to reduce these calcifications and no evidence to support a better cardiovascular outcome with calcification reduction, although data from animal research and from human cells in vivo on the actions of matrix Gla protein as an active calcification inhibitor show promising results. ${ }^{40-42}$ The use of statins reduces the cardiovascular event rate in almost all patient groups, but data on their calcification inhibiting properties are conflicting. ${ }^{43-48}$

To our knowledge, there are no studies exploring the effect of treating all cardiovascular risk factors in patients based only on the presence of calcifications. However, extensive coronary calcifications justify further investigations for coronary plaques. Therefore, we feel that the practicing physician is also justified to screen subjects, in whom calcifications are accidentally detected, for treatable risk factors. If these are present, the cardiovascular risk according to risk charts should be assessed. If the outcome exceeds the threshold defined in guidelines, the physician should take measures to reduce the cardiovascular risk of his or her patient. 


\section{References}

1. Gidding SS, Bookstein LC, Chomka EV. Usefulness of electron beam tomography in adolescents and young adults with heterozygous familial hypercholesterolemia. Circulation 1998; 98:2580-3.

2. Vliegenthart R, Hollander M, Breteler MMB, van der Kuip DAM, Hofman A, Oudkerk M, Witteman JCM. Stroke Is Associated With Coronary Calcification as Detected by Electron-Beam CT: The Rotterdam Coronary Calcification Study. Stroke 2002; 33:462-465.

3. Kondos GT, Hoff JA, Sevrukov A, Daviglus ML, Garside DB, Devries SS, Chomka EV, Liu K. Electronbeam tomography coronary artery calcium and cardiac events: a 37-month follow-up of 5635 initially asymptomatic low- to intermediate-risk adults. Circulation 2003; 107:2571-6.

4. Shaw LJ, Raggi P, Schisterman E, Berman DS, Callister TQ. Prognostic value of cardiac risk factors and coronary artery calcium screening for all-cause mortality. Radiology 2003; 228:826-33.

5. Iribarren C, Sidney S, Sternfeld B, Browner WS. Calcification of the aortic arch: risk factors and association with coronary heart disease, stroke, and peripheral vascular disease. Jama 2000; 283:2810-5.

6. Iribarren C, Go AS, Tolstykh I, Sidney S, Johnston SC, Spring DB. Breast vascular calcification and risk of coronary heart disease, stroke, and heart failure. J Womens Health (Larchmt) 2004; 13:381-9; discussion 390-2.

7. Hollander M, Hak AE, Koudstaal PJ, Bots ML, Grobbee DE, Hofman A, Witteman JCM, Breteler MMB. Comparison Between Measures of Atherosclerosis and Risk of Stroke: The Rotterdam Study. Stroke 2003; 34:2367-2372.

8. Kemmeren JM, van Noord PA, Beijerinck D, Fracheboud J, Banga JD, van der Graaf Y. Arterial calcification found on breast cancer screening mammograms and cardiovascular mortality in women: The DOM Project. Doorlopend Onderzoek Morbiditeit en Mortaliteit. Am J Epidemiol 1998; 147:33341.

9. Niskanen L, Siitonen O, Suhonen M, Uusitupa MI. Medial artery calcification predicts cardiovascular mortality in patients with NIDDM. Diabetes Care 1994; 17:1252-6.

10. Pletcher MJ, Tice JA, Pignone M, Browner WS. Using the coronary artery calcium score to predict coronary heart disease events: a systematic review and meta-analysis. Arch Intern Med 2004; 164:1285-92.

11. Kemmeren JM, Beijerinck D, van Noord PA, Banga JD, Deurenberg JJ, Pameijer FA, van der Graaf Y. Breast arterial calcifications: association with diabetes mellitus and cardiovascular mortality. Work in progress. Radiology 1996; 201:75-8.

12. Becker A, Knez A, Becker C, Leber A, Anthopounou L, Boekstegers P, Steinbeck G. Prediction of serious cardiovascular events by determining coronary artery calcification measured by multi-slice computed tomography. Dtsch Med Wochenschr 2005; 130:2433-8.

13. Becker A, Leber A, Becker C, Knez A. Predictive value of coronary calcifications for future cardiac events in asymptomatic individuals. Am Heart J 2008; 155:154-60.

14. Egger M, Smith GD, Altman DG. Systematic reviews in health care meta-analysis in context: BMJ publishing group, 2001:487.

15. LaMonte MJ, FitzGerald SJ, Church TS, Barlow CE, Radford NB, Levine BD, Pippin JJ, Gibbons LW, Blair $\mathrm{SN}$, Nichaman MZ. Coronary artery calcium score and coronary heart disease events in a large cohort of asymptomatic men and women. Am J Epidemiol 2005; 162:421-9.

16. Arad Y, Goodman KJ, Roth M, Newstein D, Guerci AD. Coronary calcification, coronary disease risk factors, C-reactive protein, and atherosclerotic cardiovascular disease events: the St. Francis Heart Study. J Am Coll Cardiol 2005; 46:158-65.

17. Budoff MJ, Shaw LJ, Liu ST, Weinstein SR, Mosler TP, Tseng PH, Flores FR, Callister TQ, Raggi P, Berman DS. Long-term prognosis associated with coronary calcification: observations from a registry of 25,253 patients. J Am Coll Cardiol 2007; 49:1860-70.

18. Benjamin EJ, Plehn JF, D'Agostino RB, Belanger AJ, Comai K, Fuller DL, Wolf PA, Levy D. Mitral annular calcification and the risk of stroke in an elderly cohort. N Engl J Med 1992; 327:374-9.

19. Blacher J, Guerin AP, Pannier B, Marchais SJ, London GM. Arterial calcifications, arterial stiffness, and cardiovascular risk in end-stage renal disease. Hypertension 2001; 38:938-42. 
20. Boon A, Lodder J, Cheriex E, Kessels F. Mitral annulus calcification is not an independent risk factor for stroke: a cohort study of 657 patients. J Neurol 1997; 244:535-41.

21. Everhart JE, Pettitt DJ, Knowler WC, Rose FA, Bennett PH. Medial arterial calcification and its association with mortality and complications of diabetes. Diabetologia 1988; 31:16-23.

22. Fox CS, Vasan RS, Parise H, Levy D, O'Donnell CJ, D'Agostino RB, Benjamin EJ. Mitral annular calcification predicts cardiovascular morbidity and mortality: the Framingham Heart Study. Circulation 2003; 107:1492-6.

23. Fox E, Harkins D, Taylor H, McMullan M, Han H, Samdarshi T, Garrison R, Skelton T. Epidemiology of mitral annular calcification and its predictive value for coronary events in African Americans: the Jackson Cohort of the Atherosclerotic Risk in Communities Study. Am Heart J 2004; 148:979-84.

24. Keelan PC, Bielak LF, Ashai K, Jamjoum LS, Denktas AE, Rumberger JA, Sheedy I, Patrick F, Peyser PA, Schwartz RS. Long-Term Prognostic Value of Coronary Calcification Detected by Electron-Beam Computed Tomography in Patients Undergoing Coronary Angiography. Circulation 2001; 104:412417.

25. Kitamura A, Iso H, Imano H, Ohira T, Okada T, Sato S, Kiyama M, Tanigawa T, Yamagishi K, Shimamoto T. Carotid intima-media thickness and plaque characteristics as a risk factor for stroke in Japanese elderly men. Stroke 2004; 35:2788-94.

26. Kizer JR, Wiebers DO, Whisnant JP, Galloway JM, Welty TK, Lee ET, Best LG, Resnick HE, Roman MJ, Devereux RB. Mitral annular calcification, aortic valve sclerosis, and incident stroke in adults free of clinical cardiovascular disease: the Strong Heart Study. Stroke 2005; 36:2533-7.

27. Lehto S, Niskanen L, Suhonen M, Ronnemaa T, Laakso M. Medial artery calcification. A neglected harbinger of cardiovascular complications in non-insulin-dependent diabetes mellitus. Arterioscler Thromb Vasc Biol 1996; 16:978-83.

28. London GM, Guerin AP, Marchais SJ, Metivier F, Pannier B, Adda H. Arterial media calcification in endstage renal disease: impact on all-cause and cardiovascular mortality. Nephrol Dial Transplant 2003; 18:1731-40.

29. Raggi P, Callister TQ, Cooil B, He ZX, Lippolis NJ, Russo DJ, Zelinger A, Mahmarian JJ. Identification of patients at increased risk of first unheralded acute myocardial infarction by electron-beam computed tomography. Circulation 2000; 101:850-5.

30. Salgueira M, del Toro N, Moreno-Alba R, Jimenez E, Areste N, Palma A. Vascular calcification in the uremic patient: a cardiovascular risk? Kidney Int Suppl 2003:S119-21.

31. Taylor AJ, Bindeman J, Feuerstein I, Cao F, Brazaitis M, O'Malley PG. Coronary calcium independently predicts incident premature coronary heart disease over measured cardiovascular risk factors: mean three-year outcomes in the Prospective Army Coronary Calcium (PACC) project. J Am Coll Cardiol 2005; 46:807-14.

32. Walsh CR, Cupples LA, Levy D, Kiel DP, Hannan M, Wilson PW, O'Donnell CJ. Abdominal aortic calcific deposits are associated with increased risk for congestive heart failure: the Framingham Heart Study. Am Heart J 2002; 144:733-9.

33. Wang AY, Wang M, Woo J, Lam CW, Li PK, Lui SF, Sanderson JE. Cardiac valve calcification as an important predictor for all-cause mortality and cardiovascular mortality in long-term peritoneal dialysis patients: a prospective study. J Am Soc Nephrol 2003; 14:159-68.

34. Wong ND, Hsu JC, Detrano RC, Diamond G, Eisenberg H, Gardin JM. Coronary artery calcium evaluation by electron beam computed tomography and its relation to new cardiovascular events. Am J Cardiol 2000; 86:495-8.

35. Gardin JM, McClelland R, Kitzman D, Lima JA, Bommer W, Klopfenstein HS, Wong ND, Smith VE, Gottdiener J. M-mode echocardiographic predictors of six- to seven-year incidence of coronary heart disease, stroke, congestive heart failure, and mortality in an elderly cohort (the Cardiovascular Health Study). Am J Cardiol 2001; 87:1051-7.

36. Okuno S, Ishimura E, Kitatani K, Fujino Y, Kohno K, Maeno Y, Maekawa K, Yamakawa T, Imanishi Y, Inaba M, Nishizawa Y. Presence of abdominal aortic calcification is significantly associated with allcause and cardiovascular mortality in maintenance hemodialysis patients. Am J Kidney Dis 2007; 49:417-25.

37. Willens HJ, Chirinos JA, Schob A, Veerani A, Perez AJ, Chakko S. The relation between mitral annular calcification and mortality in patients undergoing diagnostic coronary angiography. Echocardiography 2006; 23:717-22. 
38. Greenland P, LaBree L, Azen SP, Doherty TM, Detrano RC. Coronary artery calcium score combined with Framingham score for risk prediction in asymptomatic individuals. Jama 2004; 291:210-5.

39. Boon A, Lodder J, Cheriex E, Kessels F. Risk of stroke in a cohort of 815 patients with calcification of the aortic valve with or without stenosis. Stroke 1996; 27:847-51.

40. Proudfoot D, Skepper JN, Shanahan CM, Weissberg PL. Calcification of human vascular cells in vitro is correlated with high levels of matrix Gla protein and low levels of osteopontin expression. Arterioscler Thromb Vasc Biol 1998; 18:379-88.

41. Luo G, Ducy P, McKee MD, Pinero GJ, Loyer E, Behringer RR, Karsenty G. Spontaneous calcification of arteries and cartilage in mice lacking matrix GLA protein. Nature 1997; 386:78-81.

42. Schurgers LJ, Teunissen KJ, Knapen MH, Kwaijtaal M, van Diest R, Appels A, Reutelingsperger CP, Cleutjens JP, Vermeer C. Novel conformation-specific antibodies against matrix gammacarboxyglutamic acid (Gla) protein: undercarboxylated matrix Gla protein as marker for vascular calcification. Arterioscler Thromb Vasc Biol 2005; 25:1629-33.

43. Kizu A, Shioi A, Jono S, Koyama H, Okuno Y, Nishizawa Y. Statins inhibit in vitro calcification of human vascular smooth muscle cells induced by inflammatory mediators. J Cell Biochem 2004; 93:1011-9.

44. Budoff MJ, Yu D, Nasir K, Mehrotra R, Chen L, Takasu J, Agrawal N, Liu ST, Blumenthal RS. Diabetes and progression of coronary calcium under the influence of statin therapy. Am Heart J 2005; 149: 695-700.

45. Cowell SJ, Newby DE, Prescott RJ, Bloomfield P, Reid J, Northridge DB, Boon NA. A randomized trial of intensive lipid-lowering therapy in calcific aortic stenosis. N Engl J Med 2005; 352:2389-97.

46. Schmermund A, Achenbach S, Budde T, Buziashvili Y, Forster A, Friedrich G, Henein M, Kerkhoff G, Knollmann F, Kukharchuk V, Lahiri A, Leischik R, Moshage W, Schartl M, Siffert W, SteinhagenThiessen E, Sinitsyn V, Vogt A, Wiedeking B, Erbel R. Effect of intensive versus standard lipid-lowering treatment with atorvastatin on the progression of calcified coronary atherosclerosis over 12 months: a multicenter, randomized, double-blind trial. Circulation 2006; 113:427-37.

47. Arad Y, Spadaro LA, Roth M, Newstein D, Guerci AD. Treatment of asymptomatic adults with elevated coronary calcium scores with atorvastatin, vitamin C, and vitamin E: the St. Francis Heart Study randomized clinical trial. J Am Coll Cardiol 2005; 46:166-72.

48. Houslay ES, Cowell SJ, Prescott RJ, Reid J, Burton J, Northridge DB, Boon NA, Newby DE. Progressive coronary calcification despite intensive lipid-lowering treatment: a randomised controlled trial. Heart 2006; 92:1207-12. 


\section{Chapter 4}

Levels of Matrix Gla Protein, a marker for vascular calcification, in human hypertension

RJMW Rennenberg, LJ Schurgers, BJ van Varik, EJP Magdeleyns, C Vermeer, PW de Leeuw, AA Kroon 


\section{Abstract}

\section{Introduction}

Increased vascular stiffness and calcifications are common among patients with hypertension and harbour an increased cardiovascular risk. The vitamin K-dependent matrix Gla-protein (MGP) plays an important role in preventing arterial calcification. We hypothesized that in hypertension the levels of MGP are already lower before calcification and atherosclerosis become manifest.

\section{Methods and results}

We measured the total fractions of both serum desphospho-MGP (t-dpMGP) and uncarboxylated MGP (t-ucMGP) levels in a group of 96 well characterized hypertensive subjects, who underwent renal angiography, and compared these levels to those in a healthy control group $(n=83)$. Data on age, sex, smoking behaviour, body mass index and blood pressure were collected and venous blood was drawn. Abdominal X-rays obtained during renal angiography in the hypertensive group were scored for the presence of vascular calcification and atherosclerosis of the abdominal aorta and renal arteries. We demonstrate that moderate to severe hypertensives have lower circulating t-dpMGP levels $(p<0.001)$ and t-ucMGP levels $(p=0.003$ ) compared to healthy controls. MGP levels did not further discriminate between the presence or absence of aortic calcification and neither did they correlate with the severity of abdominal aorta atherosclerosis on abdominal X-rays in hypertensives.

\section{Conclusions}

Hypertensive patients have significantly lower t-dpMGP and t-ucMGP levels compared to healthy adults, but there was no significant correlation of either of these MGP fractions with aortic atherosclerosis or calcification in these subjects. 


\section{Introduction}

Vascular calcification is considered to be an independent marker of increased cardiovascular risk. ${ }^{1}$ Although hypertensive patients have more vascular calcifications than normotensive subjects, circulating concentrations of Matrix Gla Protein (MGP), an $11 \mathrm{kD}$ vitamin $\mathrm{K}$-dependent protein and a potent inhibitor of calcification, have never been measured in this group., ${ }^{2,3}$ MGP was first discovered in bone and is mainly produced by vascular smooth muscle cells and chondrocytes. It appears to accumulate at sites of calcification. ${ }^{4-9}$ MGP modulates the effects of Bone Morphogenetic Protein type 2 and binds directly to calcium crystals in the vascular matrix. ${ }^{10}$ During maturation, MGP undergoes two posttranslational modifications: carboxylation (which is essential for its calcification inhibitory activity) and phosphorylation (which promotes cellular secretion). Circulating levels of total uncarboxylated MGP (t-ucMGP, i.e. the sum of phosphorylated and non-phosphorylated ucMGP species) have been demonstrated to correlate inversely with arterial calcifications and cardiovascular disease and mortality. ${ }^{11-13}$ In hypertension, less functional MGP, and therefore less protection against calcification, may contribute to the tendency of enhanced vascular calcification, resulting in increased blood pressures and hence the increased cardiovascular risk. ${ }^{14}$ To explore the potential association between serum MGP levels and either atherosclerosis or vascular calcification in hypertensive patients we scored the presence of calcification and aortic atherosclerosis on angiographic images in a group of well characterized hypertensive subjects and compared the MGP species with those of a healthy control group.

\section{Patients and Methods}

\section{Patients}

We studied 96 consecutive patients who were referred to our outpatient clinic because of treatment resistant hypertension and suspicion of renal artery stenosis. As a control group, we selected 83 age- and sex-matched, healthy volunteers who participated in an osteoporosis screening study. The study protocol had been approved by the medical ethics committee and all subjects gave informed consent before inclusion in the study. The hypertensive patients were investigated after stopping their antihypertensive drugs for three weeks before the scheduled renal angiography. Data on age, sex, smoking behavior, body mass index (BMI, $\mathrm{kg} / \mathrm{m}^{2}$ ) were collected in both groups whereas blood pressure (average of 3 office measurements [Accutorr Plus, Datascope corporation Fairfield, NY, USA]) was assessed only in the hypertensive group. In all subjects venous blood was drawn after an overnight fast. The images obtained during angiography in the hypertensive group were scored for the presence of atherosclerotic renal artery stenosis ( $>20 \%$ reduction in luminal 
diameter) since the presence thereof is associated with more severe atherosclerosis and an increased cardiovascular risk. ${ }^{15}$ Furthermore, the presence of vascular calcification (on antero-posterior and lateral views), and atherosclerosis of the abdominal aorta were assessed by an experienced radiologist and two of the authors (RR and AK) independently of each other. In case of discrepancies, consensus was reached. Based on the images, atherosclerosis could be classified as absent, moderate (atherosclerosis without renal artery stenosis), and severe (renal artery stenosis present), whereas calcification was scored as present or not present.

\section{Measurements}

Blood was collected by venapuncture in serum tubes $(10 \mathrm{ml}$; BD Vacutainer systems, Plymouth, UK) and stored for 20 minutes at room temperature before centrifugation $(15 \mathrm{~min}$ at $3000 \mathrm{~g})$. Serum was separated and stored at $-80^{\circ} \mathrm{C}$ until use. Both total desphospho-MGP ( $t$-dpMGP, i.e. the sum of carboxylated and uncarboxylated dpMGP species) and t-ucMGP were measured. Test kits for t-dpMGP detection in serum were obtained from Biomedica (Vienna, Austria) and this test was performed in all 186 subjects. From 75 patients and 83 controls we had sufficient serum to also measure t-ucMGP. Details of both MGP tests have been described elsewhere. ${ }^{16}$ In the hypertensive group we also measured levels of fasting blood glucose, serum creatinine, and total cholesterol with an automated analyzer (Beckmann Synchron CX 7-2, Fullerton, CA, USA). Endogenous creatinine clearance (ECC) was estimated using the Cockcroft and Gault formula. ${ }^{17}$

\section{Statistical analysis}

Normally distributed variables are expressed as means and standard deviations. Not normally distributed data are expressed as medians with their range. To compare the difference between means we used Student's t-test for normally distributed data and Mann-Whitney-U test for non-normally distributed data. For between-group comparisons of categorical data, Chi-square tests were used. To assess the difference between the means of more than 2 groups we used one-way ANOVA. Statistical calculations were performed using SPSS for Windows V16.0 (SPSS, Chicago, IL, USA). A $p$-value of $<0.05$ was considered to denote significance.

\section{Results}

The characteristics of both groups are shown in Table 4.1. As expected control subjects had a lower body mass index but smoking behaviour was not significantly different. Figure 4.1 shows the serum t-dpMGP and t-ucMGP distribution: the mean serum $t$-dpMGP and t-ucMGP in the hypertensive group were significantly lower than in the control group $(5.6 \pm 1.4 \mathrm{nmol} / \mathrm{l}$ versus $7.2 \pm 1.3 \mathrm{nmol} / \mathrm{l}, \quad \mathrm{p}<0.001$ and 
$4361 \pm 1111 \mathrm{nmol} / \mathrm{l}$ versus $4909 \pm 1138 \mathrm{nmol} / \mathrm{l}$ respectively). It should be noted that the absolute concentrations of t-ucMGP were three orders of magnitude higher than those of t-dpMGP. In the hypertensive group we found 25 atherosclerotic renal artery stenoses, identifying the subjects with severe atherosclerosis of the abdominal aorta and renal artery. The characteristics of these hypertensive subjects classified according to the severity of atherosclerosis are shown in Table 4.2. Hypertensive subjects with more severe atherosclerosis were older, smoked more often, had a slightly lower BMI, and their pulse pressure was higher indicating that they had stiffer arteries. Their ECC was lower, and their glucose levels were higher. Although there appeared to be a trend for lower t-ucMGP and higher t-dpMGP levels in patients with more severe atherosclerosis (Table 4.2), the difference between groups was not statistically significant ( $p=0.679$ and $p=0.083$, respectively). As expected, there was a strong correlation between atherosclerosis and calcification $(r=0,563, p<0.001)$ but no statistically significant correlations were observed between both t-dpMGP or t-ucMGP levels and the presence of calcification ( $p=0.475$ and $p=0.164$, respectively).

Table 4.1 Clinical characteristics of hypertensive and control subjects.

\begin{tabular}{lccc}
\hline Variable & $\begin{array}{c}\text { Control population } \\
\mathrm{n}=83\end{array}$ & $\begin{array}{c}\text { hypertensive population } \\
\mathrm{n}=96\end{array}$ & p value \\
\hline Age $(\mathrm{yr})$ & $54 \pm 9$ & $53 \pm 10$ & 0.541 \\
Body mass index $\left(\mathrm{Kg} / \mathrm{m}^{2}\right)$ & $25 \pm 3$ & $27 \pm 5$ & 0.006 \\
Male/female & $34 / 49$ & $53 / 43$ & 0.057 \\
(ever) Smoking (\%) & 51 & 62 & 0.081 \\
Systolic blood pressure $(\mathrm{mmHg})$ & $\mathrm{nd}$ & $170 \pm 25$ & \\
Diastolic blood pressure $(\mathrm{mmHg})$ & $\mathrm{nd}$ & $101 \pm 14$ & \\
\hline
\end{tabular}

nd, no data available

Table 4.2 Clinical characteristics of 96 hypertensive patients.

\begin{tabular}{|c|c|c|c|c|}
\hline \multirow{3}{*}{ Variable } & No & Moderate & Severe & \multirow{3}{*}{$\begin{array}{c}\text { Difference } \\
\text { between } \\
\text { groups }^{*}\end{array}$} \\
\hline & \multicolumn{3}{|c|}{ atherosclerosis atherosclerosis atherosclerosis } & \\
\hline & $\mathrm{n}=48$ & $n=23$ & $n=25$ & \\
\hline Age (yr) & $48 \pm 10$ & $56 \pm 6$ & $58 \pm 6$ & $<0.001$ \\
\hline Male/female & $23 / 25$ & $14 / 9$ & $16 / 9$ & 0.348 \\
\hline (ever) Smoking (\%) & 40 & 91 & 84 & $<0.001$ \\
\hline Body mass index $\left(\mathrm{kg} / \mathrm{m}^{2}\right)$ & $28 \pm 5$ & $27 \pm 4$ & $25 \pm 5$ & 0.054 \\
\hline Systolic blood pressure (mmHg) & $166 \pm 26$ & $171 \pm 22$ & $178 \pm 24$ & 0.170 \\
\hline Diastolic blood pressure (mmHg) & $103 \pm 14$ & $100 \pm 12$ & $98 \pm 15$ & 0.335 \\
\hline Pulse pressure (mmHg) & $63 \pm 16$ & $71 \pm 15$ & $80 \pm 22$ & 0.001 \\
\hline Creatinine $(\mu \mathrm{mol} / \mathrm{l})$ & $84 \pm 22$ & $88 \pm 23$ & $92 \pm 33$ & 0.530 \\
\hline Estimated Creatinine clearance $(\mathrm{ml} / \mathrm{min})^{\natural}$ & $103 \pm 22$ & $93 \pm 23$ & $84 \pm 24$ & 0.010 \\
\hline Fasting serum glucose $(\mathrm{mmol} / \mathrm{l})$ & $5.5 \pm 1.0$ & $6.5 \pm 2.6$ & $6.7 \pm 2.3$ & 0.013 \\
\hline Total cholesterol (mmol/l) & $5.4 \pm 1.0$ & $5.9 \pm 1.4$ & $5.4 \pm 1.0$ & 0.278 \\
\hline t-dpMGP (nmol/l) & $5.3 \pm 1.5$ & $6.1 \pm 1.4$ & $5.6 \pm 1.2$ & 0.083 \\
\hline t-ucMGP (nmol/l) & $4610 \pm 1188$ & $4157 \pm 1024$ & $4065 \pm 963$ & 0.152 \\
\hline
\end{tabular}

* Chi-square with categorical data, otherwise one way ANOVA, " according to the Cockcroft and Gault formula, t-dpMGP: total desphospho Matrix Gla Protein, t-ucMGP: total uncarboxylated Matrix Gla Protein 

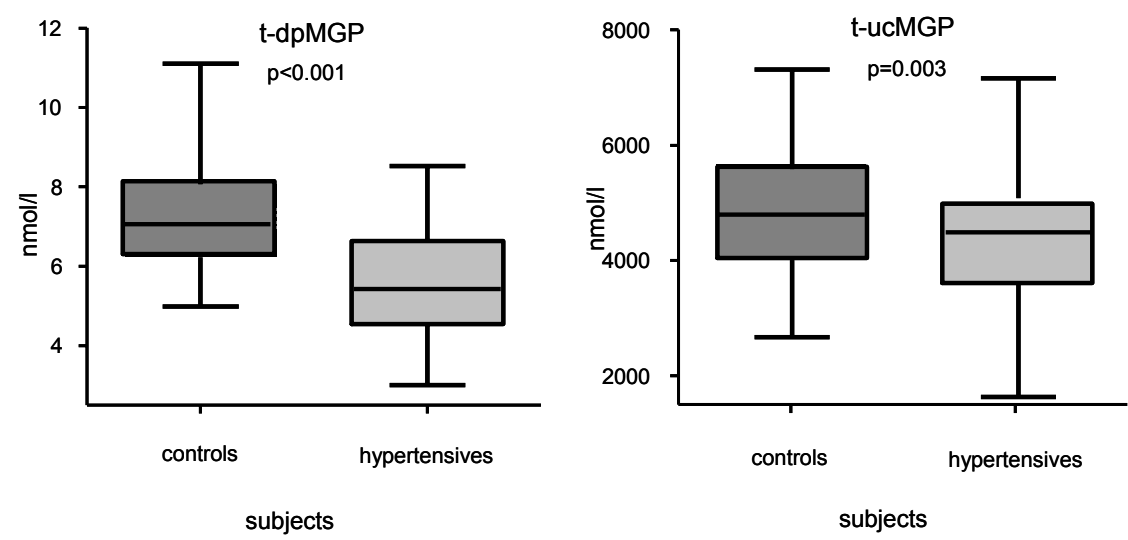

Figure 4.1 Serum t-dpMGP (a) and t-ucMGP (b) distribution.

Box plot of serum total desphospho-MGP (t-dpMGP) (a) and total uncarboxylatedMGP (tucMGP) (b) distribution. The mean values are indicated by a horizontal bar. In the hypertensive group the mean serum t-dpMGP and t-ucMGP concentrations were significantly lower than in the control group $(p<0.001$ and $p=0.003$ respectively).

\section{Discussion}

In the present study we demonstrate that t-dpMGP and t-ucMGP are significantly lower in treatment-resistant hypertensive patients as compared to healthy controls. However, although the correlation coefficient was as expected negative, we found no significant association between t-dpMGP or t-ucMGP with either calcification or the degree of atherosclerosis of the abdominal aorta. Although t-ucMGP levels appeared to be lower in subjects with renal artery stenosis (Table 4.2), this was not statistically significant.

Low circulating levels of both t-dpMGP and t-ucMGP have been reported to be associated with the development of cardiovascular disease and vascular calcification and may reflect low levels of total MGP synthesis. ${ }^{12,16,18}$ This is consistent with the observation that low constitutive MGP synthesis in the vasculature, e.g. in relation to the T $-138 \mathrm{C}$ and G -7 A promoter polymorphisms of the MGP gene, was also found to be correlated with a higher prevalence of cardiovascular disease although there was no significant association of this polymorphism with atherosclerosis or calcification of the abdominal aorta. ${ }^{19,20}$

Some authors have speculated that in the absence of vascular calcification, most of the MGP produced by vascular smooth muscle cells is spilled over to the blood stream. ${ }^{6,11}$ This is in accordance with the data from our study in which t-dpMGP and tucMGP concentrations in hypertensive patients were lower than in healthy controls. The mechanism underlying these differences is unclear but may also be related to the 
increased pressure and shear stress in hypertension which has been shown to change the vascular smooth muscle cell fenotype. ${ }^{21-23}$ Interestingly, in an experimental model for high blood pressure and increased shear stress the MGP expression was increased several fold. ${ }^{24}$ Since hypertension is a known risk factor for calcification, we hypothesize that the vessel wall responds to the increased shear stress by a) maximizing MGP expression and b) increasing cellular MGP secretion. However, the vascular vitamin $\mathrm{K}$ status has been shown to be insufficient for full MGP carboxylation in healthy adults, so probably also in our patient population. ${ }^{25}$ Hence the increased MGP production will largely result in the generation of the inactive MGP. MGP phosphorylation has been reported to stimulate cellular MGP secretion. ${ }^{26}$ Therefore, increased phosphorylation may be a second mechanism by which more MGP can be set free in the vessel wall, which would explain the decrease in non-phosphorylated MGP. Unfortunately, the lack of an assay for phosphorylated MGP hampers testing this hypothesis. In all cardiovascular patient groups tested thus far an inverse correlation between circulating t-ucMGP and the extent of vascular calcification has been observed. This has been explained by binding of UCMGP (via its phosphoserine residues) to the calcium precipitates in the vasculature, by fragmentation of MGP or lower production due to vascular smooth muscle cell apoptosis or differentiation in calcified arteries. ${ }^{16,21,27,28}$ Such trend with t-ucMGP was observed in our hypertensive patients after stratification for extent of atherosclerosis, but the effect did not reach statistical significance (Table 4.2). ${ }^{29}$ The same mechanisms as described above may underlie the lack of correlation between t-ucMGP and vascular calcification in our study but might become statistically significant in larger populations or when more sensitive techniques to detect vascular calcification are used. Currently, placebo controlled vitamin $\mathrm{K}$ intervention trials in patients with vascular calcification have started to test whether increased vitamin $\mathrm{K}$ intake may help to optimize MGP carboxylation resulting in less calcification, a decrease in blood pressure, or both.

Our study has several limitations. First, this is a cross-sectional analysis. Therefore, it is not possible to establish a cause and effect relationship. Second, we only studied treatment-resistant hypertensive patients, and MGP levels as seen in these patients may not occur in subjects with milder degrees of hypertension. Third, the number of patients we studied may have been too small to detect differences between the various hypertensive subgroups. Fourth, the method we used to determine calcification is not the most optimal imaging technique to visualise calcification and results may vary with the method of imaging.

In conclusion, treatment-resistant hypertensive subjects have significantly lower t-dpMGP and t-ucMGP levels compared to healthy adults. We found no statistically significant association between t-dpMGP and t-ucMGP and calcification or atherosclerosis. Whether supplementation with high doses of vitamin $\mathrm{K}$ should be considered as a treatment option by which either the rate of vascular calcification or the blood pressure may be decreased should be determined in future research. 


\section{References}

1. Rennenberg RJ, Kessels AG, Schurgers LJ, van Engelshoven JM, de Leeuw PW, Kroon AA. Vascular calcifications as a marker of increased cardiovascular risk: A meta-analysis. Vasc Health Risk Manag 2009;5:185-97.

2. Schurgers LJ, Cranenburg EC, Vermeer C. Matrix Gla-protein: the calcification inhibitor in need of vitamin K. Thromb Haemost 2008;100:593-603.

3. Cetin M, Cetin R, Tamer N. Prevalence of breast arterial calcification in hypertensive patients. Clin Radiol 2004;59:92-5.

4. Luo G, Ducy P, McKee MD, Pinero GJ, Loyer E, Behringer RR, Karsenty G. Spontaneous calcification of arteries and cartilage in mice lacking matrix GLA protein. Nature 1997;386:78-81.

5. Dhore CR, Cleutjens JP, Lutgens E, Cleutjens KB, Geusens PP, Kitslaar PJ, Tordoir JH, Spronk HM, Vermeer C, Daemen MJ. Differential expression of bone matrix regulatory proteins in human atherosclerotic plaques. Arterioscler Thromb Vasc Biol 2001;21:1998-2003.

6. Price PA, Faus SA, Williamson MK. Warfarin causes rapid calcification of the elastic lamellae in rat arteries and heart valves. Arterioscler Thromb Vasc Biol 1998;18:1400-7.

7. Farzaneh-Far A, Davies JD, Braam LA, Spronk HM, Proudfoot D, Chan SW, O'Shaughnessy KM, Weissberg PL, Vermeer C, Shanahan CM. A polymorphism of the human matrix gammacarboxyglutamic acid protein promoter alters binding of an activating protein-1 complex and is associated with altered transcription and serum levels. J Biol Chem 2001;276:32466-73.

8. Shanahan CM, Cary NR, Metcalfe JC, Weissberg PL. High expression of genes for calcificationregulating proteins in human atherosclerotic plaques. J Clin Invest 1994;93:2393-402.

9. Price PA, Urist MR, Otawara Y. Matrix Gla protein, a new gamma-carboxyglutamic acid-containing protein which is associated with the organic matrix of bone. Biochem Biophys Res Commun 1983;117:765-71.

10. Murshed M, Schinke T, McKee MD, Karsenty G. Extracellular matrix mineralization is regulated locally; different roles of two gla-containing proteins. J Cell Biol 2004;165:625-30.

11. Braam LA, Dissel P, Gijsbers BL, Spronk HM, Hamulyak K, Soute BA, Debie W, Vermeer C. Assay for human matrix gla protein in serum: potential applications in the cardiovascular field. Arterioscler Thromb Vasc Biol 2000;20:1257-61.

12. Jono S, Ikari Y, Vermeer C, Dissel P, Hasegawa K, Shioi A, Taniwaki H, Kizu A, Nishizawa Y, Saito S. Matrix Gla protein is associated with coronary artery calcification as assessed by electron-beam computed tomography. Thromb Haemost 2004;91:790-4.

13. Schurgers LJ, Teunissen KJ, Knapen MH, Geusens P, van der Heijde D, Kwaijtaal M, van Diest R, Ketteler $\mathrm{M}$, Vermeer $\mathrm{C}$. Characteristics and performance of an immunosorbent assay for human matrix Gla-protein. Clin Chim Acta 2005;351:131-8.

14. Jensky NE, Criqui $\mathrm{MH}$, Wright $\mathrm{MC}$, Wassel $\mathrm{CL}$, Brody SA, Allison MA. Blood pressure and vascular calcification. Hypertension 2010;55:990-7.

15. Fava C, Minuz P, Patrignani P, Morganti A. Renal artery stenosis and accelerated atherosclerosis: which comes first? Journal of hypertension 2006;24:1687-96.

16. Cranenburg EC, Vermeer C, Koos R, Boumans ML, Hackeng TM, Bouwman FG, Kwaijtaal M, Brandenburg VM, Ketteler M, Schurgers LJ. The Circulating Inactive Form of Matrix Gla Protein (ucMGP) as a Biomarker for Cardiovascular Calcification. Journal of vascular research 2008;45:427-36.

17. Cockcroft DW, Gault MH. Prediction of creatinine clearance from serum creatinine. Nephron 1976;16:31-41.

18. Schurgers L, Teunissen KJ, Knapen M H, Kwaijtaal M, van Diest R, Appels A, Reutelingsperger CP, Cleutjens JP, Vermeer C. Novel conformation-specific antibodies against matrix gammacarboxyglutamic acid (Gla) protein: undercarboxylated matrix Gla protein as marker for vascular calcification. Arterioscler Thromb Vasc Biol 2005;25:1629-33.

19. Herrmann SM, Whatling C, Brand E, Nicaud V, Gariepy J, Simon A, Evans A, Ruidavets JB, Arveiler D, Luc G, Tiret L, Henney A, Cambien F. Polymorphisms of the human matrix gla protein (MGP) gene, vascular calcification, and myocardial infarction. Arterioscler Thromb Vasc Biol 2000;20:2386-93. 
20. Kobayashi N, Kitazawa R, Maeda S, Schurgers L, Kitazawa S. T-138C Polymorphism of Matrix Gla Protein Promoter Alters Its Expression but is not Directly Associated with Atherosclerotic Vascular Calcification. Kobe J Med Sci 2004;50:69-81.

21. Weissberg PL, Cary NR, Shanahan CM. Gene expression and vascular smooth muscle cell phenotype. Blood Press Suppl 1995;2:68-73.

22. Lehoux S, Tedgui A. Signal transduction of mechanical stresses in the vascular wall. Hypertension 1998;32:338-45.

23. Mustonen E, Pohjolainen V, Aro J, Pikkarainen S, Leskinen H, Ruskoaho H, Rysa J. Upregulation of cardiac matrix Gla protein expression in response to hypertrophic stimuli. Blood pressure 2009;18:286-93.

24. Wesselman JP, Kuijs R, Hermans JJ, Janssen GM, Fazzi GE, van Essen H, Evelo CT, Struijker-Boudier HA, De Mey JG. Role of the Rhoa/Rho kinase system in flow-related remodeling of rat mesenteric small arteries in vivo. Journal of vascular research 2004;41:277-90.

25. Berkner KL, Runge KW. The physiology of vitamin K nutriture and vitamin K-dependent protein function in atherosclerosis. J Thromb Haemost 2004;2:2118-32.

26. Wajih N, Borras T, Xue W, Hutson SM, Wallin R. Processing and transport of matrix gammacarboxyglutamic acid protein and bone morphogenetic protein-2 in cultured human vascular smooth muscle cells: evidence for an uptake mechanism for serum fetuin. The Journal of biological chemistry 2004;279:43052-60.

27. Proudfoot D, Skepper JN, Hegyi L, Bennett MR, Shanahan CM, Weissberg PL. Apoptosis regulates human vascular calcification in vitro: evidence for initiation of vascular calcification by apoptotic bodies. Circulation research 2000;87:1055-62.

28. Schurgers LJ, Spronk HM, Skepper JN, Hackeng TM, Shanahan CM, Vermeer C, Weissberg PL, Proudfoot D. Post-translational modifications regulate matrix Gla protein function: importance for inhibition of vascular smooth muscle cell calcification. J Thromb Haemost 2007;5:2503-11.

29. Rennenberg RJ, de Leeuw PW, Kessels AG, Schurgers L, Vermeer C, van Engelshoven JM, Kemerink GJ, Kroon AA. Calcium scores and matrix Gla protein levels: association with vitamin $\mathrm{K}$ status. European journal of clinical investigation 2010;40:344-9. 



\section{Chapter 5}

Renal handling of matrix Gla protein in humans with moderate to severe hypertension

RJMW Rennenberg, LJ Schurgers, C Vermeer, JBJ Scholte, AJHM Houben, PW de Leeuw, AA Kroon

Hypertens Res 2008;31:1745-51 


\section{Abstract}

\section{Objective}

Vascular calcifications are common among patients with hypertension. The vitamin K-dependent protein matrix Gla-protein plays an important role in preventing arterial calcification. Since decrease of renal clearance in patients with hypertension is a prevalent clinical problem, we aimed to study the renal clearance of matrix Gla-protein from the circulation in patients with hypertension and a wide range of creatinine clearances.

\section{Methods and results}

From 90 moderate to severe hypertensive patients scheduled for renal angiography, renal arterial and renal venous blood was sampled prior to administration of contrast material to determine total renal and single kidney clearance of matrix Gla-protein.

Average renal fractional extraction of matrix Gla-protein was $12.8 \%$. There was no significant correlation between creatinine clearance (range 26-154) and renal fractional extraction of matrix Gla-protein in this population. The extraction of matrix Gla-protein was not influenced by the presence of a renal artery stenosis.

\section{Conclusions}

In this study, we demonstrate that the kidney is able to extract matrix Gla-protein from the plasma at a constant level of $12.8 \%$ independent of renal function in hypertensive subjects. 


\section{Introduction}

Small peptides usually are able to freely pass the glomerular barrier and their extraction by the kidney does not drop until glomerular filtration rate has fallen substantially. Previously, we assessed the renal extraction of small hormonal peptides such as leptin and growth hormone. ${ }^{1,2}$ Another peptide, for which it would be relevant to measure its renal extraction is matrix Gla-protein (MGP), an 10 KD vitamin $\mathrm{K}$-dependent protein and a potent inhibitor of vascular calcifications. Almost all tissues, including the kidney, contain carboxylase and vitamin K, necessary to convert uncarboxylated MGP into the active carboxylated MGP. Although first discovered in bone, MGP is mainly produced by vascular smooth muscle cells and chondrocytes and it appears to accumulate at sites of calcifications. ${ }^{3-8}$ Part of the MGP synthesized in the tissues spills over to plasma, where it can be measured in concentrations between 5 and $19 \mathrm{nmol} / \mathrm{l}$. Because of the insolubility of MGP, this protein probably circulates complexed to "chaperone" (lipo) proteins or other structures. An example is the MGPmineral complex in which MGP is bound to fetuin to form a soluble complex that can be transported by the plasma. ${ }^{9}$

Circulating levels of MGP correlate inversely with arterial calcifications and cardiovascular disease. ${ }^{10-12}$ Low serum levels of MGP are associated with a greater degree of coronary calcification and angina pectoris. ${ }^{11,12}$ The carboxylation status of MGP is also correlated to markers of active calcification in dialysis patients. ${ }^{13}$ Moreover, hypertensive patients have more vascular calcifications than normotensive subjects, which may contribute to their increased vascular risk. ${ }^{14}$ Lower levels of circulating MGP may be due to either to less spill over into or to enhanced clearance from the circulation. So far, the mechanisms by which MGP is removed from the circulation are still elusive and, in particular, no information is available on the role of the kidney in MGP clearance. This prompted us to set up the present study which was designed to explore whether the kidneys extract MGP and, if so, to what extent. Due to the invasive nature of this study, measurements were confined to hypertensive patients in whom renal angiography was indicated. Furthermore this protocol allowed us to distinguish a potential effect of a renal artery stenosis on MGP handling. This is the first publication about MGP extraction in the human kidney.

\section{Methods}

\section{Patients}

During a 19-months period, consecutive patients were recruited from the Internal Medicine outpatient hypertension clinic. All hypertensive patients between 18 and 65 years of age were routinely screened for the presence of clinical clues indicating renal artery stenosis, as defined by the Working Group on Renovascular Hypertension and 
others. ${ }^{15-17}$ A total of 133 patients with at least one clinical clue besides hypertension were scheduled for renal angiography on suspicion of having renal artery stenosis. In 90 of these patients antihypertensive drugs, or other types of medication that could influence flow through the kidney, could safely be withheld for a period of three weeks preceding angiography. These patients were enrolled in the present study after they had given written informed consent. The study was approved by our local ethics committee. The 43 remaining patients who had to be excluded did not differ from the study group with respect to relevant clinical variables (blood pressure levels, sex, age, body mass index (BMI), smoking habits, blood glucose, cholesterol levels and estimated creatinine clearance).

\section{Angiography and sampling}

At the angiosuite, catheters were placed into the renal artery and vein without the use of contrast material. Subsequently, blood samples were drawn simultaneously from the artery and both the left and right renal vein for determination of MGP. In a subgroup of the patients we also measured arterial and venous osteocalcin. Blood sampling was followed by selective measurements of renal blood flow by means of the ${ }^{133}$ Xenon washout technique. ${ }^{18-20}$ Angiography was performed only after all measurements had been completed to avoid disturbance of renal hemodynamics or tubular function by contrast material. Measurements were performed in both the left and the right renal vein because previous studies have shown a side difference in renal blood flow irrespective of the presence of a renal artery stenosis. ${ }^{21}$

To determine the possible excretion of MGP into the urine we also measured MGP concentrations in overnight morning urine of 5 healthy volunteers.

\section{Measurements}

Blood samples were spun immediately at $3000 \mathrm{~g}$ for 15 minutes at $4^{\circ} \mathrm{C}$. Serum was transferred into separate tubes and stored at $-80^{\circ} \mathrm{C}$ until use. Test kits for MGP detection in serum were obtained from Biomedica (Vienna, Austria). The principle of the assay is that of a competitive enzyme-linked immuno-sorbent assay (ELISA) in which microwell plates are coated with a mouse monoclonal antibody against human MGP. Synthetic MGP peptide in human serum, which was affinity stripped to remove native human MGP, is used as calibrator. Biotinylated MGP added simultaneously to the wells with standards, samples or controls is used as tracer. Detection of bound tracer is accomplished with HRP-labeled streptavidine. ${ }^{12}$ The test detects total MGP, bound and unbound, carboxylated and uncarboxylated. The intra- and inter-assay coefficients of variation of this test are both around $10 \%$. Osteocalcin (OC) was measured using a commercially available ELISA (Takara bio inc. Japan). ${ }^{22}$ 
Biochemical variables, including total cholesterol, creatinine and glucose were measured using an automated chemistry analyzer (Beckmann Synchron CX 7-2, Fullerton CA). Endogenous creatinine clearance (ECC) was calculated from peripheral venous creatinine concentrations with the formula of Cockcroft and Gault. ${ }^{23}$ Human kidney tissue was obtained from our department of pathology. After deparaffinization and rehydration, tissue was stained for hematoxylin and eosin to demonstrate tissue integrity. For immunostaining with mAb MGP antibody, sections were heated in $0.2 \%$ $(\mathrm{w} / \mathrm{v})$ citric acid at $\mathrm{pH} 6.0$ for 15 minutes before washing with phosphate-buffered saline and incubation with anti-MGP3-15 $(5 \mu \mathrm{g} / \mathrm{ml})$. All antibodies were diluted in blocking reagent (Roche Diagnostics, Mannheim, Germany). Negative control was performed by substitution for an irrelevant antibody. Biotinylated sheep anti-mouse IgG (Amersham Biosciences, Little Chalfont, UK) was used as a second antibody, followed by incubation with avidin-linked alkaline phosphatase complex (Dako, Golstrup, Denmark); staining was performed by the alkaline phosphatase kit I (Vector Laboratories, Burlingame, CA). All specimens were counterstained using hematoxylin and sections were mounted using imsol-mount.

\section{Calculations}

Mean renal blood flow (MRBF) was determined by means of the ${ }^{133}$ Xenon-washout technique as described previously. ${ }^{20,24}$ Flow data were analyzed for the right and the left kidney separately and expressed in $\mathrm{ml}^{\mathrm{min}}$. $^{-1}(100 \mathrm{~g} \text { of renal tissue })^{-1}$. Mean renal plasma flow (MRPF) was calculated with the formula MRPF=MRBF $\times(1-\mathrm{Ht})$, where $\mathrm{Ht}$ is the arterial hematocrit. Total arterial MGP delivery to the kidneys amounts to: arterial $M G P \times\left(M R P F_{L}+M R P F_{R}\right)$, where $M R P F_{L}$ and $M R P F_{R}$ represent mean renal plasma flow through the left and right kidney, respectively. Single kidney fractional extraction (SKFE) of MGP was derived from the formula: $((A-V) / A) \times 100 \%$, where $A$ and $\mathrm{V}$ represent the MGP concentrations in the renal artery and vein. Renal MGP uptake by each kidney was computed as mean renal plasma flow $\times$ (arterial MGP concentration - renal venous MGP concentration) and expressed in pmol. $\mathrm{min}^{-1}(100 \mathrm{~g})^{-1}$. Total renal uptake was taken as the sum of the uptake by the right and the left kidney. Total venous efflux of MGP can be calculated as: $\left(V_{L} \times M R P F_{L}\right)+\left(V_{R} \times M R P F_{R}\right)$ where $V_{L}$ and $V_{R}$ represent the concentrations of MGP in the left and right renal vein respectively. Renal fractional extraction (RFE) of MGP can be derived from the formula (total arterial delivery - total venous efflux) $\times(\text { total arterial delivery })^{-1} \times 100 \%$. Total renal clearance of MGP can be calculated as: $\left(\mathrm{SKFE}_{\mathrm{L}} \times \mathrm{MRPF}_{\mathrm{L}}\right)+\left(\mathrm{SKFE}_{R} \times \mathrm{MRPF}_{\mathrm{R}}\right)$. For OC we calculated single kidney fractional extraction and renal uptake for the left kidney, since only samples from the left side were taken for comparison.

\section{Statistical analysis}

Normally distributed variables are expressed as means with standard deviations. Data which show a non-normal distribution are expressed as median and ranges. Renal 
MGP and OC extraction were correlated with clearance parameters by use of Spearman correlation. To assess differences between means the unpaired t test was used. Welch's correction was applied when the variances were significantly different. Statistical calculations and data management were performed using SPSS for Windows V11.0 (SPSS, Chicago, IL). A p-value of $<0.05$ was considered to denote statistical significance.

\section{Results}

Of the 133 hypertensive patients who underwent angiography, 90 patients were without medication at the time of the procedure. Table 4.1 shows the anthropometric characteristics of these patients. In a total of 18 kidneys in 12 patients ${ }^{133}$ Xenon washout measurements were impossible or incomplete, e.g. due to misplacement of the catheter or because the renal artery was too narrow to allow the catheter to be advanced far enough. In 23 of the 90 patients renal angiography showed renal artery stenosis of varying degree with a minimum of $20 \%$. In eight patients bilateral renal artery stenosis was present. Patients with renal artery stenosis were significantly older, (had) smoked more often and had a significantly lower ECC (Table 5.1).

Table 5.1 Clinical characteristics of the study population.

\begin{tabular}{|c|c|c|c|c|}
\hline Variable & $\begin{array}{l}\text { All subjects } \\
\qquad n=90\end{array}$ & $\begin{array}{c}\text { Subjects with } \\
\text { RAS } \\
n=23\end{array}$ & $\begin{array}{c}\text { Subjects without } \\
\text { RAS } \\
n=67\end{array}$ & p-value \\
\hline Age (yr) & $52 \pm 10$ & $58 \pm 6$ & $50 \pm 10$ & $0.0001+$ \\
\hline Body mass index $\left(\mathrm{kg} / \mathrm{m}^{2}\right)$ & $27 \pm 5$ & $26 \pm 5$ & $28 \pm 4$ & 0.11 \\
\hline Male/female (n) & $51 / 39$ & $16 / 7$ & $35 / 32$ & 0.15 \\
\hline (ever) Smoking (\%) & 62 & 83 & 55 & 0.02 \\
\hline Systolic blood pressure (mmHg) & $164 \pm 24$ & $171 \pm 23$ & $162 \pm 24$ & 0.15 \\
\hline Diastolic blood pressure (mmHg) & $97 \pm 14$ & $97 \pm 14$ & $98 \pm 14$ & 0.73 \\
\hline Creatinine $(\mu \mathrm{mol} / \mathrm{L})$ & $87 \pm 26$ & $93 \pm 34$ & $85 \pm 23$ & $0.29+$ \\
\hline $\begin{aligned} \text { Creatinine clearance } & \text { ( } \mathrm{ml} / \mathrm{min}) \\
& \text { (median, range) }\end{aligned}$ & $\begin{array}{c}97 \pm 26 \\
98,26-154\end{array}$ & $\begin{array}{c}86 \pm 29 \\
80,29-153\end{array}$ & $\begin{array}{c}101 \pm 24 \\
99,26-154\end{array}$ & $\begin{array}{l}0.02 \\
0.02\end{array}$ \\
\hline Fasting serum glucose (mmol/l) & $6.1 \pm 2.0$ & $6.7 \pm 2.4$ & $5.9 \pm 1.8$ & $0.14+$ \\
\hline Total cholesterol (mmol/l) & $5.5 \pm 1.1$ & $5.5 \pm 1.0$ & $5.6 \pm 1.2$ & 0.72 \\
\hline
\end{tabular}

Data are shown as mean \pm SD; RAS = renal artery stenosis; there was no significant correlation between body mass index or age and MGP levels; $\dagger$, Unpaired t test with Welch's correction, comparing subjects with and without RAS.

Concentrations of MGP were lower in renal venous than in arterial blood. Arterial MGP averaged $6.4 \mathrm{nmol} / \mathrm{I} \pm 1.5$ (mean $\pm \mathrm{SD}$ ) whereas the average MGP concentrations in the left and the right renal vein were $5.5 \pm 1.4$ and $5.7 \pm 0.7 \mathrm{nmol} / \mathrm{l}$ respectively (Table 5.2). A significant positive relationship was found between arterial MGP concentrations and both left and right venous MGP concentrations. $(r=0.78, p<0.0001$ 
and $r=0.63, p<0.0001$, respectively) and also between arterial and renal vein concentrations of $\mathrm{OC}(r=0.89, p<0.0001$, Figure 5.1). Plotting total renal venous outflow against arterial delivery (Figure 5.2), shows that MGP is extracted by the kidney and that the renal extraction efficiency is constant over a wide range of arterial delivery. Overall fractional renal extraction of MGP was $12.8 \%$. Overall fractional renal extraction of OC was $31.7 \%$.

Table 5.2 Renal clearance assessments analysed per kidney.

\begin{tabular}{|c|c|c|c|c|c|c|}
\hline Variable & $\begin{array}{l}\text { All subjects } \\
\qquad \mathrm{n}=90\end{array}$ & $\begin{array}{c}\text { Left } \\
\text { kidney } \\
\mathrm{n}=90\end{array}$ & $\begin{array}{c}\text { Right } \\
\text { kidney } \\
\mathrm{n}=90\end{array}$ & $\begin{array}{c}\text { Kidneys } \\
\text { with RAS } \\
\mathrm{n}=31\end{array}$ & $\begin{array}{c}\text { Kidneys } \\
\text { without RAS } \\
n=149\end{array}$ & p value ${ }^{*}$ \\
\hline Left renal vein MGP (nmol/l) & $5.5(1.4)$ & $5.5(1.4)$ & - & $5.7(1.2)$ & $5.4(1.4)$ & 0.47 \\
\hline Right renal vein MGP (nmol/l) & $5.7(0.7)$ & - & $5.7(0.7)$ & $6.3(1.9)$ & $5.6(1.2)$ & $0.20+$ \\
\hline Arterial MGP (nmol/l) & $6.4(1.5)$ & - & - & $6.8(1.7)$ & $6.3(1.4)$ & 0.16 \\
\hline $\begin{array}{l}\text { Mean renal plasma flow } \\
\text { (ml/min./100g of renal tissue) }\end{array}$ & - & $109(36.8)$ & $131(40.2)$ & $87.3(35.8)$ & $127.9(35.8)$ & $<0.0001$ \\
\hline Total venous efflux (nmol/l) & $1307(409.3)$ & - & - & - & - & \\
\hline $\begin{array}{l}\text { Total arterial MGP delivery } \\
(\mathrm{nmol} / \mathrm{l})\end{array}$ & 1508 (467.9) & - & - & 1187 (454.4)‡ & $1555(468.3) \ddagger$ & 0.002 \\
\hline $\begin{array}{l}\text { Total renal uptake } \\
\text { (pmol/min./100g of renal tissue) }\end{array}$ & $198(186.4)$ & - & - & - & - & \\
\hline $\begin{array}{l}\text { Total renal uptake left kidney } \\
\text { (pmol/min./100g of renal tissue) }\end{array}$ & $94.9(99.8)$ & - & - & $105.0(84.3)$ & $92.7(103.4)$ & 0.67 \\
\hline $\begin{array}{l}\text { Total renal uptake right kidney } \\
\text { (pmol/min./100g of renal tissue) }\end{array}$ & $95.6(160.2)$ & - & - & $10.2(84.9)$ & $111.1(166.1)$ & $0.004+$ \\
\hline SKFE (\%) & - & $14(12.8)$ & $10(14.5)$ & - & - & \\
\hline Renal fractional extraction (\%) & $12.8(11.1)$ & & & $11.5(13.2)$ & $12.6(10.5)$ & 0.98 \\
\hline $\begin{array}{l}\text { MGP clearance }(\mathrm{ml} / \mathrm{min} . / 100 \mathrm{~g} \text { of } \\
\text { renal tissue) }\end{array}$ & 28 & 15 & 13 & 10 & 16 & 0.07 \\
\hline
\end{tabular}

Data are shown as mean $\pm \mathrm{SD}$; comparison between stenosis present and absent SKFE $=$ single kidney fractional extraction; $\dagger$, Unpaired t test with Welch's correction because of significantly different variances; ₹ results applicable to patient not to single kidney

Thirty-five of the patients had normal renal function while 22, 26, 5, 2 and 0 patients were in chronic kidney disease stages $1,2,3,4$, and 5 respectively. There was no correlation between either serum creatinine or ECC and the renal fractional extraction of MGP ( $r=0.15, p=0.2$ and $r=0.04 p>0.7$ respectively).(Figure 5.3a) However, renal fractional extraction of $\mathrm{OC}$, which was only measured at the left side, showed a significant but weak correlation with ECC $(r=0.35 p=0.03)$. Renal extraction of MGP and $\mathrm{OC}$ did not correlate with age, blood pressure (Figure 5.3b), the presence of stenosis or 24-h albumin excretion.

The fact that the kidneys are involved in the extraction of MGP from the circulation may imply that MGP-related peptides are found in urine. However, in the overnight morning urine of 5 healthy volunteers urine-MGP concentrations averaged only $1.14 \mathrm{nmol} / \mathrm{l}$ (range 0 to 1.8). This is close to the lower detection limit and suggests 
that virtually no detectable forms of MGP are excreted in urine. Unfortunately, proteolytic decay cannot be excluded completely because no protease inhibitors were added to the collected urine.
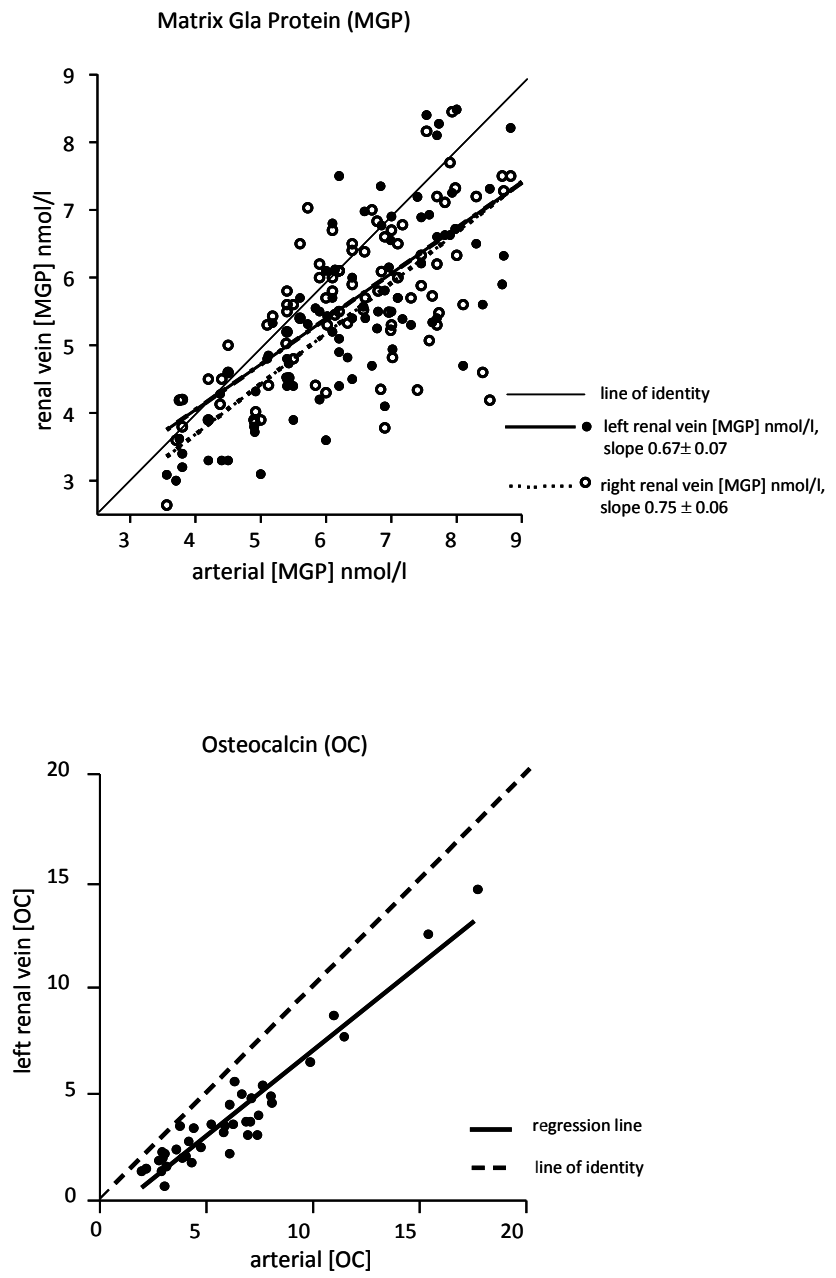

Figure 5.1 Correlation between arterial and venous concentrations of Matrix Gla protein and Osteocalcin.

Extraction of MGP and OC versus arterial concentration of MGP and OC showing increased extraction with increasing arterial concentration. The line of identity represents no effect on MGP and OC concentration when blood passes through the kidney. 


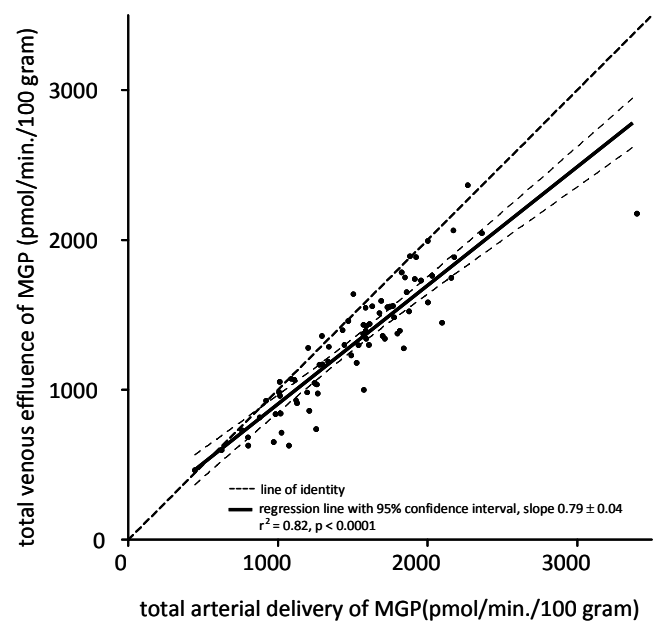

Figure 5.2 Total venous effluence versus total arterial delivery of Matrix Gla protein.

Total venous efflux of MGP plotted against total arterial delivery. The line of identity represents no effect on MGP concentration when blood passes through the kidney. The majority of the patients are depicted below the line of identity indicating extraction of MGP from the circulation.
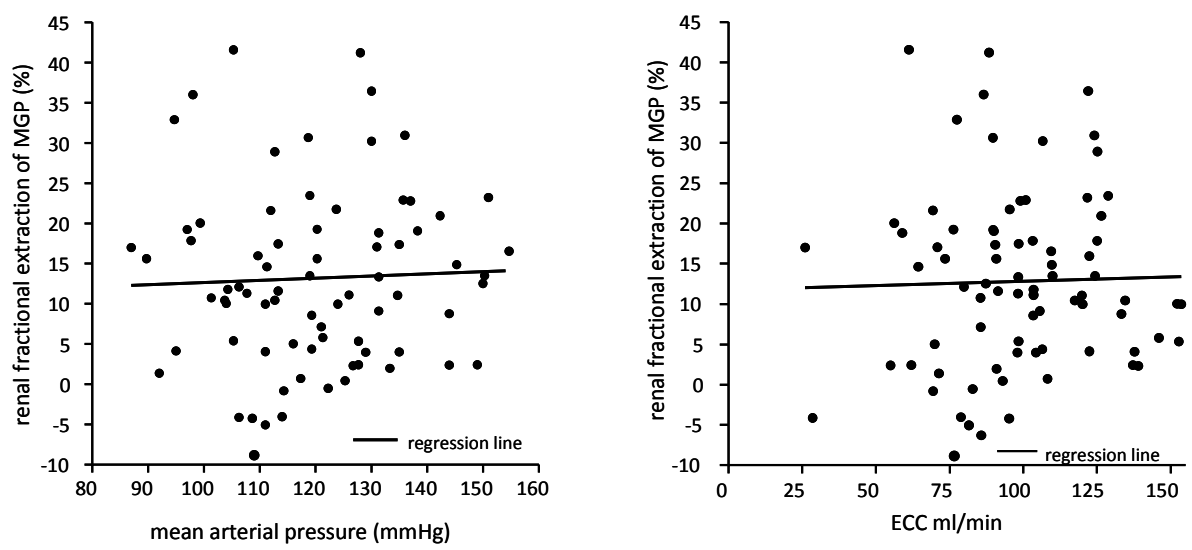

Figure 5.3 a Correlation between renal function and renal fractional extraction of MGP. Renal fractional extraction of MGP showing no correlation with endogenous creatinine clearance estimated by the Cockcroft and Gault formula.

b Correlation between mean arterial pressure and renal fractional extraction of MGP Renal fractional extraction of MGP showing no correlation with mean arterial pressure (calculated from 24 hour ambulatory blood pressure measurement) 


\section{Discussion}

In the present study we demonstrated that the kidney is able to extract MGP from the circulation. This extraction of MGP is independent of renal function and the presence of renal artery stenosis or albuminuria, although we must admit that patients with more advanced stages of chronic kidney disease were either excluded (stage V) or relatively underrepresented (stage III and IV). As there is virtually no excretion of MGP into the urine of healthy volunteers, our data are compatible with the view that the extracted MGP is metabolized on its way through the kidney. However, we cannot fully exclude the possibility that normal tubular cell- and brush border function might be impaired in subjects with renal artery stenosis or renal insufficiency, thus resulting in incomplete reabsorption and breakdown of MGP which might then be detectable in urine. Given its small size, MGP is likely to be filtered by the glomerulus and then reabsorbed and broken down in the proximal tubuli. This mechanism has been demonstrated for many other small proteins like leptin, and growth hormone. ${ }^{1,2}$ Moreover, on the basis of its small size, Price et al suggested that MGP is rapidly cleared by the kidney. ${ }^{9}$ Although clearance might be impaired because of MGP being complexed to larger structures, experimental data on this issue are lacking. So far, attemps to determine the exact molecular size of the fetuin mineral complex have been unsuccesfull, but it is likely to be greater than $250 \mathrm{KD} .{ }^{9}$ Thus, it is unlikely that the complexed form of MGP is filtered by the glomerulus. The fractional extraction of total MGP (bound or unbound to carriers) passing through the kidney was $12.8 \%$. It should be emphasized, however, that our data on renal extraction of MGP are valid only when there is no renal production of this protein. We do not know whether this is truly the case. Indeed, high levels of MGP mRNA have been reported in the kidney, were it was found in discrete tissue specific cell types. ${ }^{6,10,25,26}$ Using an MGP antibody we stained apparently healthy kidney tissue obtained from our department of pathology. The control was done with a nonsense antibody and was negative. It can be seen that MGP is abundantly present in the epithelial cells of the distal tubules (Figure 5.4). This localization suggests local production of MGP because in the distal tubules there is virtually no protein reabsorption. MGP can also be seen in the small arterioles of the kidney, mainly aligned along the elastic lamina. Therefore, it is possible that part of the venous MGP is produced by the kidney. If this is really the case, the true extraction of MGP by the kidney would be even greater than measured in this study. 


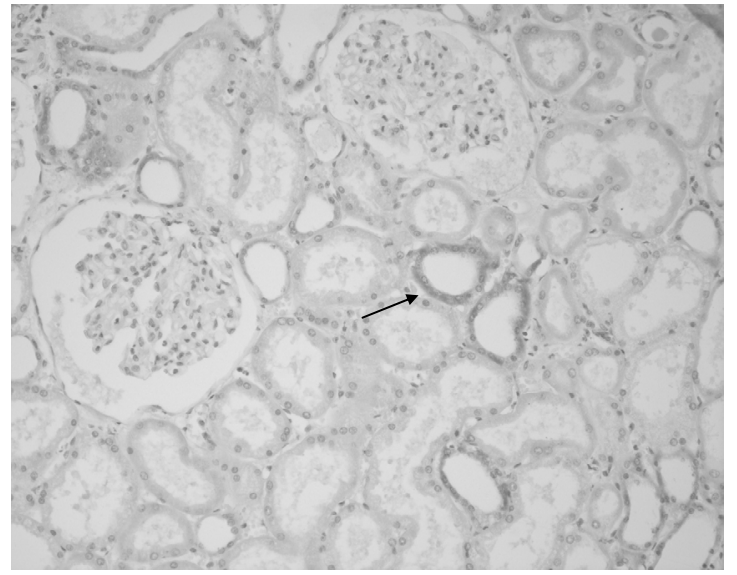

Figure 5.4 MGP in a human renal biopsy specimen.

The immunohistochemical localization of MGP in a human kidney specimen. A section displaying distal tubules was stained with anti-MGP-antibodies (dark grey, arrow) and counterstained with haematoxylin. The control sample, which was stained with a nonsense antibody, was negative (data not shown).

Because it cannot entirely be excluded that some MGP is produced in the kidney, which might influence actual clearance as assessed by our method, we also measured osteocalcin $(\mathrm{OC})$ concentrations in samples from renal arterial blood and the left renal vein $^{25,27}$. OC is comparable to MGP with respect to electrical charge and is only slightly different in size (5.8 kD vs $10 \mathrm{kD}$ ). It is, therefore, assumed to have the same clearance characteristics as MGP. Since $O C$ is exclusively produced by osteoblasts and odontoblasts the renal clearance of this peptide is not influenced by its production. ${ }^{28}$ To estimate MGP clearance assuming there is no production we measured clearance of OC. From OC also only fragments can be measured in urine. ${ }^{29,30}$ The observed difference in clearance of about $19 \%$ between MGP and OC might suggest that this percentage of venous MGP is added to the blood flowing through the kidney by production.

Renal calcification, inflammation or oxidized LDL are among the factors that stimulate osteogenic regulatory genes, which may induce up-regulation of renal MGP expression. ${ }^{31}$ Some authors have speculated that if calcification is totally absent most of the MGP produced by vascular smooth muscle cells in the matrix is spilled over to plasma, thereby increasing its concentration in the venous effluent relative to arterial levels. ${ }^{6,10}$ Whether hypertension and associated oxidative stress cause increased vascular calcification and therefore less "spillover" of MGP to the circulation or vice versa, or that lower MGP levels cause arterial calcification with increased arterial stiffening eventually resulting in hypertension, is not known. The fact that the 
majority of hypertensive patients have no obvious vascular calcifications together with our finding that venous MGP levels are comparable between subjects without or with renal artery stenosis speaks in favour of the blood pressure related "trapping" of MGP in the vessel wall.

Clearly, our study has some limitations. Amongst others, the test used to measure MGP detects total MGP antigen. At present, it is impossible to distinguish between different conformations of MGP or between free MGP and MGP present in the mineral complex bound to fetuin. Since the latter is too large to be removed by filtration in the kidney, the amount of MGP that is actually extracted most likely represents the unbound fraction of MGP. This may, in fact, be another explanation for the small differences between arterial and renal venous MGP levels. Another limitation of our study may be the exclusion of 43 out of 133 consecutive patients because they could not stop their medication prior to angiography. However, since their clinical characteristics were comparable to the patients who did participate, it is unlikely that this has caused significant bias.

In conclusion, we demonstrated that the kidney is able to extract MGP from the circulation and that this extraction is not impaired when renal function is jeopardized. 


\section{References}

1. Fogteloo AJ, Meinders AE, Pijl H, Kroon AA, Frolich M, De Leeuw PW. Renal clearance of endogenous leptin in hypertensive humans with or without renal artery stenosis. Am J Physiol Endocrinol Metab 2001;281:E400-4.

2. Buijs MM, de Leeuw PW, Houben AJ, Kroon AA, Frolich M, Pijl H, Meinders AE. Renal contribution to increased clearance of exogenous growth hormone in obese hypertensive patients. J Clin Endocrinol Metab 2005;90:795-9.

3. Price PA, Urist MR, Otawara Y. Matrix Gla protein, a new gamma-carboxyglutamic acid-containing protein which is associated with the organic matrix of bone. Biochem Biophys Res Commun 1983;117:765-71.

4. Luo G, Ducy P, McKee MD, Pinero GJ, Loyer E, Behringer RR, Karsenty G. Spontaneous calcification of arteries and cartilage in mice lacking matrix GLA protein. Nature 1997;386:78-81.

5. Dhore CR, Cleutjens JP, Lutgens E, Cleutjens KB, Geusens PP, Kitslaar PJ, Tordoir JH, Spronk HM, Vermeer C, Daemen MJ. Differential expression of bone matrix regulatory proteins in human atherosclerotic plaques. Arterioscler Thromb Vasc Biol 2001;21:1998-2003.

6. Price PA, Faus SA, Williamson MK. Warfarin causes rapid calcification of the elastic lamellae in rat arteries and heart valves. Arterioscler Thromb Vasc Biol 1998;18:1400-7.

7. Farzaneh-Far A, Davies JD, Braam LA, Spronk HM, Proudfoot D, Chan SW, O'Shaughnessy KM, Weissberg PL, Vermeer C, Shanahan CM. A polymorphism of the human matrix gammacarboxyglutamic acid protein promoter alters binding of an activating protein-1 complex and is associated with altered transcription and serum levels. J Biol Chem 2001;276:32466-73.

8. Shanahan CM, Cary NR, Metcalfe JC, Weissberg PL. High expression of genes for calcificationregulating proteins in human atherosclerotic plaques. J Clin Invest 1994;93:2393-402.

9. Price PA, Thomas GR, Pardini AW, Figueira WF, Caputo JM, Williamson MK. Discovery of a high molecular weight complex of calcium, phosphate, fetuin, and matrix gamma-carboxyglutamic acid protein in the serum of etidronate-treated rats. J Biol Chem 2002;277:3926-34.

10. Braam LA, Dissel P, Gijsbers BL, Spronk HM, Hamulyak K, Soute BA, Debie W, Vermeer C. Assay for human matrix gla protein in serum: potential applications in the cardiovascular field. Arterioscler Thromb Vasc Biol 2000;20:1257-61.

11. Jono S, Ikari Y, Vermeer C, Dissel P, Hasegawa K, Shioi A, Taniwaki H, Kizu A, Nishizawa Y, Saito S. Matrix Gla protein is associated with coronary artery calcification as assessed by electron-beam computed tomography. Thromb Haemost 2004;91:790-4.

12. Schurgers LJ, Teunissen KJ, Knapen MH, Geusens P, van der Heijde D, Kwaijtaal M, van Diest R, Ketteler $\mathrm{M}$, Vermeer $\mathrm{C}$. Characteristics and performance of an immunosorbent assay for human matrix Gla-protein. Clin Chim Acta 2005;351:131-8.

13. Hermans MM, Vermeer C, Kooman JP, Brandenburg V, Ketteler M, Gladziwa U, Rensma PL, Leunissen KM, Schurgers L. Undercarboxylated matrix GLA protein levels are decreased in dialysis patients and related to parameters of calcium-phosphate metabolism and aortic augmentation index. Blood Purif 2007;25:395-401.

14. Cetin M, Cetin R, Tamer N. Prevalence of breast arterial calcification in hypertensive patients. Clin Radiol 2004;59:92-5.

15. Anderson GH Jr, Blakeman N, Streeten DH. Prediction of renovascular hypertension. Comparison of clinical diagnostic indices. Am J Hypertens 1988;1:301-4.

16. Krijnen P, van Jaarsveld BC, Steyerberg EW, Man in 't Veld AJ, Schalekamp MA, Habbema JD. A clinical prediction rule for renal artery stenosis. Ann Intern Med 1998;129:705-11.

17. Detection, evaluation, and treatment of renovascular hypertension. Final report. Working Group on Renovascular Hypertension. Arch Intern Med 1987;147:820-9.

18. de Leeuw PW, Birkenhager WH. Use of the xenon-133 washout technique in diagnosing renovascular disease in hypertension. Nephron 10986;44(S1):5-7.

19. Ladefoged J. Measurements of the renal blood flow in man with the 133 xenon wash-out technique. A description of the method. Scand J Clin Lab Invest 1966;18:299-315. 
20. Wierema TK, Houben AJ, Kroon AA, Koster D, van der Zander K, van Engelshoven JM, de Leeuw PW. Nitric oxide dependence of renal blood flow in patients with renal artery stenosis. J Am Soc Nephrol 2001;12:1836-43.

21. van Onna M, Houben AJ, Kroon AA, Wierema TK, Koster D, van Engelshoven JM, de Leeuw PW. Asymmetry of renal blood flow in patients with moderate to severe hypertension. Hypertension 2003;41:108-13.

22. Koyama N, Ohara K, Yokota H, Kurome T, Katayama M, Hino F, Kato I, Akai T. A one step sandwich enzyme immunoassay for gamma-carboxylated osteocalcin using monoclonal antibodies. J Immunol Methods 1991;139:17-23.

23. Cockcroft DW, Gault MH. Prediction of creatinine clearance from serum creatinine. Nephron 1976; 16:31-41.

24. De Leeuw PW, Birkenhäger WH. Use of the xenon-133 washout technique in diagnosing renovascular disease in hypertension. Nephron 1986;44:5-7.

25. Fraser JD, Price PA. Lung, heart, and kidney express high levels of mRNA for the vitamin K-dependent matrix Gla protein. Implications for the possible functions of matrix Gla protein and for the tissue distribution of the gamma-carboxylase. J Biol Chem 1988;263:11033-6.

26. Cancela ML, Price PA. Retinoic acid induces matrix Gla protein gene expression in human cells. Endocrinology 1992;130:102-8.

27. Cancela ML, Hu B, Price PA. Effect of cell density and growth factors on matrix GLA protein expression by normal rat kidney cells. J Cell Physiol 1997;171:125-34.

28. Price PA, Williamson MK, Lothringer JW. Origin of the vitamin K-dependent bone protein found in plasma and its clearance by kidney and bone. J Biol Chem 1981;256:12760-6.

29. Ivaska KK, Kakonen SM, Gerdhem P, Obrant KJ, Pettersson K, Vaananen HK. Urinary osteocalcin as a marker of bone metabolism. Clin Chem 2005;51:618-28.

30. Ivaska KK, Pettersson K, Nenonen A, Uusi-Rasi K, Heinonen A, Kannus P, Vaananen HK. Urinary osteocalcin is a useful marker for monitoring the effect of alendronate therapy. Clin Chem 2005;51:2362-5.

31. Demer LL, Tintut Y. Mineral exploration: search for the mechanism of vascular calcification and beyond: the 2003 Jeffrey M. Hoeg Award lecture. Arterioscler Thromb Vasc Biol 2003;23:1739-43. 


\section{Chapter 6}

Non-phosphorylated uncarboxylated Matrix Gla

Protein, a marker of insufficient inhibition of

calcification, is related to blood pressure and arterial stiffness: the Hoorn Study

RJMW Rennenberg, L Engelen, R Henry, LJ Schurgers, C Vermeer, AA Kroon, JM Dekker, G Nijpels, CDA Stehouwer 


\section{Abstract}

\section{Introduction}

Arterial calcification is associated with a higher cardiovascular risk. Among the potential mechanisms explaining this association are increased arterial stiffness and greater peripheral resistance resulting in increased mean arterial pressure. Arterial calcification is actively regulated and matrix Gla protein (MGP) plays a central role in its inhibition. To become fully functional, MGP needs to undergo two posttranslational modifications, i.e. phosphorylation and carboxylation. We investigated the association between non-phosphorylated and uncarboxylated MGP (dp-ucMGP), which thus is a marker of insufficient inhibition of calcification, arterial stiffness and blood pressure.

\section{Methods}

We studied 822 individuals from the Hoorn Study. Dp-ucMGP, blood pressure and arterial stiffness were measured. We tested for linear trends of individuals' characteristics across tertiles of dp-ucMGP and performed multiple linear regression analyses.

\section{Results}

Levels of dp-ucMGP were higher in older individuals, women, individuals with higher body mass index and greater waist to hip ratio, and individuals with impaired glucose metabolism or type 2 diabetes, higher blood pressures, prior cardiovascular disease, smoking, and lower estimated glomerular filtration rate. Multiple regression analysis showed that higher levels of dp-ucMGP were significantly associated with with greater carotid artery Young's elastic modulus $(\beta=0.110, p=0.032)$ and with greater systemic arterial compliance $(\beta=0.116, p=0.002)$, and with higher systolic $(\beta=1.584, p=0.003)$, diastolic $(\beta=0.913, p=0.009)$ and mean arterial pressure $(\beta=1.137, p=0.008)$.

\section{Conclusion}

These results suggest that MGP, possibly through its effects on large and small artery calcification, may influence arterial stiffening and blood pressure. 


\section{Introduction}

Arterial calcification is associated with a higher risk for cardiovascular events. ${ }^{1}$ The mechanisms explaining this association are not fully understood, but may involve at least two pathways. First, calcification of large arteries increases arterial stiffness, which in turn increases the risk for left ventricular hypertrophy, myocardial infarction and stroke. ${ }^{2,3}$ Second, calcification of smaller arteries ${ }^{4,5}$ may contribute to greater peripheral resistance which, other things being equal, will increase mean arterial pressure. ${ }^{6,7}$

Arterial calcification is not an inert endpoint of atherosclerosis but an actively regulated process, ${ }^{8,9}$ with mediators that stimulate and inhibit calcification, respectively. ${ }^{10}$ Among the inhibitors, matrix Gla protein (MGP) plays a central role, both by inhibiting the calcification-stimulating effect of bone morphogenetic protein type 2 and by preventing calcium deposition locally in the vascular wall. ${ }^{11}$ MGP is an $11 \mathrm{kD}$ vitamin K-dependent protein which accumulates at sites of calcification. ${ }^{12}$ Although it was first discovered in bone, it is mainly produced by vascular smooth muscle cells and chondrocytes. ${ }^{13-16}$ During its cellular synthesis, MGP may undergo two posttranslational modifications: carboxylation (essential for its calcification inhibitory activity) and phosphorylation (promoting cellular secretion and local retention, and thus activity). ${ }^{17}$ It is currently thought that the plasma level of MGP which is not phosphorylated and uncarboxylated (dp-ucMGP; as assessed by a dual antibody assay) is the best reflection of insufficient inhibition of calcification. ${ }^{18-21}$

These data raise the possibility that dp-ucMGP is a determinant not only of arterial calcification, but also of arterial stiffness and blood pressure. In view of these considerations, we tested the hypothesis that dp-ucMGP is associated with arterial stiffness and blood pressure in elderly individuals from a population-based cohort.

\section{Methods}

For the present study, we used data from the 2000 Hoorn Study follow-up examination and data from a diabetes screening study, both of which were population-based. The exact composition of the study sample has been described in detail elswhere. ${ }^{22}$ The study included 822 individuals, of whom 290 had normal glucose metabolism (NGM), 187 had impaired glucose metabolism (IGM), and 345 had type 2 diabetes mellitus (DM2). The local ethics committee approved the study. All participants gave their written informed consent.

\section{General data}

Health status, medical history, smoking behaviour, and current medication use were assessed by a questionnaire. ${ }^{23}$ Body mass index and the waist-to-hip ratio were 
calculated. Venous blood was drawn to prepare citrated plasma and all samples were stored at $-80^{\circ} \mathrm{C}$ until use. Fasting glucose, glycated haemoglobin, serum total, highdensity- and low-density-lipoprotein cholesterol, and triglycerides were determined as described previously. ${ }^{24}$ Glomerular filtration rate (eGFR) was estimated from fasting creatinine levels using the MDRD formula. ${ }^{25}$ Dp-ucMGP was measured in plasma using a sandwich ELISA (VitaK BV, Maastricht, The Netherlands). ${ }^{17,26}$

\section{Blood pressure and arterial stiffness estimates}

Brachial systolic (SBP) and diastolic (DBP) pressures were assessed with the patient in supine position in the left upper arm at 5-minute intervals with an oscillometric device (Colin Press-Mate, BP-8800, Komaki, Aichi, Japan). The average of 8 blood pressure measurements done in the supine position during the ultrasound investigations was calculated. Brachial pulse pressure was calculated as mean systolic minus mean diastolic pressure, and brachial mean arterial pressure (MAP) as ( 2 mean diastolic pressure + mean systolic pressure) $/ 3$.

We assessed arterial stiffness estimates of the aorta, the carotid artery, the brachial artery, and the femoral artery. Aortic pressures were derived by tonometry with a piezo-resistive pressure transducer (SPT-301, Millar Instruments, Houston, Texas, USA) connected to a waveform analysis device (SphygmoCor, AtCor Medical, West Ryde, New South Wales, Australia) as described previously. ${ }^{22}$ A single observer unaware of the participants' clinical status obtained properties of the right common carotid (10 $\mathrm{mm}$ proximal to the carotid bulb), the right common femoral $(20 \mathrm{~mm}$ proximal to the flow divider), and the right brachial $(20 \mathrm{~mm}$ proximal to the antecubital fossa) arteries, with the use of an ultrasound scanner equipped with an 7.5-MHz linear probe (350 Series, Pie Medical, Maastricht, The Netherlands). The scanner was connected to a PC equipped with vessel wall movement detection software and an acquisition system (Wall Track System, Pie Medical, Maastricht, The Netherlands). This setup enables measurements of diameter, distension, and intimamedia thickness (IMT). ${ }^{22,27,28}$ The mean diameter, distension, and IMT of 3 measurements were used in the analyses. Pulse pressure at the carotid and femoral artery was calculated according to the calibration method described by Kelly and Fitchett, with use of distension waveforms as adapted by Van Bortel et al. ${ }^{29,30}$ Distensibility and compliance coefficients were calculated from diameter, distension, and pulse pressure, as follows. ${ }^{31}$

Distensibility coefficient $=\left(2 \Delta D * D+\Delta D^{2}\right) /\left(\Delta P * D^{2}\right)$ in $10^{-3} * \mathrm{kPa}^{-1}$

Compliance coefficient $=\pi\left(2 \mathrm{D} * \Delta \mathrm{D}+\mathrm{D}^{2}\right) /(4 * \Delta \mathrm{P})$ in $\mathrm{mm}^{2} * \mathrm{kPa}^{-1}$,

where $\Delta \mathrm{D}$ is distension, $\mathrm{D}$ is diameter, and $\Delta \mathrm{P}$ is pulse pressure. The distensibility coefficient reflects the arterial elastic properties, whereas the compliance coefficient reflects the arterial buffering capacity. From IMT, diameter, and carotid distensibility, we calculated Young's elastic modulus $\left(E_{\text {inc }}\right)$, an indicator of the intrinsic elastic wall properties: 
$\mathrm{E}_{\mathrm{inc}}=$ diameter/(IMT * distensibility coefficient) in $\mathrm{kPa}$

The reproducibility of these methods was described in detail elswhere. ${ }^{22}$

\section{Statistical analyses}

We used ANOVA (or $\chi^{2}$ tests for dichotomous variables) to test for a linear trend of subject characteristics across tertiles of dp-ucMGP. Multiple linear regression analyses were used to investigate the associations between dp-ucMGP (key independent variable) and blood pressure and arterial properties (outcome variables). Because the Hoorn Study population was stratified according to age, sex, and glucose tolerance status (i.e. NGM, IGM and DM2) and the outcome variables are affected by age, sex, glucose tolerance status and, for arterial stiffness estimates, mean arterial pressure, ${ }^{32}$ these variables were considered in adjusted models. We used brachial mean arterial pressure obtained during the ultrasound assessment of arterial stiffness for all adjustments because mean arterial pressure is constant throughout the arterial tree ${ }^{33}$ and because brachial pressures thus obtained were determined more precisely than at the initial assessment (because of the greater number of observations). Then, we additionally adjusted for other potential confounders or mediating variables (i.e. prior cardiovascular disease, use of blood pressure lowering medication, current smoking and body mass index). Because compromised kidney function (i.e. eGFR) might influence stiffness and the clearance of small proteins like MGP, we additionally adjusted the analyses for eGFR in order to investigate the extent to which this variable explained (i.e. attenuated) the associations between dp-ucMGP and outcome variables. To investigate whether the associations between dp-ucMGP and the outcome variables differed according to glucose tolerance status (i.e. NGM, IGM or DM2), we added interaction terms between dp-ucMGP and glucose tolerance status to the models.

In order to enable comparison of the strength of all associations, we used standardized values of the variables regarding arterial properties.

All statistical analyses were carried out using the Statistical Package for Social Sciences, version 15.0 (SPSS Inc., Chicago, IL, USA). A p-value <0.05 was considered statistically significant.

\section{Results}

In 116 subjects, either the plasma sample volume was insufficient for measurement of dp-ucMGP $(n=70)$ or the data on main potential confounders or mediating variables were incomplete (age, sex, glucose tolerance status, height or MAP, $n=46$ ). The 116 individuals excluded, compared to those included, were significantly younger, had a higher BMI, were more frequently diabetic, had higher blood pressures and MAP, and a lower eGFR (data not shown). Table 6.1 shows subjects' characteristics according to 
tertiles of dp-ucMGP ( $n=706)$. Dp-ucMGP levels were significantly higher in older subjects, women, subjects with higher body mass index and greater waist-to-hip ratio, and subjects with impaired glucose metabolism or type 2 diabetes, higher blood pressures, prior cardiovascular disease, non-smokers, and lower estimated glomerular filtration rate.

Table 6.1 Baseline characteristics of the study population according to tertiles of plasma dp-ucMGP

\begin{tabular}{|c|c|c|c|c|}
\hline & \multicolumn{3}{|c|}{ Plasma dp-ucMGP in pM } & \multirow{3}{*}{$p$ for trenc } \\
\hline & $<427$ & $427-651$ & $>651$ & \\
\hline & $(n=235)$ & $(n=236)$ & $(n=235)$ & \\
\hline Age (y) & $66.5 \pm 7.0$ & $69.0 \pm 6.6$ & $70.3 \pm 6.5$ & $<0.001$ \\
\hline $\operatorname{Sex}(m / f)(n)$ & $131 / 104$ & $129 / 107$ & $93 / 142$ & $<0.001$ \\
\hline Body mass index $\left(\mathrm{kg} / \mathrm{m}^{2}\right)$ & $26.3 \pm 3.6$ & $27.6 \pm 3.8$ & $28.3 \pm 3.4$ & $<0.001$ \\
\hline \multicolumn{5}{|l|}{ Waist-to-hip ratio } \\
\hline Men & $0.97 \pm 0.07$ & $0.99 \pm 0.06$ & $1.01 \pm 0.06$ & $<0.001$ \\
\hline Women & $0.85 \pm 0.07$ & $0.88 \pm 0.13$ & $0.89 \pm 0.08$ & 0.003 \\
\hline NGM/IGM/DM2 (\%) & $46 / 18 / 36$ & $41 / 24 / 35$ & $31 / 30 / 39$ & 0.030 \\
\hline Antidiabetic medication (\%) & 6 & 6 & 10 & 0.162 \\
\hline $\mathrm{HbA}_{1 c}(\%)$ & $6.0 \pm 0.8$ & $6.1 \pm 0.7$ & $6.1 \pm 0.8$ & 0.307 \\
\hline Total cholesterol (mmol/l) & $5.6 \pm 1.1$ & $5.7 \pm 1.0$ & $5.7 \pm 1.0$ & 0.526 \\
\hline HDL-cholesterol (mmol/l) & $1.4 \pm 0.4$ & $1.4 \pm 0.4$ & $1.4 \pm 0.4$ & 0.612 \\
\hline LDL-cholesterol (mmol/l) & $3.6 \pm 0.9$ & $3.7 \pm 0.9$ & $3.6 \pm 0.9$ & 0.324 \\
\hline Triglycerides (mmol/l) & $1.5 \pm 0.9$ & $1.5 \pm 0.7$ & $1.6 \pm 0.8$ & 0.156 \\
\hline Lipid-lowering medication (\%) & 11 & 18 & 19 & 0.017 \\
\hline Supine systolic blood pressure $(\mathrm{mmHg})$ & $138 \pm 20$ & $143 \pm 18$ & $148 \pm 21$ & $<0.001$ \\
\hline Supine diastolic blood pressure $(\mathrm{mmHg})$ & $76 \pm 9$ & $78 \pm 9$ & $78 \pm 9$ & 0.013 \\
\hline Pulse pressure $(\mathrm{mmHg})$ & $62 \pm 14$ & $65 \pm 14$ & $70 \pm 17$ & $<0.001$ \\
\hline Mean arterial pressure $(\mathrm{mmHg})$ & $97 \pm 12$ & $100 \pm 11$ & $102 \pm 12$ & $<0.001$ \\
\hline Hypertension (\%) & 60 & 70 & 77 & $<0.001$ \\
\hline Blood pressure lowering medication (\%) & 25 & 37 & 48 & $<0.001$ \\
\hline Prior cardiovascular disease (\%) & 44 & 46 & 53 & 0.049 \\
\hline Current smoking (\%) & 19 & 15 & 11 & 0.020 \\
\hline eGFR (ml/min per $\left.1.73 \mathrm{~m}^{2} \mathrm{BSA}\right)$ & $64 \pm 10$ & $60 \pm 11$ & $58 \pm 12$ & $<0.001$ \\
\hline
\end{tabular}

Data are expressed as mean \pm SD or percentages. NGM, normal glucose metabolism; IGM, impaired glucose metabolism; DM2, type 2 diabetes; eGFR, glomerular filtration rate as estimated by the MDRD formula.

Table 6.2 shows arterial wall properties according to tertiles of dp-ucMGP. Higher dp-ucMGP levels were associated with lower distensibility and compliance coefficients in the carotid, brachial and femoral arteries; with a greater Young's elastic modulus in the carotid artery; with a greater aortic augmentation index; and with lower systemic arterial compliance. In addition, higher dp-ucMGP levels were associated with greater diameters (carotid and brachial arteries), less distension (carotid artery), and greater pulse pressures (carotid, brachial and femoral arteries). 
Table 6.2 Arterial wall properties according to tertiles of plasma dp-ucMGP

\begin{tabular}{|c|c|c|c|c|}
\hline & \multicolumn{3}{|c|}{ Plasma dp-ucMGP in pM } & \multirow{2}{*}{$p$ for trend } \\
\hline & $<427$ & $441-651$ & $>651$ & \\
\hline \multicolumn{5}{|l|}{ Carotid artery $\left(n=624^{*}\right)$} \\
\hline Diameter $(\mathrm{mm})$ & $7.8 \pm 1.1$ & $8.1 \pm 1.1$ & $8.1 \pm 1.1$ & 0.001 \\
\hline Distension $(\mu \mathrm{m})$ & $353 \pm 111$ & $352 \pm 94$ & $330 \pm 116$ & 0.044 \\
\hline Pulse pressure (mmHg) & $59 \pm 14$ & $61 \pm 14$ & $67 \pm 20$ & $<0.001$ \\
\hline Intima media thickness (mm) & $0.85 \pm 0.16$ & $0.88 \pm 0.18$ & $0.87 \pm 0.17$ & 0.147 \\
\hline Distensibility coefficient $\left(10^{-3} / \mathrm{kPa}\right)$ & $12.7 \pm 4.6$ & $11.6 \pm 4.1$ & $10.5 \pm 4.5$ & $<0.001$ \\
\hline Compliance coefficient $\left(\mathrm{mm}^{2} / \mathrm{kPa}\right)$ & $0.58 \pm 0.26$ & $0.57 \pm 0.19$ & $0.51 \pm 0.23$ & 0.004 \\
\hline Young's elastic modulus $\left(10^{3} \mathrm{kPa}\right)$ & $0.87 \pm 0.47$ & $0.93 \pm 0.37$ & $1.11 \pm 0.66$ & $<0.001$ \\
\hline \multicolumn{5}{|l|}{ Brachial artery $\left(n=632^{*}\right)$} \\
\hline Diameter (mm) & $4.6 \pm 0.7$ & $4.8 \pm 0.7$ & $4.6 \pm 0.7$ & 0.002 \\
\hline Distension $(\mu \mathrm{m})$ & $145 \pm 69$ & $147 \pm 69$ & $142 \pm 65$ & 0.743 \\
\hline Pulse pressure (mmHg) & $62 \pm 14$ & $65 \pm 14$ & $70 \pm 17$ & $<0.001$ \\
\hline Distensibility coefficient $\left(10^{-3} / \mathrm{kPa}\right)$ & $8.2 \pm 4.4$ & $7.6 \pm 3.9$ & $7.3 \pm 3.8$ & 0.070 \\
\hline Compliance coefficient $\left(\mathrm{mm}^{2} / \mathrm{kPa}\right)$ & $0.13 \pm 0.07$ & $0.13 \pm 0.07$ & $0.12 \pm 0.06$ & 0.026 \\
\hline \multicolumn{5}{|l|}{ Femoral artery $\left(n=600^{*}\right)$} \\
\hline Diameter $(\mathrm{mm})$ & $10.1 \pm 1.7$ & $10.1 \pm 1.7$ & $9.9 \pm 1.5$ & 0.217 \\
\hline Distension $(\mu \mathrm{m})$ & $214 \pm 84$ & $203 \pm 64$ & $200 \pm 71$ & 0.114 \\
\hline Pulse pressure (mmHg) & $67 \pm 16$ & $71 \pm 17$ & $74 \pm 20$ & $<0.001$ \\
\hline Distensibility coefficient $\left(10^{-3} / \mathrm{kPa}\right)$ & $5.2 \pm 2.5$ & $4.6 \pm 1.7$ & $4.4 \pm 2.0$ & 0.001 \\
\hline Compliance coefficient $\left(\mathrm{mm}^{2} / \mathrm{kPa}\right)$ & $0.41 \pm 0.22$ & $0.36 \pm 0.17$ & $0.33 \pm 0.17$ & $<0.001$ \\
\hline \multicolumn{5}{|l|}{ Central arterial stiffness } \\
\hline C-F transit time $(\mathrm{ms})\left(\mathrm{n}=296^{\#}\right)$ & $56 \pm 17$ & $54 \pm 16$ & $52 \pm 17$ & 0.403 \\
\hline Aortic Alx (\%) $\left(n=583^{* \#}\right)$ & $31 \pm 9$ & $32 \pm 9$ & $34 \pm 8$ & 0.032 \\
\hline $\mathrm{SAC}(\mathrm{ml} / \mathrm{mmHg})\left(\mathrm{n}=526^{*}\right)^{\mathrm{a}}$ & $0.77 \pm 0.30$ & $0.73 \pm 0.33$ & $0.69 \pm 0.29$ & 0.063 \\
\hline $\mathrm{SAC}(\mathrm{ml} / \mathrm{mmHg})\left(\mathrm{n}=586^{*}\right)^{\mathrm{b}}$ & $1.07 \pm 0.35$ & $1.07 \pm 0.36$ & $0.96 \pm 0.31$ & 0.002 \\
\hline
\end{tabular}

Data are expressed as mean \pm SD or percentages. C-F, carotid to femoral; Alx, augmentation index; SAC, systemic arterial compliance. ${ }^{a}$ as estimated by the time decay method; ${ }^{b}$ as estimated by the stroke volume to pulse pressure ratio; ${ }^{*}$ these variables could not be assessed in all subjects because of logistical or technical difficulties, the latter mainly due to obesity (body mass index of those with qualitatively satisfactory examinations versus those without, $26.9 \pm 3.3$. vs. $30.5 \pm 4.5 \mathrm{~kg} / \mathrm{m}^{2}, \mathrm{p}<0.001$ ); ${ }^{\#}$ this variable was not available in all subjects owing to device availability.

Table 6.3 shows the results of multivariable regression analyses with blood pressures as outcomes. After adjustment for age, sex, glucose tolerance status, the use of blood pressure lowering medication, prior cardiovascular disease, smoking, body mass index and estimated glomerular filtration rate, higher dp-ucMGP levels were significantly associated with higher SBP and DBP and MAP, but not with pulse pressure (Table 6.3, models 1-3). After adjustment for MAP, the associations between dp-ucMGP and SBP and DBP were no longer statistically significant (Table 6.3, model 4). In parallel fashion, after adjustment for systolic or diastolic blood pressure, the association between dp-ucMPG and MAP also was not statistically significant (Table 6.3, models 4 and 5). 
Table 6.3 Associations of dp-ucMGP with blood pressure

\begin{tabular}{|c|c|c|c|}
\hline Model & $\beta$ & $95 \% \mathrm{Cl}$ & $\mathrm{p}$ \\
\hline \multicolumn{4}{|l|}{ Systolic blood pressure $(n=706)$} \\
\hline 1: adjusted for age, sex and GTS & 2.042 & $0.679 ; 3.404$ & 0.003 \\
\hline 2: 1 + BP med, CVD, smoking, BMI & 1.557 & $0.199 ; 2.914$ & 0.025 \\
\hline $3: 2+e G F R$ & 1.584 & $0.201 ; 2.968$ & 0.025 \\
\hline $4: 2+\mathrm{MAP}$ & -0.185 & $-0.719 ; 0.349$ & 0.496 \\
\hline \multicolumn{4}{|l|}{ Diastolic blood pressure $(n=706)$} \\
\hline 1: adjusted for age, sex and GTS & 1.090 & $0.423 ; 1.757$ & 0.001 \\
\hline 2: 1 + BP med, CVD, smoking, BMI & 0.947 & $0.279 ; 1.615$ & 0.006 \\
\hline $3: 2+e G F R$ & 0.913 & $0.232 ; 1.593$ & 0.009 \\
\hline $4: 2+$ MAP & 0.093 & $-0.174 ; 0.360$ & 0.496 \\
\hline \multicolumn{4}{|l|}{ Mean arterial pressure $(n=706)$} \\
\hline 1: adjusted for age, sex and GTS & 1.407 & $0.579 ; 2.235$ & 0.001 \\
\hline 2: 1 + BP med, CVD, smoking, BMI & 1.150 & $0.325 ; 1.975$ & 0.006 \\
\hline $3: 2+e G F R$ & 1.137 & $0.296 ; 1.978$ & 0.008 \\
\hline $4: 2+S B P$ & 0.279 & $-0.044 ; 0.603$ & 0.091 \\
\hline $5: 2+\mathrm{DBP}$ & 0.076 & $-0.253 ; 0.406$ & 0.649 \\
\hline \multicolumn{4}{|l|}{ Pulse pressure $(n=706)$} \\
\hline 1: adjusted for age, sex and GTS & 0.952 & $-0.065 ; 1.968$ & 0.066 \\
\hline 2: 1 + BP med, CVD, smoking, BMI & 0.609 & $-0.410 ; 1.629$ & 0.241 \\
\hline $3: 2+e G F R$ & 0.671 & $-0.367 ; 1.710$ & 0.205 \\
\hline $4: 2+\mathrm{MAP}$ & -0.278 & $-1.079 ; 0.523$ & 0.496 \\
\hline
\end{tabular}

$\beta$ represents the increase (in $\mathrm{mmHg}$ ) in blood pressure per SD increase in dp-ucMGP. GTS, glucose tolerance status; BP med, use of blood pressure lowering medication; CVD, prior cardiovascular disease; BMI, body mass index; eGFR, estimated glomerular filtration rate; MAP, mean arterial pressure; SBP, systolic blood pressure; DBP, diastolic blood pressure

Table 6.4 shows the results of multivariable regression analyses with peripheral arterial stiffness estimates as outcomes. After adjustment for age, sex, glucose tolerance status, height and MAP, higher dp-ucMGP levels were significantly associated with greater carotid artery Young's elastic modulus, but not with carotid, brachial or femoral artery distensibility or compliance (Table 6.4, models 1-3). Additional adjustments for other potential confounders or mediating variables did not materially change these results (Table 6.4, models 4-5). The association between dpucMGP levels and carotid artery Young's elastic modulus appeared to be driven by an association between dp-ucMGP levels and carotid artery distension. After adjustment for age, sex, glucose tolerance status, height and MAP, higher dp-ucMGP levels were significantly and inversely associated with carotid artery distension (standardized $\beta$, -0.085 (95\% confidence interval, -0.164 to $-0.006, p=0.035)$ ), but not with carotid artery diameter, pulse pressure, or intima-media thickness. Additional adjustment for the use of blood pressure lowering medication, prior cardiovascular disease, smoking, body mass index and estimated glomerular filtration rate did not materially change these results (data not shown). 


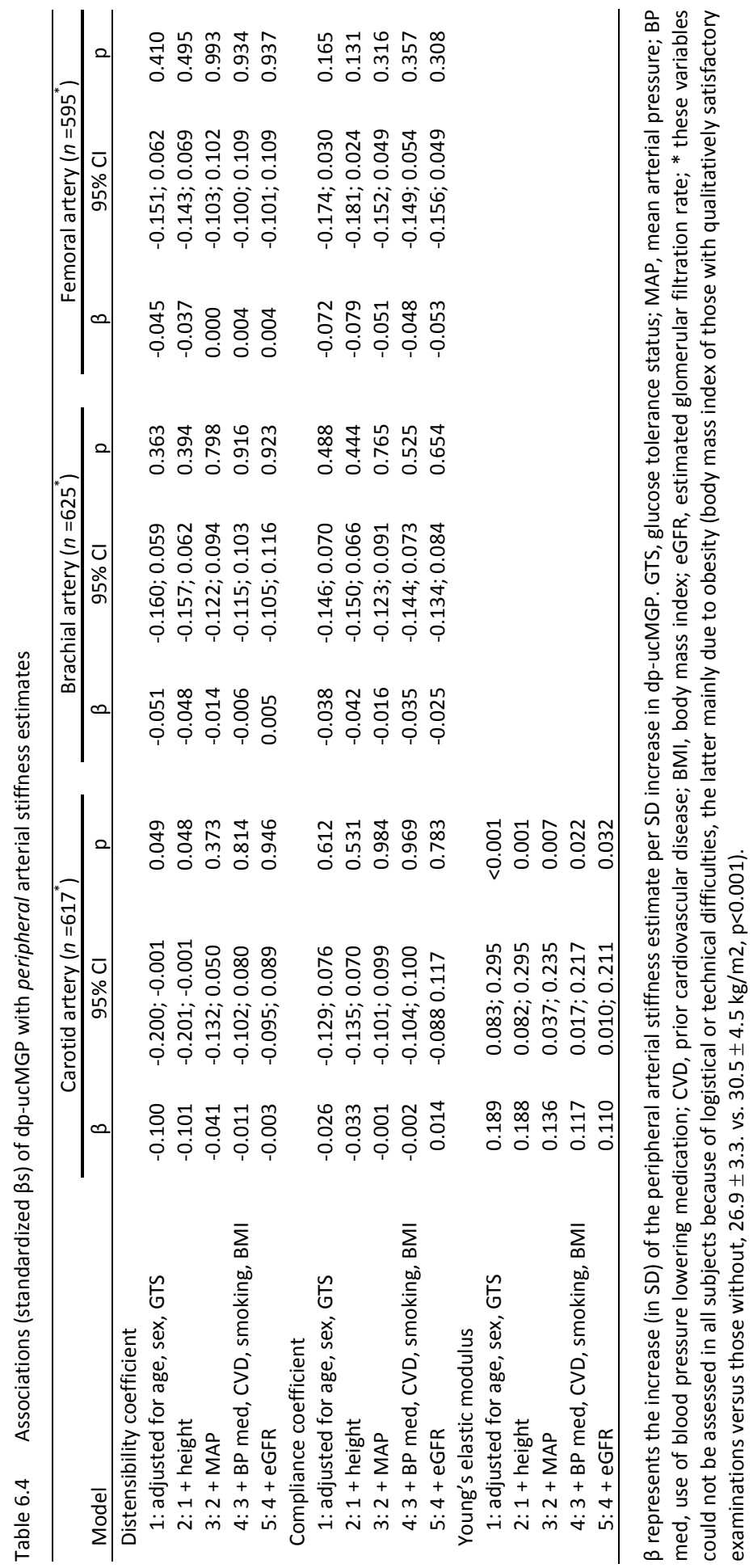


Table 6.5 shows the results of multivariable regression analyses with central arterial stiffness estimates as outcomes. After adjustment for age, sex, glucose tolerance status, height and MAP, higher dp-ucMGP levels were significantly associated with greater systemic arterial compliance (time decay method), but not with carotidfemoral transit time, aortic augmentation index and systemic arterial compliance according to the stroke volume to pulse pressure ratio (Table 6.5, models 1-3). Additional adjustments for other potential confounders or mediating variables did not materially change these results (Table 6.5, models 4-5).

The associations between dp-ucMGP levels and blood pressure and arterial stiffness did not differ according to glucose tolerance status (data not shown).

Table 6.5 Associations (standardized $\beta$ s) of dp-ucMGP with central arterial stiffness estimates

\begin{tabular}{|c|c|c|c|}
\hline Model & $\beta$ & $95 \% \mathrm{Cl}$ & $\mathrm{p}$ \\
\hline \multicolumn{4}{|l|}{ Carotid-femoral transit time $\left(\mathrm{n}=292^{\#}\right)$} \\
\hline 1: adjusted for age, sex, GTS & -0.080 & $-0.267 ; 0.107$ & 0.399 \\
\hline $2: 1+$ height & -0.082 & $-0.271 ; 0.106$ & 0.389 \\
\hline $3: 2+M A P$ & -0.060 & $-0.240 ; 0.119$ & 0.509 \\
\hline 4: 3 + BP med, CVD, smoking, BMI & -0.072 & $-0.248 ; 0.104$ & 0.422 \\
\hline 5: $4+$ eGFR & -0.074 & $-0.251 ; 0.102$ & 0.408 \\
\hline \multicolumn{4}{|l|}{ Aortic augmentation index $\left(n=577^{*}\right)$} \\
\hline 1: adjusted for age, sex, GTS & 0.071 & $-0.006 ; 0.148$ & 0.071 \\
\hline $2: 1+$ height & 0.072 & $-0.004 ; 0.148$ & 0.065 \\
\hline $3: 2+$ MAP & 0.042 & $-0.032 ; 0.116$ & 0.264 \\
\hline 4: 3 + BP med, CVD, smoking, BMI & 0.057 & $-0.016 ; 0.130$ & 0.126 \\
\hline $5: 4+e G F R$ & 0.051 & $-0.023 ; 0.125$ & 0.178 \\
\hline \multicolumn{4}{|c|}{ Systemic arterial compliance (time-decay) $\left(n=521^{*}\right)$} \\
\hline 1: adjusted for age, sex, GTS & 0.078 & $0.003 ; 0.154$ & 0.042 \\
\hline $2: 1+$ height & 0.078 & $0.002 ; 0.153$ & 0.043 \\
\hline $3: 2+M A P$ & 0.127 & $0.057 ; 0.197$ & $<0.001$ \\
\hline 4: 3 + BP med, CVD, smoking, BMI & 0.109 & $0.039 ; 0.180$ & 0.002 \\
\hline $5: 4+e G F R$ & 0.116 & $0.045 ; 0.188$ & 0.002 \\
\hline \multicolumn{4}{|c|}{ Systemic arterial compliance (SV:PP) ( $\left.n=581^{*}\right)$} \\
\hline 1: adjusted for age, sex, GTS & -0.012 & $-0.112 ; 0.088$ & 0.810 \\
\hline $2: 1+$ height & -0.019 & $-0.119 ; 0.081$ & 0.715 \\
\hline $3: 2+$ MAP & 0.044 & $-0.048 ; 0.136$ & 0.346 \\
\hline $4: 3+\mathrm{BP}$ med, CVD, smoking, BMI & 0.025 & $-0.068 ; 0.117$ & 0.599 \\
\hline $5: 4+e G F R$ & 0.032 & $-0.061 ; 0.126$ & 0.494 \\
\hline
\end{tabular}

$\beta$ represents the increase (in SD) of the central arterial stiffness estimate per SD increase in dp-ucMGP. GTS, glucose tolerance status; MAP, mean arterial pressure; BP med, use of blood pressure lowering medication; CVD, prior cardiovascular disease; BMI, body mass index; eGFR, estimated glomerular filtration rate; SV, stroke volume; PP, pulse pressure; " this variable was not available in all subjects owing to device availability; ${ }^{*}$ these variables could not be assessed in all subjects because of logistical or technical difficulties, the latter mainly due to obesity (body mass index of those with qualitatively satisfactory examinations versus those without, $26.9 \pm 3.3$. vs. $30.5 \pm 4.5 \mathrm{~kg} / \mathrm{m}^{2}, \mathrm{p}<0.001$ ). 


\section{Discussion}

This study had two main findings. First, higher levels of dp-ucMGP were significantly associated with higher systolic, diastolic and mean arterial pressure. Second, higher levels of dp-ucMGP were significantly associated with greater carotid artery Young's elastic modulus and with greater systemic arterial compliance. These results suggest that MGP, possibly through its effects on small and large artery calcification, may influence blood pressure and arterial stiffening.

Although a clear positive association has been found between vascular calcification and blood pressure, ${ }^{4}$ this is the first study to show an association between dp-ucMGP and blood pressure. In animal studies, blocking the carboxylation of MGP (and hence increasing levels of dp-ucMGP) with warfarin induces higher systolic blood pressures. ${ }^{34}$ We found that higher levels of dp-ucMGP were associated with both mean and systolic pressure, and that these associations decreased after mutual adjustment (Table 6.3). These data raise the possibility that dp-ucMGP is associated with both the steady (MAP) and the pulsatile (SBP) component of blood pressure, possibly through insufficient inhibition of both small and large artery calcification. This hypothesis requires further investigation.

The relationship between circulating MGP levels and arterial stiffness has only been studied in subjects with renal insufficiency; results have been inconsistent. In an elderly dialysis population, total ucMGP and aortic augmentation index were inversely related; on the other hand, there was no association between total dpMGP or total ucMGP and arterial stiffness in children on dialysis treatment or after a renal transplant. ${ }^{35-37}$ Our current study in an elderly population with mild renal insufficiency showed a significant association between dp-ucMGP and stiffness in the carotid artery as reflected by a greater Young's elastic modulus. It should moreover be noted that, because dp-ucMGP is associated with MAP, MAP may (in part) mediate the effect of dp-ucMGP on arterial stiffness. If this is the case, then adjustment, for MAP, of the association of dp-ucMGP with arterial stiffness, as in model 3 (Table 6.4 and 6.5), amounts to overadjustment. In agreement with our results, recent studies showed a significant correlation between dp-ucMGP levels, arterial calcification and risk of mortality. ${ }^{21,38}$ In addition, in postmenopausal women, a high vitamin $\mathrm{K}$ intake (and hence lower dp-ucMGP levels) was associated with a positive effect on Young's elastic modulus of the carotid artery (no change compared to an increase on placebo), a greater carotid distensibility and compliance coefficient, and a lower pulse pressure. ${ }^{39}$ Taken together, these findings suggest that insufficient inhibition of arterial calcification, as reflected by dp-ucMGP levels, is associated with stiffening of the carotid artery.

After adjustment for confounders or mediating variables, higher dp-ucMGP levels were positively associated with systemic compliance as determined with the time decay method. The explanation for this association is unclear but one possibility is that higher dp-ucMGP levels are associated with a greater aortic diameter (not 
measured in this study), as MGP is involved in vascular remodelling resulting in less vascular elastin and more collagen in the aorta of rats treated with warfarin to block MGP function. ${ }^{34}$

This study had several limitations. First, 116 individuals were excluded because of insufficient material or data. However, as their cardiovascular risk profile was significantly worse compared to those included, we would expect associations, in these individuals, between dp-ucMGP and the outcome variables to be either similar to those observed (in which case the main conclusions will remain unaffected) or stronger (in which case the associations reported are actually underestimated). Second, we had no direct measurements of arterial calcification and so could not directly investigate the hypothesis that dp-ucMGP was associated with outcome variables through arterial calcification. Finally, we studied an elderly Caucasian population, and results thus are not necessarily generalizable to younger populations or other ethnicities.

In conclusion, our data show that higher dp-ucMGP levels are associated with higher systolic, diastolic and mean arterial pressure, and with a greater carotid artery Young's elastic modulus and greater systemic arterial compliance. The mechanism behind these associations may involve arterial calcification. Dp-ucMGP levels can be lowered by vitamin $\mathrm{K}$ and this raises the question whether vitamin $\mathrm{K}$ supplementation could lower blood pressure and decrease arterial stiffness resulting in lower cardiovascular morbidity and mortality. In general, our data suggest that vitamin-K status may be a target of treatment to decrease blood-pressure- and arterial-stiffnessrelated cardiovascular risk. 


\section{References}

1. Rennenberg RJ, Kessels AG, Schurgers LJ, van Engelshoven JM, de Leeuw PW, Kroon AA. Vascular calcifications as a marker of increased cardiovascular risk: A meta-analysis. Vasc Health Risk Manag 2009;5:185-97.

2. Adragao T, Pires A, Lucas C, Birne R, Magalhaes L, Goncalves M, Negrao AP. A simple vascular calcification score predicts cardiovascular risk in haemodialysis patients. Nephrol Dial Transplant 2004;19:1480-8.

3. Blacher J, Guerin AP, Pannier B, Marchais SJ, London GM. Arterial calcifications, arterial stiffness, and cardiovascular risk in end-stage renal disease. Hypertension 2001;38:938-42.

4. Jensky NE, Criqui MH, Wright MC, Wassel CL, Brody SA, Allison MA. Blood pressure and vascular calcification. Hypertension 2010;55:990-7.

5. Rennenberg RJ, van Varik BJ, Schurgers $\amalg$, Hamulyak K, Ten Cate H, Leiner T, Vermeer C, de Leeuw PW, Kroon AA. Chronic coumarin treatment is associated with increased extracoronary arterial calcification in humans. Blood 2010;115:5121-3.

6. Guerin AP, London GM, Marchais SJ, Metivier F. Arterial stiffening and vascular calcifications in endstage renal disease. Nephrol Dial Transplant 2000;15:1014-21.

7. McEniery CM, McDonnell BJ, So A, Aitken S, Bolton CE, Munnery M, Hickson SS, Yasmin Maki-Petaja, KM, Cockcroft JR, Dixon AK, Wilkinson IB. Aortic calcification is associated with aortic stiffness and isolated systolic hypertension in healthy individuals. Hypertension 2009;53:524-31.

8. Demer LL, Tintut Y. Mineral exploration: search for the mechanism of vascular calcification and beyond: the 2003 Jeffrey M. Hoeg Award lecture. Arterioscler Thromb Vasc Biol 2003;23:1739-43.

9. Shanahan CM. Vascular calcification. Curr Opin Nephrol Hypertens 2005;14:361-7.

10. Rennenberg RJ, Schurgers L, Kroon AA, Stehouwer CD. Arterial calcifications. J Cell Mol Med 2010;14:2203-10.

11. Murshed M, Schinke T, McKee MD, Karsenty G. Extracellular matrix mineralization is regulated locally; different roles of two gla-containing proteins. J Cell Biol 2004;165:625-30.

12. Schurgers LJ, Teunissen KJ, Knapen MH, Kwaijtaal M, van Diest R, Appels A, Reutelingsperger CP, Cleutjens JP, Vermeer C. Novel conformation-specific antibodies against matrix gammacarboxyglutamic acid (Gla) protein: undercarboxylated matrix Gla protein as marker for vascular calcification. Arterioscler Thromb Vasc Biol 2005;25:1629-33.

13. Price PA, Urist MR, Otawara Y. Matrix Gla protein, a new gamma-carboxyglutamic acid-containing protein which is associated with the organic matrix of bone. Biochem Biophys Res Commun 1983;117:765-71.

14. Price PA, Faus SA, Williamson MK. Warfarin causes rapid calcification of the elastic lamellae in rat arteries and heart valves. Arterioscler Thromb Vasc Biol 1998;18:1400-7.

15. Luo G, Ducy P, McKee MD, Pinero GJ, Loyer E, Behringer RR, Karsenty G. Spontaneous calcification of arteries and cartilage in mice lacking matrix GLA protein. Nature 1997;386:78-81.

16. Shanahan CM, Cary NR, Metcalfe JC, Weissberg PL. High expression of genes for calcificationregulating proteins in human atherosclerotic plaques. J Clin Invest 1994;93:2393-402.

17. Cranenburg EC, Koos R, Schurgers LJ, Magdeleyns EJ, Schoonbrood TH, Landewe RB, Brandenburg VM, Bekers $\mathrm{O}$, Vermeer $\mathrm{C}$. Characterisation and potential diagnostic value of circulating matrix Gla protein (MGP) species. Thromb Haemost 2010;104:811-22.

18. Jono S, Ikari Y, Vermeer C, Dissel P, Hasegawa K, Shioi A, Taniwaki H, Kizu A, Nishizawa Y, Saito S. Matrix Gla protein is associated with coronary artery calcification as assessed by electron-beam computed tomography. Thromb Haemost 2004;91:790-4.

19. Braam LA, Dissel P, Gijsbers BL, Spronk HM, Hamulyak K, Soute BA, Debie W, Vermeer C. Assay for human matrix gla protein in serum: potential applications in the cardiovascular field. Arterioscler Thromb Vasc Biol 2000;20:1257-61.

20. Schurgers LJ, Teunissen KJ, Knapen MH, Geusens $P$, van der Heijde D, Kwaijtaal M, van Diest R, Ketteler $\mathrm{M}$, Vermeer $\mathrm{C}$. Characteristics and performance of an immunosorbent assay for human matrix Gla-protein. Clin Chim Acta 2005;351:131-8. 
21. Schurgers L, Barreto DV, Barreto FC, Liabeuf S, Renard C, Magdeleyns EJ, Vermeer C, Choukroun G, Massy ZA. The circulating inactive form of matrix gla protein is a surrogate marker for vascular calcification in chronic kidney disease: a preliminary report. Clin J Am Soc Nephrol 2010;5:568-75.

22. Henry RM, Kostense PJ, Spijkerman AM, Dekker JM, Nijpels G, Heine RJ, Kamp O, Westerhof N, Bouter LM, Stehouwer CD. Arterial stiffness increases with deteriorating glucose tolerance status: the Hoorn Study. Circulation 2003;107:2089-95.

23. Mooy JM, Grootenhuis PA, de Vries H, Valkenburg HA, Bouter LM, Kostense PJ, Heine RJ. Prevalence and determinants of glucose intolerance in a Dutch caucasian population. The Hoorn Study. Diabetes Care 1995;18:1270-3.

24. Spijkerman AM, Adriaanse MC, Dekker JM, Nijpels G, Stehouwer CD, Bouter LM, Heine RJ. Diabetic patients detected by population-based stepwise screening already have a diabetic cardiovascular risk profile. Diabetes Care 2002;25:1784-9.

25. Levey AS, Bosch JP, Lewis JB, Greene T, Rogers N, Roth D. A more accurate method to estimate glomerular filtration rate from serum creatinine: a new prediction equation. Modification of Diet in Renal Disease Study Group. Ann Intern Med 1999;130:461-70.

26. Schurgers LJ, Cranenburg EC, Vermeer C. Matrix Gla-protein: the calcification inhibitor in need of vitamin K. Thromb Haemost 2008;100:593-603.

27. Hoeks AP, Brands PJ, Willigers JM, Reneman RS. Non-invasive measurement of mechanical properties of arteries in health and disease. Proc Inst Mech Eng [H] 1999;213:195-202.

28. Hoeks AP, Willekes C, Boutouyrie P, Brands PJ, Willigers JM, Reneman RS. Automated detection of local artery wall thickness based on M-line signal processing. Ultrasound Med Biol 1997;23:1017-23.

29. Van Bortel LM, Balkestein EJ, van der Heijden-Spek JJ, Vanmolkot FH, Staessen JA, Kragten JA, Vredeveld JW, Safar ME, Struijker Boudier HA, Hoeks AP. Non-invasive assessment of local arterial pulse pressure: comparison of applanation tonometry and echo-tracking. J Hypertens 2001;19: 1037-44.

30. Kelly R, Fitchett D. Noninvasive determination of aortic input impedance and external left ventricular power output: a validation and repeatability study of a new technique. J Am Coll Cardiol 1992;20: 952-63.

31. Van Bortel LM, Duprez D, Starmans-Kool MJ, Safar ME, Giannattasio C, Cockcroft J, Kaiser DR, Thuillez C. Clinical applications of arterial stiffness, Task Force III: recommendations for user procedures. Am J Hypertens 2002;15:445-52.

32. Stehouwer CD, Henry RM, Ferreira I. Arterial stiffness in diabetes and the metabolic syndrome: a pathway to cardiovascular disease. Diabetologia 2008;51:527-39.

33. Nichols WW, O'Rourke MF. McDonald's blood flow in arteries. Theoretical, Experimental and Clinical Principles. 5th ed. London, UK: Edward Arnold; 2005.

34. Essalihi R, Dao HH, Yamaguchi N, Moreau P. A new model of isolated systolic hypertension induced by chronic warfarin and vitamin K1 treatment. Am J Hypertens 2003;16:103-10.

35. van Summeren MJ, Hameleers JM, Schurgers LJ, Hoeks AP, Uiterwaal CS, Kruger T, Vermeer C, Kuis W, Lilien MR. Circulating calcification inhibitors and vascular properties in children after renal transplantation. Pediatr Nephrol 2008;23:985-93.

36. Shroff RC, Shah V, Hiorns MP, Schoppet M, Hofbauer LC, Hawa G, Schurgers L, Singhal A, Merryweather I, Brogan P, Shanahan C, Deanfield J, Rees L. The circulating calcification inhibitors, fetuin-A and osteoprotegerin, but not matrix Gla protein, are associated with vascular stiffness and calcification in children on dialysis. Nephrol Dial Transplant 2008;23:3263-71.

37. Hermans MM, Vermeer C, Kooman JP, Brandenburg V, Ketteler M, Gladziwa U, Rensma PL, Leunissen KM, Schurgers LJ. Undercarboxylated matrix GLA protein levels are decreased in dialysis patients and related to parameters of calcium-phosphate metabolism and aortic augmentation index. Blood Purif 2007;25:395-401.

38. Ueland T, Gullestad L, Dahl CP, Aukrust P, Aakhus S, Solberg OG, Vermeer C, Schurgers LJ. Undercarboxylated matrix Gla protein is associated with indices of heart failure and mortality in symptomatic aortic stenosis. J Int Med 2010;268:483-92.

39. Braam LA, Hoeks AP, Brouns F, Hamulyak K, Gerichhausen MJ, Vermeer C. Beneficial effects of vitamins $D$ and $K$ on the elastic properties of the vessel wall in postmenopausal women: a follow-up study. Thromb Haemost 2004;91:373-80. 


\section{Chapter 7}

\section{Calcium scores and Matrix Gla Protein levels:} association with vitamin $\mathrm{K}$ status

RJMW Rennenberg, PW de Leeuw, AGH Kessels, LJ Schurgers, C Vermeer, JMA van Engelshoven, GJ Kemerink, AA Kroon

Eur J Clin Invest 2010;40:344-9 


\section{Abstract}

\section{Background}

Vascular calcification in humans is associated with an increased cardiovascular risk. Carboxylated matrix Gla protein (cMGP) inhibits vascular calcification. Vitamin $\mathrm{K}$ is an essential cofactor for the activation of uncarboxylated matrix Gla protein (ucMGP). It has been suggested that patients on long term treatment with vitamin $\mathrm{K}$ antagonists develop aortic valve calcifications due to lower levels of circulating MGP. We therefore hypothesized that arterial calcification and a low vitamin $\mathrm{K}$ status are associated with ucMGP. To that aim we measured arterial calcium scores, the osteocalcin ratio (OCR), as a proxy for vitamin $\mathrm{K}$ status, and ucMGP.

\section{Materials and Methods}

In 36 hypertensive patients we determined the Agatston score with CT scans of the abdominal aorta, carotid and coronary arteries. The total calcium score was calculated as the sum of the separate Z-scores.

\section{Results}

The total calcium Z-score was significantly correlated to age $(r=0.683, p<0.001)$, smoking $(r=0.372, p=0.026)$, total cholesterol $(r=0.353, p=0.034)$, LDL cholesterol $(r=0.490, p=0.003)$, triglycerides $(r=0.506, p=0.002)$, fasting glucose $(r=0.454, p=0.005)$, systolic blood pressure $(r=0.363, p=0.029)$ and pulse pressure $(r=0.685$, $p<0.001)$. In multivariate regression analyses OCR and total calcium score were significantly associated with ucMGP.

\section{Conclusion}

We found a positive association of total arterial calcium score and a high OCR (reflecting low vitamin $\mathrm{K}$ status) with ucMGP serum levels. This warrants further studies to explore the pathophysiological background of this phenomenon. 


\section{Introduction}

Arterial calcification in humans is a risk factor for cardiovascular complications, not only in patients with established cardiovascular disease ${ }^{1}$, diabetes ${ }^{2,3}$ and chronic kidney disease $e^{4,5}$ but also in asymptomatic individuals. ${ }^{6-8}$ Vascular calcification is a complex process resembling bone formation. ${ }^{9}$ Matrix Gla protein (MGP) plays a central role in the inhibition of calcification by influencing the function of bone morphogenetic protein type 2 and preventing the deposition of calcium in the vascular matrix. ${ }^{10,11}$ Activation of MGP requires carboxylation, which is a vitamin $\mathrm{K}$ dependent process. The balance between levels of active, carboxylated MGP (CMGP) and inactive, uncarboxylated MGP (UCMGP) may, therefore, be important in counteracting arterial calcification.

Several studies have reported on an association between high vitamin $\mathrm{K}$ intake and reduced cardiovascular risk or less arterial calcification. ${ }^{12-14}$ On the other hand, the use of vitamin $\mathrm{K}$ antagonists is associated with increased coronary and cardiac valve calcification. ${ }^{15,16}$ Studies on the relationship between coronary artery calcification and MGP gave conflicting results. ${ }^{17,18}$ In this respect, vitamin $\mathrm{K}$ status may be of importance since studies with vascular smooth muscle cells have shown that MGP production is triggered by extra cellular calcium. ${ }^{19}$ In human this has also been studied in isolated vascular smooth muscle cells but not in vivo. ${ }^{20}$

As it is not clear to what extent circulating levels of MGP and vitamin $\mathrm{K}$ status are associated with calcified lesions in the arterial vasculature we performed the present study. We measured ucMGP levels and the osteocalcin ratio (OCR), as a proxy for vitamin $\mathrm{K}$ status, in a cohort of well-characterised, moderately hypertensive patients and used computer tomography (CT) to quantify calcification of the coronary and carotid arteries, as well as of the abdominal aorta. Our hypothesis was that subjects with the highest ucMGP levels would have the highest calcium scores and the lowest vitamin $\mathrm{K}$ status.

\section{Methods}

\section{Patients}

During a 10-month period, we recruited 40 consecutive patients who had been referred to our outpatient clinic for evaluation of hypertension. Subjects were not included if they had intravascular stents, which makes interpretation of coronary calcium scores difficult, had an age below 18 years, tried to achieve pregnancy or were pregnant. Assessments included data on smoking habits (never smoked, history of smoking or current smoker), body mass index (BMI, calculated as $\mathrm{kg} / \mathrm{m}^{2}$ ), ambulatory blood pressure measurements (following 3 weeks cessation of antihypertensive medication), fasting levels of blood glucose, lipid profile and serum 
creatinine. We also took blood samples for the determination of UCMGP and the OCR. Blood samples were centrifuged immediately at $3500 \mathrm{~g}$ for 10 minutes at $4^{\circ} \mathrm{C}$. Serum was separated and stored at $-80^{\circ} \mathrm{C}$ until use. Additionally, we performed a CT scan of the carotid arteries, the coronary arteries and the abdominal aorta. The study protocol was approved by the local ethics committee and all patients gave written informed consent.

\section{Measurements}

We measured 24-hour ambulatory blood pressure with Space Labs 90217 (Space labs Healthcare, inc. Washington, US). Pulse pressure was calculated as the difference between the systolic and diastolic value of the 24-hour ambulatory measurements. Glucose levels, lipids and serum creatinine were measured with an automated chemistry analyzer (Beckmann Synchron CX 7-2, Fullerton CA). Endogenous creatinine clearance (ECC), as a proxy of glomerular filtration rate, was calculated from serum creatinine concentrations with the formula of Cockcroft and Gault. ${ }^{21}$

Since CMGP cannot be readily assayed in the laboratory, ucMGP is measured together with vitamin $\mathrm{K}$ in order to asses the cMGP status. The principle of the ucMGP assay is that of a competitive enzyme-linked immuno-sorbent assay (ELISA) in which micro well plates are coated with a mouse monoclonal antibody against human ucMGP (VitaK BV, Maastricht, the Netherlands). ${ }^{22}$ In brief, anti-ucMGP was coupled to a micro titer plate via polyclonal rabbit-anti-mouse IgG (Dako, Heeverlee, Belgium). After washing, $5 \mu \mathrm{l}$ of serum sample or standard were mixed with tracer (biotinylated peptide consisting of residues 35-54 in human MGP), transferred to the micro titer plate and incubated overnight at $4^{\circ} \mathrm{C}$. After washing, the plate was incubated with streptavidine-peroxidase (Zymed, Breda, The Netherlands) and stained with tetramethylbenzidine (KPL protein research products, Gennep, The Netherlands). The process was stopped by adding $\mathrm{H}_{2} \mathrm{SO}_{4}$, and the plate was read at $450 \mathrm{~nm}$. The lower limit of detection was $98 \mathrm{nM}$, with intra- and inter-assay coefficients of variation of $6 \%$ and $11.4 \%$. $^{22}$

We refrained from estimating vitamin $\mathrm{K}$ intake as information from dietary questionnaires is notoriously unreliable. Because it is also difficult to measure vitamin $\mathrm{K}$ levels reliably, the OCR, defined as uncarboxylated osteocalcin divided by carboxylated osteocalcin, was used instead as a proxy for vitamin $\mathrm{K}$ status. ${ }^{23-26}$ A lower OCR reflects higher vitamin $\mathrm{K}$ levels. Two commercially available test kits (Takara bio inc. Japan) were used to determine the OCR. One is specific for carboxylated osteocalcin, the other measures non-carboxylated osteocalcin. The principle of the measurement is similar to that of the MGP measurements and utilises ELISA techniques. Carboxylated MGP is estimated by dividing the level of ucMGP by the OCR.

High-resolution computer tomography (CT) was performed on a Toshiba Aquilion multi/4 scanner (Toshiba, Zoetermeer, Netherlands) using 120 kilovolt, 2 mm slice 
width and a field of view between $240 \mathrm{~mm}$ and $320 \mathrm{~mm}$. Cardiac gated CT of the chest, with special attention to the depiction of the coronary arteries, covered the complete heart (additional scan parameters: tube current $250 \mathrm{~mA}$, rotation time $0.32 \mathrm{~s}$, pitch 0.8). Carotid artery calcifications were measured from about $7 \mathrm{~cm}$ below the bifurcation up to $3 \mathrm{~cm}$ of the external and internal carotid arteries ( $300 \mathrm{~mA}, 0.5 \mathrm{~s}$, 1.4). The abdominal aorta was scanned from the top of the highest kidney to the bottom of the lowest kidney with a minimum distance of $10 \mathrm{~cm}(250 \mathrm{~mA}, 0,5 \mathrm{~s}, 1.4)$. Calcification was analyzed using Sclmage's volumetric cardiac scoring software, version NETRA MD v.1.06.00a. Calcium was depicted as any pixel equal to or over 130 Hounsfield units. Coronary calcification was expressed as Agatston scores. ${ }^{27}$

\section{Statistical analysis}

Normally distributed variables are expressed as means with standard deviations; otherwise they are expressed as medians with their minimum and maximum value. Calcium scores were measured in the coronaries, both the right and the left carotid artery and the abdominal aorta. The total calcium Z-score was then calculated as the sum of the individual Z-scores (calculated by subtracting the mean calcification score from the individual test score divided by the standard deviation of the calcification score). Trend analyses using the Kruskal Wallis test was done with variables that appeared to be related to increasing levels of ucMGP. Known risk factors for calcification were also correlated with the total calcium score. Spearman's Rho was used for non-normally distributed data. With ucMGP (logarithmically transformed for regression analysis because of a non-normal distribution) as the dependent variable and total calcium Z-score and OCR as the key independent variables of interest, multivariate regression analysis was performed (model 1). Age, sex and ECC (model 2 and 3) were added to the model as potential confounders. Although they are not known as potential confounders of MGP levels we also performed this regression analysis using smoking habits, $\mathrm{BMI}$ and systolic blood pressure as confounders (model 4). Additionally, this was also done with fasting glucose levels and LDL cholesterol (model 5). Beta coefficients with 95\% confidence interval (CI) are reported. Statistical calculations were performed using SPSS for Windows v.16.0 (SPSS, Chicago, IL). A pvalue $<0.05$ was considered statistically significant.

\section{Results}

Four patients had to be excluded from the analyses because they had intra-coronary stents. Table 7.1 shows the patient characteristics of the remaining 36 patients. The median ucMGP level was $4708 \mathrm{nmol} / \mathrm{l}$ (range 2031-9603 nmol/l). This is comparable to that of a healthy non-hypertensive reference population (4976 nmol/l; 2685-8187). ${ }^{22}$ The median OCR was 1.2 (0.1-14.0), which suggests a relatively low vitamin $\mathrm{K}$ status in 
these patients. ${ }^{24}$ The median coronary score was 65 , indicating that these subjects had only minor amounts of calcium in their coronary arteries. Table 7.2 represents data according to tertiles of UcMGP. Although there seemed to be a trend for OCR, coronary score, abdominal aorta score and total calcification Z score with ucMGP, this was not statistically significant. Total calcium Z score, however, was significantly correlated to age $(r=0.683, p<0.001)$, smoking $(r=0.372, p=0.026)$, total cholesterol $(r=0.353, p=0.034)$, LDL cholesterol $(r=0.490, p=0.003)$, triglycerides $(r=0.506$, $p=0.002)$, fasting glucose $(r=0.454, p=0.005)$, systolic blood pressure $(r=0.363$, $p=0.029)$ and pulse pressure $(r=0.685, p<0.001)$. Carboxylated MGP and OCR were only significantly correlated to calcification of the left carotid artery $(r=0.504, p=0.003$ and $r=-0.399, p=0.021$, respectively). There was no significant univariate correlation between total calcium score and OCR, ucMGP or CMGP. However, in crude multivariate regression analyses, and also in a model adjusted for age alone, adjusted for age, sex and ECC, adjusted for smoking habits, BMI and systolic blood pressure or adjusted for fasting glucose levels and LDL, the OCR was significantly associated with (log-)ucMGP. Except for the crude analysis and model 4 and 5, this was also true for the association with total arterial calcium-Z score. There was significant collinearity between total arterial calcium-Z score and the confounders used in model 4 and 5 , which possibly explains the non significant result. (Table 7.3). There was no significant association of the calcium sub-scores of the coronary arteries, aorta, and right or left carotid arteries with (log-)ucMGP. (Table 7.4)

Tabel 7.1 Patient characteristics.

\begin{tabular}{|c|c|c|c|c|}
\hline \multirow[t]{2}{*}{ Variable } & \multicolumn{2}{|c|}{ Total group } & \multicolumn{2}{|c|}{ Tertiles of ucMGP serum levels } \\
\hline & $(n=36)$ & $\mathrm{T} 1$ (12) & T2 (12) & T3 (12) \\
\hline Age (year) & $53 \pm 10$ & $55 \pm 10$ & $54 \pm 9$ & $51 \pm 11$ \\
\hline Male/Female (n) & $19 / 17$ & $10 / 2$ & $5 / 7$ & $4 / 8$ \\
\hline (Ever) smoking $\mathrm{n}(\%)$ & $24(67)$ & $9(75)$ & $7(58)$ & $8(67)$ \\
\hline Body Mass Index $\left(\mathrm{kg} / \mathrm{m}^{2}\right)$ & $27 \pm 5$ & $27 \pm 4$ & $26 \pm 6$ & $27 \pm 4$ \\
\hline Ambulatory SBP (mmHg) & $162 \pm 22$ & $158 \pm 18$ & $172 \pm 18$ & $157 \pm 26$ \\
\hline Ambulatory DBP (mmHg) & $97 \pm 13$ & $94 \pm 12$ & $104 \pm 15$ & $94 \pm 10$ \\
\hline Total cholesterol (mmol/l) & $6.0 \pm 1.1$ & $6.3 \pm 1.5$ & $5.8 \pm 0.9$ & $5.9 \pm 0.7$ \\
\hline HDL cholesterol (mmol/l) & $1.31 \pm 0.38$ & $1.3 \pm 0.3$ & $1.3 \pm 0.4$ & $1.4 \pm 0.5$ \\
\hline LDL cholesterol* $(\mathrm{mmol} / \mathrm{l})$ & $3.9(1.8-6.0)$ & $3.9(1.8-6.0)$ & $3.8(2.3-5.1)$ & $3.9(3.1-4.6)$ \\
\hline Triglycerides" $(\mathrm{mmol} / \mathrm{l})$ & $1.62(0.49-12.42)$ & $2.37(0.57-4.16)$ & $1.18(0.49-4.36)$ & $1.63(0.95-12.42)$ \\
\hline Fasting glucose ${ }^{*}(\mathrm{mmol} / \mathrm{l})$ & $5.6(4.5-10.5)$ & $5.6(4.7-10.5)$ & $5.4(4.5-8.1)$ & $5.5(4.5-9.9)$ \\
\hline Estimated creatinine clearance $(\mathrm{ml} / \mathrm{min})$ & $98 \pm 28$ & $104 \pm 30$ & $94 \pm 26$ & $94 \pm 29$ \\
\hline
\end{tabular}

Unless indicated otherwise data are expressed as means \pm standard deviation. ${ }^{*}$, denotes median values with minimum and maximum between brackets. SBP, systolic blood pressure; DBP, diastolic blood pressure; HDL, high density lipoprotein; LDL, low density lipoprotein 
Table 7.2 Results of measurements divided by tertiles of serum ucMGP levels.

\begin{tabular}{lccc}
\hline Variable & \multicolumn{2}{c}{ Tertiles (mean and range) of ucMGP serum levels } \\
Tertile $(\mathrm{n})$ & $\mathrm{T} 1(12)$ & $\mathrm{T} 2(12)$ & T3 (12) \\
\hline UcMGP $(\mathrm{nmol} / \mathrm{l})$ & $3471(2031-4260)$ & $4708(4351-5215)$ & $6126(5416-9603)$ \\
OCR & $1.0(0.2-2.7)$ & $1.4(0.5-2.5)$ & $2.1(0.1-14.0)$ \\
cMGP $(\mathrm{nmol} / \mathrm{l})$ & $3237(1257-18889)$ & $3475(1759-10043)$ & $3199(665-82118)$ \\
Coronary score & $145(0-1546)$ & $111(1-3866)$ & $36(0-5951)$ \\
Abdominal aorta score & $1365(0-13063)$ & $834(0-21438)$ & $359(0-12944)$ \\
Left carotid artery score & $2(0-772)$ & $56(0-713)$ & $36(0-1789)$ \\
Right carotid artery score & $2(0-987)$ & $71(0-769)$ & $0(0-2253)$ \\
total calcium Z-score & $-1.2(-2.0-5.5)$ & $-1.4(-2.0-5.5)$ & $-1.9(-2.0-11.9)$ \\
\hline
\end{tabular}

Data are expressed as medians with minimum and maximum values (non-normal distribution). UcMGP, uncarboxylated Matrix Gla Protein; OCR, osteocalcin ratio; CMGP, carboxylated Matrix Gla Protein

Table 7.3 Multivariate regression analysis with (log-)ucMGP as the dependent variable.

\begin{tabular}{lcc}
\hline Model* $^{*}$ & $\begin{array}{c}\text { Total calcification Z-score } \\
\text { Beta } 10^{-3}(95 \% \mathrm{Cl})\end{array}$ & $\begin{array}{c}\text { Osteocalcin ratio } \\
\text { Beta } 10^{-3}(95 \% \mathrm{Cl})\end{array}$ \\
\hline 1 & $7(-7-20)^{\mathrm{NS}}$ & $24(7-40)$ \\
2 & $16(1-31)$ & $23(4-42)$ \\
3 & $18(4-32)$ & $25(6-43)$ \\
4 & $9(-6-24)^{\mathrm{NS}}$ & $29(11-48)$ \\
5 & $12(-2-27)^{\mathrm{NS}}$ & $22(5-40)$ \\
\hline
\end{tabular}

Model 1: crude; Model 2: adjusted for age; Model 3: adjusted for age, sex and estimated creatinine clearance; Model 4: adjusted for smoking habits, body mass index and systolic blood pressure; Model 5: adjusted for fasting glucose levels and LDL-cholesterol. OCR, osteocalcin ratio; $95 \% \mathrm{Cl}, 95 \%$ confidence interval. All results were statistically significant with the exception of those figures indicated with NS (not significant). There was significant collinearity between the confounders in models 4 and 5 and total calcification Z-score.

Table 7.4 Correlation of ucMGP with calcium sub-scores.

\begin{tabular}{lc}
\hline Localisation & Correlation coefficient $^{*}$ \\
\hline Left carotid artey & $0.026(p=0.882)$ \\
Right carotid artery & $-0.077(p=0.656)$ \\
Coronary arteries & $-0.065(p=0.706)$ \\
Aorta & $-0.185(p=0.280)$ \\
\hline
\end{tabular}

* Spearmans Rho

\section{Discussion}

This study shows a significant positive association between ucMGP, total arterial calcium score and low vitamin $\mathrm{K}$ status. Vitamin $\mathrm{K}$ status was, on average, lower in these hypertensive patients than has been reported for a healthy control population with the same average age. ${ }^{24}$ Lower ucMGP levels are clearly associated with higher 
vitamin $\mathrm{K}$ levels. Because carboxylation is an intracellular process, we assume that this is explained by clearance of UcMGP and generation of CMGP in the presence of sufficient vitamin K. However, except for the calcification score of the left carotid artery there was no significant correlation between CMGP or OCR with any of the other calcium sub-scores or the total calcification Z-score.

To our knowledge, this is the first study showing an association between calcium scores and ucMGP in relatively healthy hypertensive subjects. Previously, only reports showing a correlation of low serum unphosphorylated MGP and UcMGP levels in populations with increased cardiovascular risk have been published. ${ }^{22,28}$ Phosphorylation of MGP is the first step in its activation and is induced by the presence of calcium. It provides the binding site of MGP to calcium. Reports on correlations between unphosphorylated MGP serum levels and coronary calcification scores have been conflicting. ${ }^{17,18,29}$ Recently, ucMGP also failed to show a correlation with markers of vascular stiffness in children on dialysis. ${ }^{30}$

The MGP that we detected in the circulation of these patients represents the noncarboxylated form of MGP. A low vitamin K status prevents carboxylation of MGP and thus makes ucMGP less functional. ${ }^{31}$ The smooth muscle cell reacts by increasing MGP production as reflected by an increase in MGP messenger RNA. ${ }^{32}$ Probably, although ucMGP binds to calcium, it is not able to halt crystal growth. The excess ucMGP is thought to be set free in the circulation, and thus could be a potential marker in calcified patients.

Our results fit well with the theory that, in the process of vascular calcification, serum levels of ucMGP initially rise because its production by vascular smooth muscle cells is triggered by calcium. The positive beta indicates that higher $Z$ scores and thus more calcification is associated with higher serum ucMGP levels in this sample of relatively healthy hypertensive subjects. In other study populations, with higher cardiovascular risk and more calcification or with renal insufficiency, lower serum ucMGP levels have been found. ${ }^{22}$ A possible explanation is that with progressing calcification most of the ucMGP is bound to the calcium in the vascular wall and is than trapped, ultimately leading to a fall in serum levels. ${ }^{22,31,33,34}$ Also, in the presence of sufficient vitamin $\mathrm{K}$, ucMGP is carboxylated to cMGP giving rise to lower ucMGP levels as is supported by the positive beta in our regression analysis. Interestingly, another explanation for the lower ucMGP serum levels in subjects with more advanced arterial calcification may be a decline in vascular smooth muscle cells because of transformation to osteoblast like cells or apoptosis. ${ }^{35,36}$

Our analyses have several limitations. Firstly, although CT is an accepted method to measure vascular calcification, our method of estimating total calcification Z-score has not been validated. Secondly, we cannot exclude that the calcium sub-scores of separate vascular regions in our analyses failed to reach significance, due to the small number of patients or confounding by age. Thirdly, our study is based on associations, and does not show a cause-and-effect relationship. Fourthly, whereas we expected lower calcification scores with higher cMGP levels, this was not found. Our method of 
estimating CMGP could be too imprecise to detect this correlation. Furthermore, the ratio of UCMGP and OCR is based on the assumption that the availability of vitamin $\mathrm{K}$ in the vascular wall is similar to that in bone. This may not be the case, giving rise to imprecise estimation of CMGP. This imprecision may have affected the association between lower calcification scores in the presence of higher levels of vitamin $\mathrm{K}$ and thus higher levels of cMGP. As far as this is concerned, it is important to realize that it has recently been shown that vitamin $\mathrm{K}$ supplementation was associated with slower progression of coronary calcium scores. ${ }^{12}$

In conclusion, we found, adjusted for potential confounders, a significant positive association of total arterial calcium score and a high OCR (reflecting low vitamin $\mathrm{K}$ status) with serum ucMGP levels in mild to moderate hypertensive patients. This is consistent with the possibility that serum ucMGP levels are stimulated by the calcification process in humans. Although these data do not prove a cause-and-effect relationship between vitamin $\mathrm{K}$ and arterial calcifications, this possibility needs to be explored in future studies. Research in this field is important for the interpretation of future studies with serum MGP, vitamin $\mathrm{K}$ and cardiovascular risk. Vitamin $\mathrm{K}$ supplementation could be a simple way to reduce cardiovascular risk by activating MGP. 


\section{References}

1. Raggi P, Callister TQ, Cooil B, He ZX, Lippolis NJ, Russo DJ, Zelinger A, Mahmarian JJ. Identification of patients at increased risk of first unheralded acute myocardial infarction by electron-beam computed tomography. Circulation. 2000;101:850-5.

2. Lehto S, Niskanen L, Suhonen M, Ronnemaa T, Laakso M. Medial artery calcification. A neglected harbinger of cardiovascular complications in non-insulin-dependent diabetes mellitus. Arterioscler Thromb Vasc Biol. 1996;16:978-83.

3. Niskanen L, Siitonen O, Suhonen M, Uusitupa MI. Medial artery calcification predicts cardiovascular mortality in patients with NIDDM. Diabetes Care. 1994;17:1252-6.

4. Blacher J, Guerin AP, Pannier B, Marchais SJ, London GM. Arterial calcifications, arterial stiffness, and cardiovascular risk in end-stage renal disease. Hypertension. 2001;38:938-42.

5. Okuno S, Ishimura E, Kitatani K, Fujino Y, Kohno K, Maeno Y, Maekawa K, Yamakawa T, Imanishi Y, Inaba M, Nishizawa Y. Presence of abdominal aortic calcification is significantly associated with allcause and cardiovascular mortality in maintenance hemodialysis patients. Am J Kidney Dis. 2007;49:417-25.

6. Budoff MJ, Shaw LJ, Liu ST, Weinstein SR, Mosler TP, Tseng PH, Flores FR, Callister TQ, Raggi P, Berman DS. Long-term prognosis associated with coronary calcification: observations from a registry of 25,253 patients. J Am Coll Cardiol. 2007;49:1860-70.

7. Iribarren C, Sidney S, Sternfeld B, Browner WS. Calcification of the aortic arch: risk factors and association with coronary heart disease, stroke, and peripheral vascular disease. Jama. 2000;283:2810-5.

8. Rennenberg RJ, Kessels AG, Schurgers LJ, van Engelshoven JM, de Leeuw PW, Kroon AA. Vascular calcifications as a marker of increased cardiovascular risk: A meta-analysis. Vasc Health Risk Manag. 2009;5:185-97.

9. Abedin $\mathrm{M}$, Tintut $\mathrm{Y}$, Demer LL. Vascular calcification: mechanisms and clinical ramifications. Arterioscler Thromb Vasc Biol. 2004;24:1161-70.

10. Zebboudj AF, Imura M, Bostrom K. Matrix GLA protein, a regulatory protein for bone morphogenetic protein-2. J Biol Chem. 2002;277:4388-94.

11. Zebboudj AF, Shin V, Bostrom K. Matrix GLA protein and BMP-2 regulate osteoinduction in calcifying vascular cells. J Cell Biochem. 2003;90:756-65.

12. Shea MK, O'Donnell CJ, Hoffmann U, Dallal GE, Dawson-Hughes B, Ordovas JM, Price PA, Williamson MK, Booth SL. Vitamin K supplementation and progression of coronary artery calcium in older men and women. Am J Clin Nutr. 2009;89:1799-807.

13. Geleijnse JM, Vermeer C, Grobbee DE, Schurgers L, Knapen MH, van der Meer IM, Hofman A, Witteman JC. Dietary intake of menaquinone is associated with a reduced risk of coronary heart disease: the Rotterdam Study. J Nutr. 2004;134:3100-5.

14. Beulens JW, Bots ML, Atsma F, Bartelink ML, Prokop M, Geleijnse JM, Witteman JC, Grobbee DE, van der Schouw YT. High dietary menaquinone intake is associated with reduced coronary calcification. Atherosclerosis. 2009;203:489-93.

15. Koos R, Krueger T, Westenfeld R, Kuhl HP, Brandenburg V, Mahnken AH, Stanzel S, Vermeer C, Cranenburg EC, Floege J, Kelm M, Schurgers LJ. Relation of circulating Matrix Gla-Protein and anticoagulation status in patients with aortic valve calcification. Thromb Haemost. 2009;101:706-13.

16. Koos R, Mahnken AH, Muhlenbruch G, Brandenburg V, Pflueger B, Wildberger JE, Kuhl HP. Relation of oral anticoagulation to cardiac valvular and coronary calcium assessed by multislice spiral computed tomography. Am J Cardiol. 2005;96:747-9.

17. Jono S, Ikari Y, Vermeer C, Dissel P, Hasegawa K, Shioi A, Taniwaki H, Kizu A, Nishizawa Y, Saito S. Matrix Gla protein is associated with coronary artery calcification as assessed by electron-beam computed tomography. Thromb Haemost. 2004;91:790-4.

18. O'Donnell CJ, Shea MK, Price PA, Gagnon DR, Wilson PW, Larson MG, Kiel DP, Hoffmann U, Ferencik M, Clouse ME, Williamson MK, Cupples LA, Dawson-Hughes B, Booth SL. Matrix Gla protein is associated with risk factors for atherosclerosis but not with coronary artery calcification. Arterioscler Thromb Vasc Biol. 2006;26:2769-74. 
19. Farzaneh-Far A, Proudfoot D, Weissberg PL, Shanahan CM. Matrix gla protein is regulated by a mechanism functionally related to the calcium-sensing receptor. Biochem Biophys Res Commun. 2000;277:736-40.

20. Proudfoot D, Skepper JN, Shanahan CM, Weissberg PL. Calcification of human vascular cells in vitro is correlated with high levels of matrix Gla protein and low levels of osteopontin expression. Arterioscler Thromb Vasc Biol. 1998;18:379-88.

21. Cockcroft DW, Gault MH. Prediction of creatinine clearance from serum creatinine. Nephron. 1976;16:31-41.

22. Cranenburg EC, Vermeer C, Koos R, Boumans ML, Hackeng TM, Bouwman FG, Kwaijtaal M, Brandenburg VM, Ketteler M, Schurgers LJ. The Circulating Inactive Form of Matrix Gla Protein (ucMGP) as a Biomarker for Cardiovascular Calcification. J Vasc Res. 2008;45:427-36.

23. Sokoll LJ, O'Brien ME, Camilo ME, Sadowski JA. Undercarboxylated osteocalcin and development of a method to determine vitamin K status. Clin Chem. 1995;41:1121-8.

24. Sokoll $\amalg$, Sadowski JA. Comparison of biochemical indexes for assessing vitamin $\mathrm{K}$ nutritional status in a healthy adult population. Am J Clin Nutr. 1996;63:566-73.

25. Jie KS, Hamulyak K, Gijsbers BL, Roumen FJ, Vermeer C. Serum osteocalcin as a marker for vitamin Kstatus in pregnant women and their newborn babies. Thromb Haemost. 1992;68:388-91.

26. Binkley NC, Krueger DC, Engelke JA, Foley AL, Suttie JW. Vitamin K supplementation reduces serum concentrations of under-gamma-carboxylated osteocalcin in healthy young and elderly adults. Am J Clin Nutr. 2000;72:1523-8.

27. Agatston AS, Janowitz WR, Hildner FJ, Zusmer NR, Viamonte M, Detrano R. Quantification of coronary artery calcium using ultrafast computed tomography. J AM Coll Cardiol. 1990;15:827-32.

28. Schurgers LJ, Teunissen KJ, Knapen MH, Geusens P, van der Heijde D, Kwaijtaal M, van Diest R, Ketteler $\mathrm{M}$, Vermeer C. Characteristics and performance of an immunosorbent assay for human matrix Gla-protein. Clin Chim Acta. 2005;351:131-8.

29. Mazzaferro S, Pasquali M, Pugliese F, Barresi G, Carbone I, Francone M, Sardella D, Taggi F. Serum levels of calcification inhibition proteins and coronary artery calcium score: comparison between transplantation and dialysis. Am J Nephrol. 2007;27:75-83.

30. Shroff RC, Shah V, Hiorns MP, Schoppet M, Hofbauer LC, Hawa G, Schurgers L, Singhal A, Merryweather I, Brogan P, Shanahan C, Deanfield J, Rees L. The circulating calcification inhibitors, fetuin-A and osteoprotegerin, but not matrix Gla protein, are associated with vascular stiffness and calcification in children on dialysis. Nephrol Dial Transplant. 2008;23:3263-71.

31. Price PA, Faus SA, Williamson MK. Warfarin causes rapid calcification of the elastic lamellae in rat arteries and heart valves. Arterioscler Thromb Vasc Biol. 1998;18:1400-7.

32. Shanahan CM, Proudfoot D, Farzaneh-Far A, Weissberg PL. The role of Gla proteins in vascular calcification. Crit Rev Eukaryot Gene Expr. 1998;8:357-75.

33. Schurgers LJ, Teunissen KJ, Knapen MH, Kwaijtaal M, van Diest R, Appels A, Reutelingsperger CP, Cleutjens JP, Vermeer C. Novel conformation-specific antibodies against matrix gammacarboxyglutamic acid (Gla) protein: undercarboxylated matrix Gla protein as marker for vascular calcification. Arterioscler Thromb Vasc Biol. 2005;25:1629-33.

34. Schurgers LJ, Spronk HM, Skepper JN, Hackeng TM, Shanahan CM, Vermeer C, Weissberg PL, Proudfoot D. Post-translational modifications regulate matrix Gla protein function: importance for inhibition of vascular smooth muscle cell calcification. J Thromb Haemost. 2007;5:2503-11.

35. Moe SM, Chen NX. Inflammation and vascular calcification. Blood Purif. 2005;23:64-71.

36. Proudfoot D, Skepper JN, Hegyi L, Bennett MR, Shanahan CM, Weissberg PL. Apoptosis regulates human vascular calcification in vitro: evidence for initiation of vascular calcification by apoptotic bodies. Circ Res. 2000;87:1055-62. 



\section{Chapter 8}

Chronic coumarin treatment is associated with increased extracoronary arterial calcification in humans

RJMW Rennenberg, BJ van Varik, LJ Schurgers, K Hamulyak, $\mathrm{H}$ ten Cate, T Leiner, $C$ Vermeer, PW de Leeuw, AA Kroon

Blood 2010;115:5121-3 


\section{Abstract}

Vascular calcification is a marker of increased cardiovascular risk. Vitamin $\mathrm{K}$ dependent Matrix Gla protein (MGP) is important in inhibiting calcification. Since MGP activation is vitamin K dependent, we performed a cross sectional study investigating the relationship between the use of vitamin $\mathrm{K}$ antagonists and extracoronary vascular calcification.

From the Dutch thrombosis services we selected 19 patients, aged <55 years and without other cardiovascular risk factors, who had used coumarins for more than 10 years, and compared these to 18 matched healthy controls. MGP was measured and a plain X-ray of the thighs was taken to assess femoral arterial calcifications. The odds ratio for calcification in patients versus controls was $8.5(95 \% \mathrm{Cl} 2.01-35.95)$. Coumarin use and MGP were associated with calcification, even after adjusting for other risk factors.

We conclude that long term use of coumarins is associated with enhanced extra-coronary vascular calcification possibly through the inhibition of MGP carboxylation. 


\section{Introduction}

Vascular calcification is a marker of increased cardiovascular morbidity and mortality. ${ }^{1}$ Matrix Gla Protein (MGP) is an important inhibitor of calcification..$^{2-5}$ In animal studies, in which carboxylation of MGP was blocked by vitamin K antagonists, excessive calcifications of the arteries were found. ${ }^{6}$ In humans calcification of the coronary arteries $(\mathrm{CaC})$ and heart valves is increased in patients on vitamin $\mathrm{K}$ antagonists, whereas intake of vitamin $\mathrm{K}$ is associated with less progression of $\mathrm{CaC}^{7-10}$ Interestingly, the association between coumarin use and $\mathrm{CaC}$ is absent in an older population, and there are no reports on extra-coronary arterial calcification in coumarin users. ${ }^{11}$ Therefore, we performed a cross sectional study in middle aged long term coumarin users and a matched control group to test the hypothesis that chronic coumarin therapy is associated with femoral artery calcification as a proxy for coronary calcification along with decreased carboxylation of MGP.

\section{Methods}

We searched the database of the southern Dutch thrombosis services. Fot the present study we selected patients younger than 55 years, who used coumarins for more than 10 years because of a cardiac valve operation or recurrent venous thrombosis, and without previous cardiovascular events. Spouses or close friends living in the same (social) environment were invited as control subjects. The study was approved by the ethics committee and all subjects gave informed consent.

Clinical assessments included data on smoking behaviour, body mass index $\left(\mathrm{kg} / \mathrm{m}^{2}\right)$, and blood pressure (average of three office measurements [Accutor Plus, Datascope corporation Fairfield, NY, USA]). Fasting glucose levels, lipid profile, calcium, phosphate, and creatinine were measured in serum with an automated analyzer (Beckmann Synchron CX 7-2, Fullerton CA, USA). Endogenous creatinine clearance (ECC) was estimated using the Cockcroft and Gault formula. ${ }^{12}$ Desphosphouncarboxylated MGP (dp-ucMGP) was measured in plasma using a sandwich ELISA (VitaK BV, Maastricht, The Netherlands) as has been described previously. ${ }^{13}$ Femoral artery calcification was assessed by soft tissue $50 \mathrm{kV}$ X-ray of the left and right thigh (Siemens Aristos FX DR-Radiology-system, Siemens Erlangen Germany) in supine position and slight endorotation of the foot. The images were digitally processed to enhance soft tissue structures (Diamond View; Siemens, Erlangen, Germany) and evaluated by an independent radiologist ( $T L)$, unaware of the clinical data. A subject was scored positive for calcification when calcium deposits were visible along one or both femoral artery regions.

Normally distributed variables are presented as mean with standard deviation, otherwise they are presented as medians with minimum and maximum value. Differences between groups were assessed using Student's t-test or Mann-Whitney-U 
test for continuous variables and Chi-square test for ordinal and dichotomous variables. Calcification was correlated with age, sex, smoking, coumarin use, BMI, systolic and diastolic blood pressure, fasting glucose, lipid profile, serum creatinine, ECC, calcium, phosphate, calcium-phosphate product and dp-ucMGP using Spearman's test for non-normally distributed variables, or Pearson's test for normally distributed data. Multiple logistic regression analyses were done with several models to evaluate the independent contribution of coumarins and dp-ucMGP to calcification. Coumarin use and dp-ucMGP were analysed separately because of collinearity. The excess risk for calcification has been expressed as odds ratio. We used SPSS 16.0.1 (SPSS inc. Chicago, Illinois) for statistical calculations; a p-value $<0.05$ was considered statistically significant.

\section{Results and discussion}

Of 21 identified patients, 2 refused to participate. Eighteen control subjects volunteered. The characteristics of patients and controls are presented in Table 8.1.

Table 8.1 Characteristics of participants according to coumarin use.

\begin{tabular}{lccc}
\hline Variable & Coumarin & No coumarin & p-value $^{*}$ \\
& $\mathrm{n}=19$ & $\mathrm{n}=18$ & \\
\hline Sex (male/female) & $15 / 4$ & $9 / 9$ & 0.065 \\
Age (years, range) & $48(33-56)$ & $46(36-53)$ & 0.213 \\
(Ever) smoking (\%) & 68 & 50 & 0.254 \\
Body Mass Index (kg/m ${ }^{2}$ ) & $29( \pm 5)$ & $25( \pm 4)$ & 0.015 \\
Systolic Blood Pressure (mmHg) & $128( \pm 13)$ & $125( \pm 19)$ & 0.592 \\
Diastolic Blood Pressure (mmHg) & $81( \pm 8)$ & $80( \pm 14)$ & 0.676 \\
Glucose (mmol/l, range) & $5.1(4.3-9.0)$ & $4.9(4.2-6.2)$ & 0.807 \\
Total cholesterol (mmol/l) & $5.9( \pm 1.2)$ & $5.5( \pm 1.1)$ & 0.303 \\
HDL cholesterol (mmol/l) & $1.18( \pm 0.3)$ & $1.40( \pm 0.4)$ & 0.058 \\
LDL cholesterol (mmol/l) & $4.1( \pm 0.8)$ & $3.7( \pm 0.9)$ & 0.173 \\
Triglycerides & $1.57( \pm 0.9)$ & $0.98( \pm 0.6)$ & 0.023 \\
Creatinine ( $\mu$ mol/l) & $81( \pm 11.5)$ & $79( \pm 16.4)$ & 0.577 \\
Estimated Creatinine Clearance (ml/min) & $120( \pm 27)$ & $105( \pm 24)$ & 0.077 \\
Calcium-phosphate product (Median, range) & $2.3(1.5-4.4)$ & $2.6(2.3-3.4)$ & 0.104 \\
\hline
\end{tabular}

HDL, high density lipoprotein; LDL, low density lipoprotein. * Chi square test was used for dichotomous variables, Students-t test for normally distributed values, and the Mann Whitney-U test for not normally distributed variables.

Median coumarin treatment duration was 13 years (range 10-29 years). Target INR in all patients (3 with aortic valve replacement) was 2,5 (range 2,0-3,0) Univariate analysis showed a correlation between femoral artery calcification and coumarin use $(r=0.515, p<0.001)$ and plasma dp-ucMGP levels $(r=0.585, p<0.001)$. Coumarin use and plasma dp-ucMGP levels showed a strong correlation $(r=0.850, p<0.001)$. Calcification was visible in 14 of 19 coumarin users compared to 4 out of 18 controls $\left(X^{2}=9.8\right.$, 
$p=0.002$ ). The average dp-ucMGP level was 1439 ( \pm 481$)$ pmol/l versus $299( \pm 163)$ $\mathrm{pmol} / \mathrm{l}$ in coumarin users and controls, respectively $(p<0.001)$. The odds ratio for calcification in coumarin users was 8,49 (95\% $\mathrm{Cl} 2.01-35.95)$. In multiple regression analysis coumarin use and dp-ucMGP levels were independently associated with the presence of calcification, and were also independent of known or accepted modifiers (Table 87.2).

Table 8.2 Regression analysis with femoral artery calcification as the dependent variable.

\begin{tabular}{lcc}
\hline Model & Coumarin use & $\begin{array}{c}\text { dp-ucMGP } \\
\text { Beta }(95 \% \mathrm{Cl})\end{array}$ \\
\hline 1 & Beta $(95 \% \mathrm{Cl})$ & $0.661(0.306-1.016)$ \\
2 & $0.515(0.220-0.809)$ & $0.623(0.261-0.985)$ \\
3 & $0.484(0.186-0.782)$ & $0.584(0.184-0.984)$ \\
4 & $0.443(0.128-0.758)$ & $0.725(0.284-1.165)$ \\
5 & $0.510(0.166-0.854)$ & $0.680(0.254-1.105)$ \\
\hline
\end{tabular}

Results are expressed as the beta for coumarin use and dp-ucMGP levels with their $95 \%$ confidence interval (CI). Model 1: crude; Model 2: adjusted for age; Model 3: adjusted for age and sex; Model 4: adjusted for age, smoking, Body Mass Index and triglycerides; Model 5: adjusted for age, fasting glucose, LDL cholesterol, estimated creatinine clearance, and calcium phosphate product.

This is the first study showing a relationship between coumarins and extra-coronary calcification. Previous research already showed more calcification in animals with vitamin $\mathrm{K}$ deficiency due to a mutant vitamin $\mathrm{K}$ epoxide reductase subcomponent-1. ${ }^{14,15}$ Also coronary calcifications have been found in patients using vitamin K-antagonists but, in contrast to our study, patients were relatively old, had other risk factors for atherosclerosis, or received coumarins for an atherosclerotic cardiovascular indication. ${ }^{7,16,17}$

The dp-ucMGP assay described here specifically detects non-phosphorylated and noncarboxylated MGP, which has little or no affinity for calcium salts. It is thought that dp-ucMGP is easily set free in the circulation. Since ucMGP is only formed during vitamin $\mathrm{K}$ deficiency, dp-ucMGP serves as a biomarker for vascular vitamin $\mathrm{K}$ status. Our data demonstrate a strong association between circulating dp-ucMGP and coumarin use, which is consistent with increased synthesis of inactive ucMGP, and subsequently less inhibition of the calcification process. In response to progressive calcification, MGP production will be upregulated, thus exhausting the local vitamin $\mathrm{K}$ stores even further, and explaining higher levels of plasma dp-ucMGP, in subjects using coumarins. ${ }^{18,19}$

In this study, we only measured femoral vascular calcification. We cannot be sure that all vessels calcify in the same manner, although it has been shown that peripheral vascular calcification correlates with coronary calcification. ${ }^{20}$ Since all vascular calcifications are associated with increased cardiovascular risk, using coumarins may have an increased cardiovascular risk despite short-term benefits of decreased thrombosis tendency. ${ }^{1,21-23}$ This would indicate a hitherto unrecognized adverse side- 
effect of long-term coumarin use in young subjects. However, prospective, and longterm studies are necessary to clarify this issue further.

There are several limitations of this study. Firstly, it is a cross-sectional analysis. A cause-and-effect relationship could therefore not be investigated. Secondly, the study result was obtained in a relatively small and selected population and should be reproduced in other cohorts. Thirdly, plain X-ray is not the most sensitive technique to detect arterial calcification, but computer tomography would have involved more radiation and is more expensive. Fourthly, there is a difference in sex distribution between the study groups. However, including sex as a confounder in multiple regression analysis did not significantly change the outcome and there is no relationship between sex and MGP levels. ${ }^{16}$ The strength of our study was that we only studied patients without other cardiovascular disease, a relatively young population (so no age bias) and the demonstration that coumarin use affected calcification independently of other risk factors.

We conclude that long term use of vitamin $\mathrm{K}$ antagonists is associated with femoral artery calcification which is possibly enhanced through the inactivation of MGP. 


\section{References}

1. Rennenberg RJ, Kessels AG, Schurgers LJ, van Engelshoven JM, de Leeuw PW, Kroon AA. Vascular calcifications as a marker of increased cardiovascular risk: A meta-analysis. Vasc Health Risk Manag. 2009;5:185-97.

2. Dhore CR, Cleutjens JP, Lutgens E, Cleutjens KB, Geusens PP, Kitslaar PJ, Tordoir JH, Spronk HM, Vermeer C, Daemen MJ. Differential expression of bone matrix regulatory proteins in human atherosclerotic plaques. Arterioscler Thromb Vasc Biol. 2001;21:1998-2003.

3. Price PA, Urist MR, Otawara Y. Matrix Gla protein, a new gamma-carboxyglutamic acid-containing protein which is associated with the organic matrix of bone. Biochem Biophys Res Commun. 1983;117:765-71.

4. Zebboudj AF, Imura M, Bostrom K. Matrix GLA protein, a regulatory protein for bone morphogenetic protein-2. J Biol Chem. 2002;277:4388-94.

5. Zebboudj AF, Shin V, Bostrom K. Matrix GLA protein and BMP-2 regulate osteoinduction in calcifying vascular cells. J Cell Biochem. 2003;90:756-65.

6. Price PA, Faus SA, Williamson MK. Warfarin causes rapid calcification of the elastic lamellae in rat arteries and heart valves. Arterioscler Thromb Vasc Biol. 1998;18:1400-7.

7. Schurgers $\mathrm{L}$, Aebert H, Vermeer C, Bultmann B, Janzen J. Oral anticoagulant treatment: friend or foe in cardiovascular disease? Blood. 2004;104:3231-2.

8. Koos R, Mahnken AH, Muhlenbruch G, Brandenburg V, Pflueger B, Wildberger JE, Kuhl HP. Relation of oral anticoagulation to cardiac valvular and coronary calcium assessed by multislice spiral computed tomography. Am J Cardiol. 2005;96:747-9.

9. Lerner RG, Aronow WS, Sekhri A, Palaniswamy C, Ahn C, Singh T, Sandhu R, McClung JA. Warfarin use and the risk of valvular calcification. J Thromb Haemost. 2009;7:2023-7.

10. Shea MK, O'Donnell CJ, Hoffmann U, Dallal GE, Dawson-Hughes B, Ordovas JM, Price PA, Williamson MK, Booth SL. Vitamin K supplementation and progression of coronary artery calcium in older men and women. Am J Clin Nutr. 2009;89:1799-807.

11. Villines TC, O'Malley PG, Feuerstein IM, Thomas S, Taylor AJ. Does Prolonged Warfarin Exposure Potentiate Coronary Calcification in Humans? Results of the Warfarin and Coronary Calcification Study. Calcif Tissue Int. 2009;85:494-500.

12. Cockcroft DW, Gault MH. Prediction of creatinine clearance from serum creatinine. Nephron. 1976;16:31-41.

13. Schurgers LJ, Cranenburg EC, Vermeer C. Matrix Gla-protein: the calcification inhibitor in need of vitamin K. Thromb Haemost. 2008;100:593-603.

14. Kohn MH, Price RE, Pelz HJ. A cardiovascular phenotype in warfarin-resistant Vkorc1 mutant rats. Artery Res. 2008;2:138-47.

15. Teichert M, Visser LE, van Schaik RH, Hofman A, Uitterlinden AG, De Smet PA, Witteman JC, Stricker $\mathrm{BH}$. Vitamin $\mathrm{K}$ epoxide reductase complex subunit 1 (VKORC1) polymorphism and aortic calcification: the Rotterdam Study. Arterioscler Thromb Vasc Biol. 2008;28:771-6.

16. Cranenburg EC, Vermeer C, Koos R, Boumans ML, Hackeng TM, Bouwman FG, Kwaijtaal M, Brandenburg VM, Ketteler M, Schurgers LJ.The Circulating Inactive Form of Matrix Gla Protein (ucMGP) as a Biomarker for Cardiovascular Calcification. J Vasc Res. 2008;45:427-36.

17. Koos R, Krueger T, Westenfeld R, Kuhl HP, Brandenburg V, Mahnken AH, Stanzel S, Vermeer C, Cranenburg EC, Floege J, Kelm M, Schurgers LJ. Relation of circulating Matrix Gla-Protein and anticoagulation status in patients with aortic valve calcification. Thromb Haemost. 2009;101:706-13.

18. Shanahan CM, Cary NR, Metcalfe JC, Weissberg PL. High expression of genes for calcificationregulating proteins in human atherosclerotic plaques. J Clin Invest. 1994;93:2393-402.

19. Shanahan CM, Cary NR, Salisbury JR, Proudfoot D, Weissberg PL, Edmonds ME. Medial localization of mineralization-regulating proteins in association with Monckeberg's sclerosis: evidence for smooth muscle cell-mediated vascular calcification. Circulation. 1999;100:2168-76.

20. Reaven PD, Sacks J. Coronary artery and abdominal aortic calcification are associated with cardiovascular disease in type 2 diabetes. Diabetologia. 2005;48:379-85.

21. Raggi P, Shaw L, Berman DS, Callister TQ. Prognostic value of coronary artery calcium screening in subjects with and without diabetes. J Am Coll Cardiol. 2004;43:1663-9. 
22. Pidal D, Sanchez Vidal MT, Rodriguez JC, Corte MD, Pravia P, Guinea O, Pidal I, Bongera M, Escribano D, Gonzalez LO, Diez MC, Venta R, Vizoso FJ. Relationship between arterial vascular calcifications seen on screening mammograms and biochemical markers of endothelial injury. Eur J Radiol. 2009;69: 87-92.

23. Raggi P, Callister TQ, Cooil B, He ZX, Lippolis NJ, Russo DJ, Zelinger A, Mahmarian JJ. Identification of patients at increased risk of first unheralded acute myocardial infarction by electron-beam computed tomography. Circulation. 2000;101:850-5. 
Chapter 9

Main findings in perspective 
118 Chapter 9 


\section{Main findings in perspective}

The studies in this thesis describe the pathobiology (chapter 1 and 2) and clinical cardiovascular risk (chapter 3 ) of vascular calcification in subjects with different comorbidities (hypertension, diabetes and renal insufficiency). The physiology of matrix Gla protein (MGP) is studied in hypertensive subjects (chapter 4 and 5). The association between MGP and vascular properties (stiffness and calcification) is addressed in subjects with normal or impaired glucose metabolism and diabetes (chapter 6), hypertensive subjects (chapter 7) and patients using vitamin $\mathrm{K}$ antagonists (chapter 8). The current chapter discusses existing knowledge and how our findings contribute to the knowledge on vascular calcification, especially in hypertensive subjects. Furthermore we discuss future perspectives of research in this field.

\section{Why is vascular calcification important?}

Cardiovascular disease is a major cause of death in the western world. ${ }^{1}$ Many risk factors have been identified and it is obvious that their treatment reduces cardiovascular risk. ${ }^{2,3}$ Despite this success, there is still a significant residual cardiovascular disease risk. Therefore it is important to identify other risk factors, like vascular calcification, and to investigate their biology and physiological consequences and perform studies to explore whether preventing or treating these other risk factors will lower cardiovascular risk.

\section{What is already known about this topic?}

In many observational studies vascular calcifications are associated with a greater cardiovascular risk. $^{4-6}$ With the emergence of more advanced imaging techniques calcification can be visualized more accurately and even spotty calcifications in atherosclerotic plaques can be seen and have been associated with an increased risk for plaque rupture. ${ }^{7}$ The majority of the research has been done on the association between coronary calcifications, assessed with electron beam computer tomography, and cardiovascular outcome. Only a few studies address the question whether other imaging modalities that detect calcifications are associated with outcome..$^{8-10}$

Only a decade ago, vascular calcifications were viewed upon as an inert endpoint of atherosclerosis. However, more and more research shows that it is a highly complex, actively regulated process which involves several genes, proteins and vitamins. ${ }^{11-14}$ Because of the increased cardiovascular risk and the active regulation of vascular calcification it is interesting to think about interventions to prevent or reduce vascular calcifications. MGP plays a central role in the inhibition of the calcification process. This protein is vitamin $\mathrm{K}$ dependent which means that it has to be carboxylated by gamma glutamylcarboxylase and vitamin $\mathrm{K}$ as a cofactor to fully exert its calcification inhibiting properties. ${ }^{15}$ First discovered in bone, it was later shown to inhibit 
calcification and to play an important role in vascular calcification. ${ }^{16,17}$ Animal experiments demonstrated that administration of vitamin $\mathrm{K}$ inhibits the progression of vascular calcification. ${ }^{18,19}$ Several human observational studies show conflicting evidence regarding the association between a high vitamin $\mathrm{K}$ intake and vascular calcification or cardiovascular complications. ${ }^{20-23}$ However, a placebo controled vitamin $\mathrm{K}$-intervention trial investigating the progression of coronary calcification in an elderly population showed slower progression in the vitamin $\mathrm{K}$ group. ${ }^{24}$ In the past few years several studies have expanded our knowledge about MGP, mainly because of the availability of an elisa test for different conformations of MGP. For instance, plasma levels of total uncarboxylated MGP decrease in populations with more extensive atherosclerosis and vascular calcification. ${ }^{25}$ However, there is almost no information about normal MGP levels or the pathophysiology of MGP in subjects prone to vascular calcification but without visible calcification as in patients with hypertension, early diabetes or metabolic syndrome, or early stages of renal insufficiency. How vascular calcification increases cardiovascular risk is still a matter of debate. ${ }^{26,27}$ It might be an important pathophysiological mechanism explaining the increased cardiovascular morbidity and mortality. Regarding the association between MGP levels and vascular calcification one would also expect an association between vascular stiffness and MGP levels but the available studies on this topic were not convincingly positive. ${ }^{28,29}$ However, these studies were performed in subjects (and in these cases children) with renal insufficiency and the mechanisms might not be comparable to those in a relatively healthy adult population.

\section{What does this thesis add to current knowledge?}

There is probably a common pathway resulting in vascular calcification that is similar in all patient groups. However, the initiation of the calcification process may depend on specific risk factors in particular patient groups with different comorbidities. Most studies with regard to calcification have been performed in subjects with renal insufficiency because vascular calcification is very prominent in these patients and, additionally, such patients regularly visit the clinic for all kind of measurements. The pathobiology, pathophysiology and clinical complications of vascular calcification in these patients has therefore been thoroughly studied. ${ }^{12,30,31}$ On the contrary, studies concerning the pathobiology of vascular calcification in other patient groups are scarce. Therefore, in chapter 1 , we discuss the differences in initiation of the calcifying process in subjects with renal insufficiency, diabetes mellitus and hypertension. In chapter 2 we review in depth the current knowledge on proteins involved in vascular calcification.

The majority of the studies describing vascular calcification as a risk factor for cardiovascular disease concern coronary calcifications and are identified using computed tomography. However, our results demonstrate that vascular calcification at any location assessed with any imaging method harbours an increased 
cardiovascular risk and mortality. In chapter 3 we provide a meta-analysis of studies concerning vascular calcification and cardiovascular endpoints. The increased risk of calcification is especially pronounced in populations with a high baseline cardiovascular risk like patients with diabetes or renal insufficiency. A limitation was the lack of a regression analyses to explore whether vascular calcification is an independent risk factor because we did not have individual patient data. Several of these individual studies however, point towards vascular calcification as an independent risk factor. ${ }^{32,33}$ Our meta-analysis reports the risk of no vascular calcification versus any vascular calcification, and we clearly show that high risk subjects can be identified according to the presence of calcification.

MGP is considered to be a (bio)marker of vascular calcification. To interpret circulating MGP levels correctly in patient populations, information about production, concentration of circulating levels and clearance of MGP is needed. In chapter 4 and 5 we studied normal plasma levels and clearance rate of MGP in hypertensive subjects. First we demonstrated that in hypertensive subjects total uncarboxylated MGP (tucMGP) and total desphospho (unphosphorylated)MGP (t-dpMGP) levels were lower compared to healthy controls. The lower t-ucMGP levels tally nicely with previous reports in the literature. The lower levels of t-ucMGP are associated with more vascular calcification. ${ }^{25,34}$ In our subjects, with presumably mild to moderate atherosclerosis we found an average concentration of t-ucMGP that is just in between normal levels and the levels in subjects wit more extensive calcification. ${ }^{25}$ Although we do not know the precise mechanism causing lower MGP concentrations, one possibilty is that subjects with mild to moderate hypertension already have some microcalcifications of blood vessels. We hypothesise that this slightly depressed tucMGP level indicates an active defence mechanism against vascular calcification. Presumably, in these subjects with on average little calcification the vascular smooth muscle cells (VSMC) are maximally defending themselves against calcification by increasing their production of MGP. ${ }^{35}$ In absence of sufficient vascular vitamin $\mathrm{K}$ this extra MGP remains uncarboxylated and does not exert its full calcification inhibiting potential. In theory, one would expect that the spillover to the circulation of this excess of non-functional MGP causes higher levels in the initial stages of the calcification process. However, with time and progressive calcification the number of VSMC decrease because of apoptosis induced by calcification and differentiation to osteoblast like cells unable to produce MGP. Hence, total production will drop possibly resulting in the lower levels as measured in subjects with vascular calcification. ${ }^{36}$ Furthermore, it's possible that MGP is trapped in the calcifying vascular wall. $^{37}$

With regard to renal clearance we showed that this remains normal even with deteriorating renal function and that it is only compromised in more severe renal insufficiency. Because we had cross sectional data, we could not prove that the abovementioned mechanisms are valid. We also do not know if this finding is unique in these subjects with mild to moderate hypertension or generalizable to other 
patient groups with early or mild to moderate atherosclerosis. More research to reveal the mechanism by which circulating MGP reflects vascular calcification is necessary.

Structural alterations of the vascular wall have an effect on vessel stiffness and compliance. For example, increased concentrations of advanced glycosylation end products(AGEs) in the vascular wall lead to stiffer arteries. ${ }^{38}$ In chapter 6 we hypothesized that abnormal levels of non phosphorylated, uncarboxylated MGP (dpucMGP) would represent excess calcification and hence increased stiffness or decreased compliance. Regrettably, we did not have any measure of calcification in the Hoorn study population. Although dpucMGP levels showed a significant trend with measures of stiffness or compliance we could not prove that this was an independent predictor of vascular stiffness. There was, however, a significant association with vascular compliance as reflected by Youngs elastic modulus of the carotid artery. In regression analysis especially mean arterial pressure (MAP) appeared to be an important confounder. There was a strong relationship between MAP and MGP indicating that blood pressure, besides giving rise to stiffer arteries, might be an important mechanism stimulating MGP production in these patients.

In chapter 7 we investigated the relationship between a total calcification score of the coronaries, carotid arteries and the abdominal aorta and vitamin $\mathrm{K}$ status and UCMGP. There was a statistically significant relationship between total vascular calcification and vitamin K status. More precisly, the poorer the vitamin K status, the more calcium in these arteries was measured. Because these are cross sectional data there is no information on a cause and effect relationship. However, these results support the concept that low vitamin $\mathrm{K}$ status results in insufficient carboxylation of MGP, and thus contributes to progression of vascular calcification. In addition, high vitamin $\mathrm{K}$ intake has been proven to be associated with a reduced risk of coronary heart disease. $^{21}$ Also, the progression of coronary calcification was slowed down with supplementation of vitamin $\mathrm{K}$ in older adults. ${ }^{24}$ Still, there are no prospective intervention studies that show a beneficial effect of vitamin $\mathrm{K}$ supplementation on cardiovascular events or outcome.

Blocking vitamin $\mathrm{K}$ action by the use of vitamin $\mathrm{K}$ antagonists (VKAs) can rapidly induce calcification of the arteries in rats. ${ }^{17}$ In addition, there are also reports on excellerated coronary and cardiac valve calcification in humans who use VKAs. ${ }^{39,40}$ However, these studies have been performed mainly in an elderly population and the study results may be confounded by indication for the use of VKAs. In chapter 8 we showed that long term use of VKAs in young subjects is associated with excessive, peripheral vascular calcification. Despite the association between VKAs and vascular calcification there are no reports on increased cardiovascular risk in patients on long term vitamin $\mathrm{K}$ antagonists. Actually, this might be difficult to prove because of the strong association between the main indications for long term use of VKAs and cardiovascular outcome. In this respect our data raise some concern regarding the increased vascular calcification and hence the associated increase in cardiovascular 
risk in young subjects without known atherosclerotic cardiovascular disease. Therefore, it might be important to consider alternative treatments for subjects needing long term anticoagulation. Fortunately, alternative ways of anticoagulation through direct thrombin inhibition or antagonising coagulation factor $\mathrm{X}$ are now on the market. However, their long term safety and their effect on vascular calcification remains to be proven.

\section{Future perspectives}

Cardiovascular risk estimation could be more precise if there was a reliable and safe method that could easily assess the amount of vascular calcification. This can be in the total vascular bed or in a single blood vessel. Today vascular investigations are still hampered by excess radiation (computer tomography) which might harm the patient or the fact that they are time consuming (ultrasound). A circulating marker that reflects (total) calcification burden would be a good surrogate to improve cardiovascular risk estimation. Vascular calcification is considered as an additional risk factor, and a biomarker could put an individual patient in a higher or lower risk category. However, whether a patient's cardiovascular risk will indeed increase or perhaps become lower depends on his total calcification burden compared to the average total calcification burden in an age and sex matched control group. These data about average calcification burden in different patient groups or healthy subjects and the consequences with regard to cardiovascular risk are scarce. Thus, this should be further investigated before calcification screening is advocated as a tool to estimate cardiovascular risk. Of course, the effectiveness and cost-effectiveness of such a strategy needs to be proven.

Because research on MGP and calcification is mainly cross sectional the exact sequence in the calcification process remains unclear. In humans, most results are only available on circulating MGP levels. Whether these MGP levels actually reflect what is happening in the vascular wall should be investigated in a follow up study with regular collection of blood samples and blood vessel biopsies or regular vascular imaging quantifying calcium and MGP measurements. Next we need to establisch normal values in different patient groups of different ages. Only when this kind of information is available, we are able to discriminate between those at risk because of vascular calcification compared to an otherwise comparable control group.

As discussed above, the calcification process is complex and involves many different genes and proteins. The possiblity of stimulating or inhibiting these genes and proteins using drugs or vitamins is challenging. Hence, vascular calcification could be prevented which might result in less cardiovascular events. Of the proteins involved in vascular calcification MGP can be modified by vitamin $\mathrm{K}^{15}$ It has been proven that MGP is a potent inhibitor of vascular calcification in animal experiments. ${ }^{41}$ It can be activated by sufficient vascular vitamin K concentrations. High doses of vitamin $\mathrm{K}$ are able to prevent progression or even induce regression of warfarin induced vascular 
calcification in rats. ${ }^{19}$ There are studies suggesting a similar effect in humans but this should be further explored in future studies. ${ }^{24}$ First we need additional prospective intervention trials investigating whether high doses of vitamin $\mathrm{K}$ are able to halt progression of vascular calcification, not only in the coronaries but also in other vascular beds like the carotid arteries or the aorta. Therefore we need a reliable reproducible method to estimate total tissue calcium. Second, we aim to prevent vascular calcification the initation mechanisms in different patient groups might request a tailor made approach. The effect of these measures on vascular calcification and ultimately on cardiovascular risk should be subject of future research. If treatment with vitamin $\mathrm{K}$ indeed leads to activation of MGP and hence less vascular calcification in humans we have a new treatable cardiovascular risk marker like cholesterol or blood glucose. These interventions could then be a possible target for treatment in order to reduce risk.

In theory, MGP levels could be used to guide the intensity of antihypertensive treatment. To further prove this, we need prospective data on the relationship between blood pressure and MGP and subsequently intervention trials with treatment guided by MGP levels compared to treatment guided by blood pressure values.

Insights in vascular calcification have changed substantially over the last decade. The discovery of several proteins, and genes heralded the beginning of an exciting new field of research concerning the mechanisms and consequences of vascular calcification. The challenge for the near future is to reveal whether vascular calcification can be treated and if so, whether this contributes to lowering cardiovascular risk. 


\section{References}

1. Vaartjes I, van Dis I, Visseren FL, Bots ML. Doodsoorzaken in Nederland in 2008: Dutch Heart Foundation; 2009.

2. Lewington S, Whitlock G, Clarke R, Sherliker P, Emberson J, Halsey J, Qizilbash N, Peto R, Collins R. Blood cholesterol and vascular mortality by age, sex, and blood pressure: a meta-analysis of individual data from 61 prospective studies with 55,000 vascular deaths. Lancet 2007;370:1829-39.

3. Staessen JA, Wang JG, Thijs L. Cardiovascular protection and blood pressure reduction: a metaanalysis. Lancet 2001;358:1305-15.

4. Blacher J, Guerin AP, Pannier B, Marchais SJ, London GM. Arterial calcifications, arterial stiffness, and cardiovascular risk in end-stage renal disease. Hypertension 2001;38:938-42.

5. Becker A, Leber A, Becker C, Knez A. Predictive value of coronary calcifications for future cardiac events in asymptomatic individuals. Am Heart J 2008;155:154-60.

6. Raggi P, Callister TQ, Cooil B, He ZX, Lippolis NJ, Russo DJ, Zelinger A, Mahmarian JJ. Identification of patients at increased risk of first unheralded acute myocardial infarction by electron-beam computed tomography. Circulation 2000;101:850-5.

7. Motoyama S, Kondo T, Sarai M, Sugiura A, Harigaya H, Sato T, Inoue K, Okumura M, Ishii J, Anno H, Virmani R, Ozaki Y, Hishida $\mathrm{H}$, Narula J. Multislice computed tomographic characteristics of coronary lesions in acute coronary syndromes. Journal of the American College of Cardiology 2007;50:319-26.

8. London GM, Guerin AP, Marchais SJ, Metivier F, Pannier B, Adda H. Arterial media calcification in endstage renal disease: impact on all-cause and cardiovascular mortality. Nephrol Dial Transplant 2003;18:1731-40.

9. Iribarren C, Sidney S, Sternfeld B, Browner WS. Calcification of the aortic arch: risk factors and association with coronary heart disease, stroke, and peripheral vascular disease. Jama 2000;283: 2810-5.

10. Wang AY, Wang M, Woo J, Lam CW, Li PK, Lui SF, Sanderson JE. Cardiac valve calcification as an important predictor for all-cause mortality and cardiovascular mortality in long-term peritoneal dialysis patients: a prospective study. J Am Soc Nephrol 2003;14:159-68.

11. Shanahan CM. Vascular calcification. Curr Opin Nephrol Hypertens 2005;14:361-7.

12. Moe SM, Chen NX. Pathophysiology of vascular calcification in chronic kidney disease. Circulation research 2004;95:560-7.

13. Demer LL, Tintut Y. Mineral exploration: search for the mechanism of vascular calcification and beyond: the 2003 Jeffrey M. Hoeg Award lecture. Arterioscler Thromb Vasc Biol 2003;23:1739-43.

14. Hruska KA, Mathew S, Saab G. Bone morphogenetic proteins in vascular calcification. Circulation research 2005;97:105-14.

15. Schurgers LJ, Cranenburg EC, Vermeer C. Matrix Gla-protein: the calcification inhibitor in need of vitamin K. Thromb Haemost 2008;100:593-603.

16. Price PA, Urist MR, Otawara Y. Matrix Gla protein, a new gamma-carboxyglutamic acid-containing protein which is associated with the organic matrix of bone. Biochem Biophys Res Commun 1983;117:765-71.

17. Price PA, Faus SA, Williamson MK. Warfarin causes rapid calcification of the elastic lamellae in rat arteries and heart valves. Arterioscler Thromb Vasc Biol 1998;18:1400-7.

18. Spronk HM, Soute BA, Schurgers L, Thijssen HH, De Mey JG, Vermeer C. Tissue-specific utilization of menaquinone-4 results in the prevention of arterial calcification in warfarin-treated rats. Journal of vascular research 2003;40:531-7.

19. Schurgers LJ, Spronk HM, Soute BA, Schiffers PM, DeMey JG, Vermeer C. Regression of warfarininduced medial elastocalcinosis by high intake of vitamin $\mathrm{K}$ in rats. Blood 2007;109:2823-31.

20. Adams J, Pepping J. Vitamin K in the treatment and prevention of osteoporosis and arterial calcification. Am J Health Syst Pharm 2005;62:1574-81.

21. Geleijnse JM, Vermeer C, Grobbee DE, Schurgers L, Knapen MH, van der Meer IM, Hofman A, Witteman JC. Dietary intake of menaquinone is associated with a reduced risk of coronary heart disease: the Rotterdam Study. J Nutr 2004;134:3100-5.

22. Villines TC, Hatzigeorgiou C, Feuerstein IM, O'Malley PG, Taylor AJ. Vitamin K1 intake and coronary calcification. Coron Artery Dis 2005;16:199-203. 
23. Gast GC, de Roos NM, Sluijs I, Bots ML, Beulens JW, Geleijnse JM, Witteman JC, Grobbee DE, Peeters $\mathrm{PH}$, van der Schouw YT. A high menaquinone intake reduces the incidence of coronary heart disease. Nutr Metab Cardiovasc Dis 2009;19:504-10.

24. Shea MK, O'Donnell CJ, Hoffmann U, Dallal GE, Dawson-Hughes B, Ordovas JM, Price PA, Williamson MK, Booth SL. Vitamin K supplementation and progression of coronary artery calcium in older men and women. Am J Clin Nutr 2009;89:1799-807.

25. Cranenburg EC, Vermeer C, Koos R, Boumans ML, Hackeng TM, Bouwman FG, Kwaijtaal M, Brandenburg VM, Ketteler M, Schurgers LJ. The Circulating Inactive Form of Matrix Gla Protein (ucMGP) as a Biomarker for Cardiovascular Calcification. Journal of vascular research 2008;45:427-36.

26. McEniery CM, McDonnell BJ, So A, Aitken S, Bolton CE, Munnery M, Hickson SS, Yasmin Maki-Petaja KM, Cockcroft JR, Dixon AK, Wilkinson IB. Aortic calcification is associated with aortic stiffness and isolated systolic hypertension in healthy individuals. Hypertension 2009;53:524-31.

27. Adragao T, Pires A, Birne R, Curto JD, Lucas C, Goncalves M, Negrao AP. A plain X-ray vascular calcification score is associated with arterial stiffness and mortality in dialysis patients. Nephrol Dial Transplant 2009;24:997-1002.

28. Shroff RC, Shah V, Hiorns MP, Schoppet M, Hofbauer LC, Hawa G, Schurgers LJ, Singhal A, Merryweather I, Brogan P, Shanahan C, Deanfield J, Rees L. The circulating calcification inhibitors, fetuin-A and osteoprotegerin, but not matrix Gla protein, are associated with vascular stiffness and calcification in children on dialysis. Nephrol Dial Transplant 2008;23:3263-71.

29. van Summeren MJ, Hameleers JM, Schurgers L, Hoeks AP, Uiterwaal CS, Kruger T, Vermeer C, Kuis W, Lilien MR. Circulating calcification inhibitors and vascular properties in children after renal transplantation. Pediatric nephrology (Berlin, Germany) 2008;23:985-93.

30. London GM, Marchais SJ, Guerin AP, Metivier F. Arteriosclerosis, vascular calcifications and cardiovascular disease in uremia. Curr Opin Nephrol Hypertens 2005;14:525-31.

31. Shanahan CM. Mechanisms of vascular calcification in renal disease. Clinical nephrology 2005;63:14657.

32. Budoff MJ, Shaw LJ, Liu ST, Weinstein SR, Mosler TP, Tseng PH, Flores FR, Callister TQ, Raggi P, Berman DS. Long-term prognosis associated with coronary calcification: observations from a registry of 25,253 patients. Journal of the American College of Cardiology 2007;49:1860-70.

33. LaMonte MJ, FitzGerald SJ, Church TS, Barlow CE, Radford NB, Levine BD, Pippin JJ, Gibbons LW, Blair SN, Nichaman MZ. Coronary artery calcium score and coronary heart disease events in a large cohort of asymptomatic men and women. Am J Epidemiol 2005;162:421-9.

34. Jensky NE, Criqui MH, Wright MC, Wassel CL, Brody SA, Allison MA. Blood pressure and vascular calcification. Hypertension 2010;55:990-7.

35. Shanahan CM, Proudfoot D, Farzaneh-Far A, Weissberg PL. The role of Gla proteins in vascular calcification. Crit Rev Eukaryot Gene Expr 1998;8:357-75.

36. Proudfoot D, Skepper JN, Hegyi L, Bennett MR, Shanahan CM, Weissberg PL. Apoptosis regulates human vascular calcification in vitro: evidence for initiation of vascular calcification by apoptotic bodies. Circulation research 2000;87:1055-62.

37. Schurgers LJ, Teunissen KJ, Knapen MH, Kwaijtaal M, van Diest R, Appels A, Reutelingsperger CP, Cleutjens JP, Vermeer C. Novel conformation-specific antibodies against matrix gammacarboxyglutamic acid (Gla) protein: undercarboxylated matrix Gla protein as marker for vascular calcification. Arterioscler Thromb Vasc Biol 2005;25:1629-33.

38. Soldatos G, Cooper ME. Advanced glycation end products and vascular structure and function. Current hypertension reports 2006;8:472-8.

39. Koos R, Mahnken AH, Muhlenbruch G, Brandenburg V, Pflueger B, Wildberger JE, Kuhl HP. Relation of oral anticoagulation to cardiac valvular and coronary calcium assessed by multislice spiral computed tomography. Am J Cardiol 2005;96:747-9.

40. Schurgers LJ, Aebert H, Vermeer C, Bultmann B, Janzen J. Oral anticoagulant treatment: friend or foe in cardiovascular disease? Blood 2004;104:3231-2.

41. Luo G, Ducy P, McKee MD, Pinero GJ, Loyer E, Behringer RR, Karsenty G. Spontaneous calcification of arteries and cartilage in mice lacking matrix GLA protein. Nature 1997;386:78-81. 
Summary 


\section{Summary}

Vascular calcification is a common condition seen among elderly subjects and subjects with a variety of cardiovascular risk factors. It is also prevalent in subjects with diabetes, renal insufficiency and hypertension. The presence of these calcifications is independently associated with a greater cardiovascular risk. The mechanisms of calcification are complex, but in the past decade abundant research has been devoted to unraveling these mechanisms. In chapter 1 we discuss current knowledge on the differences in the initiating mechanisms and give an overview of the common pathway to vascular calcification. We discuss these mechanisms related to diabetes, renal insufficiency and hypertension.

Many of the factors involved in the calcifciation process are proteins. In recent studies these proteins have all been implicated to play a stimulating or inhibiting role in de calcification process. In chapter $\mathbf{2}$ we discuss the biological properties of these proteins and their role in the calcification mechanism. We elaborate on possibilities to influence the function of these proteins in order to prevent or decrease calcification progression.

Chapter 3 gives the results of a meta-analysis of observational studies concerning vascular calcification and cardiovascular outcome. It is clear that any vascular calcification detected, independently of the imaging method used, harbours an increased cardiovascular risk in the patient.

Different average serum levels of the calcification inhibitory protein matrix gla protein (MGP) have been found in different patient groups. Subjects with the highest cardiovascular risk have the lowest levels of uncarboxylated MGP (UCMGP). There was no information about the average level of uncarboxylated and unphosphorylated MGP in hypertensive subjects. In chapter 4 we present these average MGP levels in subjects with mild to moderate hypertension and compare them to a normotensive control group. On average, both total unphosphorylated MGP and total uncarboxylated MGP were lower in hypertensive subjects. This suggests a tendency for vascular calcification in these mild to moderate hypertensive subjects although this is not always visible on imaging.

Of the proteins mentioned in chapter 2, matrix gla protein (MGP) plays a central role in inhibiting calcification. Although the associations of MGP levels with cardiovascular risk and vascular calcification have been abundantly studied, little is known about clearance of this protein from the circulation. In chapter 5 we present our study measuring renal clearance of MGP. As expected the renal clearance of this relatively small protein is not compromised in a wide range of renal function. Serum levels of MGP are mainly independent of renal function, probably unless the estimated glomerular filtration rate falls below $20 \mathrm{ml} / \mathrm{min}$.

Because of the association of MGP levels and vascular calcification and secondly the association between vascular calcification and arterial stiffness we hypothesized that MGP serum levels are also associated with arterial stiffness. We investigated this 
hypothesis in the Hoorn study population, an elderly population in which extensive measurements of arterial stiffness were done. The results are presented in chapter 6 . There is a positive association with central arterial stiffness as reflected by Young's elastic modulus of the carotid artery, but no association, independent of confounding factors, was seen in any of the other stiffness variables. However, there was a significant association of unphosphorylated and un carboxylated MGP levels with blood pressure, possibly proving that this is an important stimulator of the calcification process as reflected by increased MGP production.

MGP probably undergoes two post translational modifications. One is phosphorylation, promoting cellular excretion, the other is carboxylation by vitamin $\mathrm{K}$. The latter is necessary for MGP to successfully inhibit the effects of BMP2 and prevent calcium precipitation in the vascular matrix. In chapter $\mathbf{7}$ we present our study investigating the relationship between total vascular calcification as measured with computer tomography, vitamin K status and MGP. There was a significant association between vitamin $\mathrm{K}$ status and total vascular calcification. Furthermore there was an association between vitamin $\mathrm{K}$ status and ucMGP levels.

Vitamin K appears to be important to increase the levels of carboxylated MGP in order to inhibit the calcification process. Excessive vascular calcification has been found in animal experiments were rodents were treated with vitamin $\mathrm{K}$ antagonists (VKA's). There is also evidence of increased coronary calcification in humans using VKA's. However these studies were cross sectional, done in an elderly population and there might be confounding by indication. In chapter 8 we investigate if treatment with VKA's in humans promotes vascular calcification independently of age and other cardiovascular risk factors in young subjects using this medication for more than 10 years. Indeed the odds ratio for having peripheral arterial calcifications in patients versus controls was 8.5 (95\% confidence interval $2.01-35.95$ )

In chapter 9 we discuss the main findings presented in this thesis. We elaborate on possible future research to further establish the clinical meaning of MGP levels and treatment of vascular calcification in order to lower cardiovascular risk in patients. 
Samenvatting 
132 


\section{Samenvatting}

Vaatcalcificaties worden regelmatig gezien en dan met name bij ouderen en personen met allerlei cardiovasculaire risicofactoren. Het komt ook veel voor bij patiënten met diabetes, nierinsufficientie en hypertensie. De aanwezigheid van dergelijke vaatwand calcificaties is onafhankelijk geassocieerd met een verhoogd cardiovasculair risico. De mechanismen die vaatverkalking veroozaken zijn complex, maar in het afgelopen decennium is er veel onderzoek gedaan om deze mechanismen op te helderen. In hoofdstuk 1 bespreken we de huidige kennis met betrekking tot de verschillende oorzaken van vaatcalcificatie in patiënten met diabetes, nierinsufficiëntie en hypertensie. Daarnaast geven we een overzicht van het mechanisme dat waarschijnlijk in al deze patiënten groepen het zelfde is.

Bij het calcificatie proces zijn veel eiwitten betrokken. Van al deze eiwitten is uitvoerig onderzocht of ze een stimulerend of remmend effect op vaatverkalking hebben. In hoofdstuk 2 bespreken we de biologische eigenschappen van deze eiwitten en hun rol in de verkalking van bloedvaten. We speculeren over de mogelijkheid om deze eiwitten zodanig te beïnvloeden dat de progressie van vaatcalcificatie geremd zou kunnen worden.

In hoofdstuk 3 beschrijven we de resultaten van een meta-analyse van observationele studies met betrekking tot vasculaire calcificaties en cardiovasculaire eindpunten. Hieruit blijkt dat alle gevonden vasculaire calcificaties, onafhankelijk van de gebruikte afbeeldingmethode, een verhoogd cardiovasculair risico voor de patiënt betekenen.

Verschillende gemiddelde serum spiegels van het vaatcalcificatie inhiberende eiwit matrix gla proteïne (MGP) zijn gemeten in verschillende patiënten groepen met een verschillende mate van cardiovasculair lijden. Groepen met het hoogste cardiovasculaire risico hebben de laagste spiegels van ongecarboxyleerd (uc) MGP. Er was tot op heden geen onderzoek naar serumspiegels van ongefosforyleerd of ongecarboxyleerd MGP in hypertensie patiënten. In hoofdstuk 4 presenteren we deze gemiddelde waarden gemeten in een groep met graad 1 tot 2 hypertensie en vergelijken die met een normotensive controlegroep. Gemiddeld genomen was zowel het totale ongefosforyleerde als ook het totale ongecarboxyleerde MGP in de hypertensiegroep verlaagd. Dit suggereert dat in deze groep er mogelijk al een verhoogde neiging tot vaatverkalking bestaat hoewel dit dan nog niet altijd zichtbaar is.

Van alle eiwitten die genoemd worden in hoofdstuk 2, speelt MGP een centrale rol in de inhibitie van het calcificatie proces. De relatie van MGP met het cardiovasculaire risico en vaatcalcificaties is dan ook uitvoerig bestudeerd. Er is echter geen onderzoek gedaan naar de klaring van dit eiwit uit de circulatie. In hoofdstuk $\mathbf{5}$ beschrijven we onze studie waarin we de renale klaring van ongefosforyleerd MGP bestuderen. Zoals verwacht is de klaring van een dergelijk klein eiwit stabiel onafhankelijk van de nierfunctie. De serumspiegels van ongefosforyleerd MGP zijn derhalve waarschijnlijk 
onafhankelijk van de nierfunctie, tenminste zolang de geschatte creatinineklaring meer dan $20 \mathrm{ml} / \mathrm{min}$ bedraagt.

Vanwege de associatie van MGP serum spiegels met vasculaire calcificatie en ten tweede de relatie van vasculaire calcificatie met vaatstijfheid hadden we de hypothese dat een verminderde hoeveelheid functioneel MGP kan leiden tot meer vaatcalcificaties en daarmee tot meer stijfheid. Deze hypothese hebben we getest in de Hoorn studie populatie, een populatie met gemiddeld oudere personen waarin uitvoerig metingen van de vaatstijfheid zijn verricht. De resultaten zijn beschreven in hoofdstuk 6. Er is een associatie tussen totaal ongefosforyleerd, ongecarboxyleerd MGP en centrale arteriële stijfheid. Dit blijkt vooral uit de significante relatie tussen dit MGP en "Young's elastic modulus" van de carotis. De associaties met andere stijfheidmaten waren in deze studie niet significant. Er was wel een sterke relatie tussen MGP en meerdere bloeddruk determinanten. Mogelijk door een stimulatie van de MGP productie door druk.

MGP ondergaat waarschijnlijk een tweetal posttranslationele modificaties. Ten eerste is er fosforylatie om de cellulaire secretie te vergemakkelijken. Ten tweede is er carboxylatie door vitamine K. Dit laatste om het calcificatie inhiberende effect door remming van BMP2 en voorkoming van calcium neerslagen in de vasculaire matrix volledig tot expressie te laten komen. In hoofdstuk 7 beschrijven we de associatie tussen totale vasculaire calcificatie (gemeten met computer tomografie), vitamine $\mathrm{K}$ status en MGP. Er was een significante relatie tussen vitamine $\mathrm{K}$ status en totale vasculaire calcificatie. Daarnaast bestond er een sterke relatie tussen vitamine $\mathrm{K}$ status en serum ucMGP.

Vitamine K lijkt derhalve belangrijk om de hoeveelheid functioneel MGP te vergroten en zo calcificatie te verminderen. In dierexperimenten heeft men dan ook excessieve verkalking gevonden als men de vorming van vitamine $\mathrm{K}$ blokkeert door het toedienen van vitamine $\mathrm{K}$ antagonisten (VKA's). Een soortgelijk effect werd gezien bij mensen die VKA's gebruikten en calcificatie van de coronairen. Deze studies waren echter cross sectioneel en verricht in een oudere populatie. Daarnaast was de indicatie voor het geven van VKA's vaak een aandoening die ook sterk geassocieerd is met vaatcalcificaties wat mogelijk een verstorende variabele zou kunnen zijn. In hoofdstuk 8 onderzoeken we de invloed van langdurig ( $>10$ jaar)VKA's gebruik op vaatcalcificaties in een jongere populatie zonder andere cardiovasculaire risicofactoren. De Odd's ratio voor het hebben van perifere vaatcalcificaties was in deze groep 8.5 (95\% betrouwbaarheids interval 2.01 - 35.95) vergeleken met een gezonde controle groep.

In hoofdstuk 9 bespreken we de belangrijkste uitkomsten van dit proefschrift en plaatsen we deze in perspectief. We speculeren over mogelijk toekomstig onderzoek om de klinische betekenis van MGP concentraties in bloed en de behandeling van vasculaire calcificaties om zodoende wellicht het cardiovasculaire risico van de patiënt verder te verlagen. 
List of publications 
136 


\section{List of publications}

Rennenberg R, Pauwels P, Vlasveld Th. A case of thymoma-associated autoimmune haemolytic anaemia. Neth J Med 1997;50:110-4.

Boonen A, Rennenberg R, van der Linden S. Thymoma-associated systemic lupus erythematosus, exacerbating after thymectomy. A case report and review of the literature. Rheumatology 2000;39:1044-6.

Rennenberg R, Koek G, van Hootegem Ph, Stockbrügger R. Pneumatosis cystoïdes intestinalis, 4 cases of a rare disease. Neth J Med. 2002;60:22-5.

Kroon A, Rennenberg R. Calciumantagonisten vandaag. Clinical Practice januari 2002.

Rennenberg R, Wolffenbuttel B, Bravenboer B. Het empty sella syndroom als oorzaak van panhypopituïtarisme. Ned Tijdschr Geneeskd 2004;148:33-6.

van Mook W, Rennenberg R, Schurink GW, van Oostenbrugge RJ, Mess W, Hofman P, de Leeuw P. Cerebral hyperperfusion syndrome. Lancet Neurology 2005;4:877-88.

Rennenberg RJ, van der Kuy PM. LDL-cholesterolverlaging: waarom, in welke mate en waarmee? Modern Medicine jaargang 30, nr 4, pagina 210-4 2006.

van Mook W, Rennenberg R, Schurink GW, van Oostenbrugge RJ, Mess W, Hofman P, Kroon A. Het cerebrale hyperperfusiesyndroom. Tijdschrift voor Neurologie en Neurochirurgie, jaargang 107 nr 3, mei-juni 2006.

Rennenberg RJ, Kroon AA, Schurgers LJ, Vermeer C, van Engelshoven JM, Kemerink G, de Leeuw PW. Calcium scores related to Matrix Gla protein and vitamin $\mathrm{K}$ status in hypertensive humans. J Hypertens 2006;24(Supp):S78.

de Leeuw PW, van der Zander K, Kroon AA, Rennenberg RJ, Koning MM. Dairy peptides: a dose dependent effect on blood pressure. J Hypertens 2006;24(Supp):S95.

Rennenberg RJ, Schurgers LJ, Vermeer C, Scholte JB, Houben AJ, de Leeuw PW, Kroon AA. Matrix Gla protein is cleared by the kidney in hypertensive humans. J Hypertens 2007;25: S403.

Rennenberg RJ, Schurgers LJ, Vermeer C, de Leeuw PW, Kroon AA. Lower levels of matrix Gla protein in patients with moderate to severe hypertension in comparison to normotensive subjects. J Hypertens 2008;25:S403-4. 
Rennenberg RJMW. De effectiviteit van een informatieboekje om gezondheidsrisico's beter te begrijpen. NTVG 2007;151:1903.

Verberk WJ, Kroon AA, Lenders JW, Kessels AG, van Montfrans GA, Smit AJ, van der Kuy PH, Nelemans PJ, Rennenberg RJ, Grobbee DE, Beltman FW, Joore MA, Brunenberg DE, Dirksen C, Thien T, de Leeuw PW; Home Versus Office Measurement, Reduction of Unnecessary Treatment Study Investigators. Self-Measurement of Blood Pressure at Home Reduces the Need for Antihypertensive Drugs. A Randomized, Controlled Trial. Hypertension. 2007;50:1019-25.

Rennenberg RJ, Schurgers LJ, Vermeer C, Scholte JB, Houben AJ, de Leeuw PW, Kroon AA. Renal handling of matrix Gla-protein in humans with moderate to severe hypertension. Hypertension Research. 2008;31:1745-51.

van Kimmenade RRJ, Januzzi JL, Bakker JA, Houben AJ, Rennenberg RJMW, Kroon AA, Crijns HJGM, van Dieijen-Visser MP, de Leeuw PW, Pinto YM. Renal clearance of Btype natriuretic peptide and amino terminal Pro-B-Type natriuretic peptide: A mechanistic study in hypertensive subjects. J Am Coll Cardiol, 2009; 53:891-2.

Rennenberg RJ, Kessels AG, Schurgers L, van Engelshoven JM, de Leeuw PJ, Kroon AA Vascular Calcifications as a marker of increased cardiovascular risk: a meta-analysis. Vasc Health Risk Manag. 2009;5:185-97.

van Mook WN, Rennenberg RJ. Het cerebraal hyperperfusiesyndroom na carotisdesobstructie. Nieuwsbrief Vasculaire Geneeskunde, 2009; nr1 pag 7-13.

Rennenberg RJMW. Vaatwandcalcificaties. Nieuwsbrief Vasculaire Geneeskunde, 2009; nr2 pag 11-13.

Rennenberg RJMW, Schurgers LJ, Vermeer C. Vitamine K bij postmenopauzale osteopenie. Nederlands Tijdschrift voor Geneeskunde 2009;153:1204-5.

van Varik GJ, Rennenberg RJ, Schurgers L, Kroon AA, de Leeuw PW. Arterial calcifciation after chronic use of vitamin-K antagonists. J Hypertens 2009;27:S235.

Rennenberg R, de Leeuw P, Kessels A, Schurgers L, Vermeer C, van Engelshoven J, Kemerink G, Kroon A. Calcium scores and matrix Gla protein, association with vitamin K status. Eur J Clin Invest. 2010;40: 344-9.

Rennenberg RJ, van Varik BJ, Schurgers LJ, Hamulyak K, Ten Cate H, Leiner T, Vermeer $C$, de Leeuw PW, Kroon AA. Chronic coumarin treatment is associated with increased extra-coronary arterial calcification in humans. Blood 2010;115:5121-3. 


\section{Boek hoofdstukken}

Rennenberg RJMW, Kroon AA. "Het medisch jaar 2007". ISBN 9789031350469. Hoofdstuk 2 "Wegrakingen" Paragraaf 2 "Syncope: algemene aspecten" 39-45.

"Klinische zorg rondom de vaatpatiënt", onder redactie van P. Kitslaar, M. Lemson, C. Schreurs, H. Bergs. Hoofdstuk 3: "Overzicht van vaataandoeningen" pagina 25-36 en hoofdstuk 12: "vasculaire geneeskunde" pag 207-217 Bohn Stafleu van Loghum, Houten 2007, isbn 9789031348329.

"Therapie in de interne geneeskunde", onder redactie van dr. A.E. Meinders, dr. R.O.B. Gans, dr. M.M. Levi, dr. J.A. Romein, dr. P. Vermeij. Hoofdstuk 2 "Hart- en vaatziekten", paragraaf 2.9 "Syncope", pag 116-118, Elsevier gezondheidszorg, Maarssen 2009, isbn 9789035230422. 
Curriculum Vitae 


\section{Curriculum Vitae}

Roger Rennenberg werd geboren in Nieuwstadt op 21 januari 1968. Na het behalen van zijn diploma aan het Serviam Lyceum te Sittard begon hij in 1987 aan de opleiding Geneeskunde te Maastricht. Het basisartsexamen werd behaald in januari 1994. $\mathrm{Na}$ enkele jaren ervaring als assistent Interne Geneeskunde en Intensive Care in het toenmalige Diaconessenhuis te Eindhoven (thans Maxima Medisch Centrum lokatie Eindhoven, opleider Dr H.R. Haak) en het Catharina Ziekenhuis te Eindhoven, begon hij in 1997 aan de opleiding tot Internist in Maastricht (opleider Prof dr H. Hillen) en het Catharina ziekenhuis te Eindhoven (opleider Dr S.J. Hoorntje). Na het voltooien van deze opleiding in april 2003 werd hij Internist en staflid bij de afdeling Interne Geneeskunde in het academisch ziekenhuis Maastricht. In oktober 2003 was hij een van de eerste afgestudeerden van de toen nieuwe subspecialisatie Vasculaire Geneeskunde (opleider Prof dr P.W. de Leeuw). Tijdens het werk als Internist, Vasculair Geneeskundige en later ook als Acuut Geneeskundige in het Maastrichts Universitair Medisch Centrum werd gewerkt aan het proefschrift. In deze periode werd ook de al langer aanwezige interesse voor het medisch onderwijs verder ontwikkeld onder andere in de functie van coschap-coördinator Interne Geneeskunde. Roger is getrouwd met Margriet Stokbroek en ze hebben vijf kinderen, Tom, Niels, Sterre, Wouter en Max (geboren in 1997, 1999, 2002, 2004, 2006). 